Universidade de São Paulo

Instituto de Física

Instituto de Química

Instituto de Biociências

Faculdade de Educação

Patricia Andrade da Silva

\title{
Mapas e redes conceituais: uma proposta metodológica para a sua construção a partir de textos
}




\section{PATRICIA ANDRADE DA SILVA}

Mapas e redes conceituais: uma proposta metodológica para a sua construção a partir de textos

Dissertação de mestrado apresentada ao Instituto de Física, ao Instituto de Química, ao Instituto de Biociências e à Faculdade de Educação da Universidade de São Paulo para a obtenção do título de Mestre em Ensino de Ciências.

Área de concentração: Ensino de Química

Orientador: Prof. Dr. Flavio Antônio Maximiano 


\section{Agradecimentos}

Ao meu orientador, Prof. Flavio, que desde a graduação contribui para a minha formação como professora de Química, tendo acreditado em meu potencial, me incentivado e orientado da melhor forma possível. Agradeço por sua paciência e dedicação em suas explicações mesmo em meio a tantas outras atividades e também por seus conselhos acadêmicos e profissionais, os quais costumaram fazer parte de muitas de nossas conversas durante minha trajetória pela USP.

À querida amiga Marianna, que desde que ingressou em nosso grupo de pesquisa se mostrou uma pessoa especial, dedicando muito de seu tempo e energia para conhecer os trabalhos desenvolvidos por mim e por outros colegas do grupo, contribuindo imensamente para o progresso desses trabalhos. Agradeço também pelo apoio e incentivo durante a elaboração dos trabalhos apresentados no XV ENEQ, em Brasília. Sua colaboração foi essencial para o êxito dos trabalhos e sua companhia contribuiu para que aquela viagem fosse lembrada como um momento muito especial.

Ao meu esposo, Francisco, pelo companheirismo e apoio incondicional durante todas as fases envolvidas na realização deste curso, me incentivando em todos os momentos e vibrando com cada etapa realizada.

À querida avó, Suzanna, por sua preciosa ajuda durante a elaboração deste trabalho, dedicando muitas de suas tardes para me auxiliar na transcrição dos dados.

A todos os meus queridos familiares e amigos que permaneceram ao meu lado apoiando, dando assistência de diversas formas e sempre incentivando a concretização deste trabalho.

Obrigada! 


\section{Resumo}

A elaboração de textos por alunos em resposta a questões dissertativas dentro do contexto escolar parece ser a forma mais convencional de se tentar avaliar o que os alunos sabem. $\mathrm{O}$ texto que um indivíduo produz procura refletir de forma aproximada a sua estrutura de conhecimentos sobre determinado tema. A leitura e análise de textos são tarefas que exigem um tempo considerável no dia-a-dia de um professor ou pesquisador e, quando há o interesse em conhecer as ideias mais relevantes sobre determinado tema para um grupo de alunos, a tarefa é ainda mais trabalhosa. O principal objetivo desta pesquisa consiste em desenvolver uma metodologia que utiliza ferramentas computacionais para transformar textos escritos por alunos em estruturas gráficas como mapas e redes de conceitos. A utilidade desta metodologia aparece tanto no contexto da pesquisa em ensino quanto na própria prática docente, já que o produto final de sua aplicação pode permitir estabelecer inferências quanto à estrutura de conhecimentos de um grupo de alunos. A investigação ocorreu a partir de dados coletados em duas disciplinas distintas de cursos de graduação do IQ-USP. Os dados coletados referem-se a produções textuais de 42 estudantes em resposta a uma questão que fornecia alguns conceitos pré-estabelecidos. A partir das respostas dos alunos foram realizados testes: (i) com dois softwares de análise de textos para a quantificação das relações entre conceitos; (ii) para verificar a influência na quantificação das relações entre conceitos partindo-se do texto como foi escrito e das proposições extraídas do mesmo e (iii) para a obtenção de diferentes tipos de estruturas gráficas. A partir dos testes realizados, foi possível concluir que o programa Hamlet $^{\circledR}$ é mais eficiente e prático do que o programa ALA-Reader ${ }^{\circledR}$ para os objetivos da presente pesquisa. Além disso, a matriz gerada pelo Hamlet ${ }^{\circledR}$ para quantificar as relações entre conceitos depende essencialmente da estrutura do texto em questão - texto original ou texto modificado. Os três tipos de estruturas gráficas construídos apresentam diferentes focos, porém, podem ser considerados complementares. As redes $\mathrm{V}+\mathrm{P}$ se mostraram interessantes para análises centradas nos conceitos pré-estabelecidos e fornecidos na questão que originou os textos dos alunos. As redes a partir de corte percentual apresentaram-se como representações bastante úteis para investigações interessadas em fazer um recorte ou destacar os aspectos considerados mais relevantes pelos alunos sobre determinado tema. Os mapas conceituais construídos neste trabalho mostraram-se como representações extremamente valiosas para conhecer a aproximada estrutura de conhecimentos dos grupos de alunos, uma vez que explicitam a natureza das relações proposicionais entre os conceitos. A construção de 
mapas conceituais partindo-se tanto dos textos originais quanto dos textos modificados permitiu concluir que as estruturas gráficas obtidas dos dois modos se aproximam bastante uma da outra, apresentando alta semelhança. Esta semelhança sugere que a utilização do programa Hamlet $^{\circledR}$ para a obtenção de matrizes que quantificam relações entre conceitos presentes em um texto na forma como foi escrito é eficiente quando comparada ao processo manual e mais demorado de se extraírem proposições de um texto para obter uma matriz.

Palavras-chave: Texto. Mapa conceitual. Rede de conceitos. Estrutura de conhecimento. 


\begin{abstract}
The drafting of essays by students in response to essay questions in the school context seems to be the most conventional way to assess the students` knowledge. The essay produced by a student seeks to approximately reflect his/her knowledge structure about a certain domain. The reading and the analysis of essays are tasks that require a considerable time in a teacher's or researcher's routine and, when the interest on knowing the most important ideas about a certain topic is verified in a group of students, the task is even harder. The main objective of this research is to develop a methodology that uses computational tools in order to transform written essays in graphic structures such as concept maps and networks graphs. This methodology could be useful not only for teaching research purposes but also for teaching practice, since the final product of its application may lead to inferences about the knowledge structure of a group of students. The investigation developed herein was based on data collected from two distinct matters of undergraduate IQ-USP. That data refer to written essays of 42 students in response to an essay question provided of some pre-established concepts. From the students' responses, tests were performed: (i) with two softwares for text analysis with a view of quantifying the relationships between concepts, (ii) to investigate the influence on the quantification of relationships between concepts, from the original text and from the propositions extracted from this original text and (iii) to obtain different types of graphic structures. From the tests that were done, it was possible to conclude that Hamlet $^{\circledR}$ consists in a more efficient and convenient program than ALA-Reader ${ }^{\circledR}$ to the objectives of this research. Furthermore, the array generated by Hamlet ${ }^{\circledR}$ program to quantify the relationships between concepts depends essentially on the structure of the essay - either the original text or the modified text. The three types of graphic structures that were built present different focuses, however, these graphic structures may be considered complementaries. The $(\mathrm{V}+\mathrm{P})$ network graphs can be thought as interesting representations that focuses on pre-established concepts that were provided on the essay questions. Network graphs from cutting percentage can be thought as representations that are more useful for investigations interested in making a cut or in highlighting the most relevant aspects of a subject by the students. The concept maps constructed in this paper can be thought as extremely valuable representations to know the approximate knowledge structure of the students groups, since they make clear the nature of the propositional relationships between concepts. The construction of concept maps starting from the original texts and also from the modified texts proved that both graphic structures
\end{abstract}


obtained are very close to each other, being highly similar. This similarity suggests that the use of the Hamlet $^{\circledR}$ program to obtain arrays that quantify relationship between concepts found in an original text is more effective in comparison to manual and time-consuming process of extracting propositions from the original text to obtain an array.

Keywords: Text. Concept map. Network graphs. Knowledge structure. 


\section{Sumário}

APRESENTAÇÃO .....................................................................................................10

Capítulo 1. INTRODUÇÃO ................................................................................................................11

Capítulo 2. FUNDAMENTAÇÃO TEÓRICA ………………........................................................14

2.1 Contextualização da pesquisa no âmbito da avaliação da aprendizagem ...........................15

2.1.1 O processo avaliativo .............................................................................................................16

2.1.2 Influências no processo avaliativo .......................................................................................................18

2.1.3 Propósitos da avaliação .................................................................................................................19

2.1.4 A importância do erro no processo avaliativo .............................................................22

2.1.5 Como deve ser a avaliação? ....................................................................................23

2.2 A importância de se tentar conhecer a organização do conhecimento .....................................25

2.3 Técnicas de mapeamento das redes de conhecimento ...............................................................28

2.3.1 Mapas conceituais ..............................................................................................................................29

2.3.2 Redes de conceitos .........................................................................................................................33

Capítulo 3. PERCURSO METODOLÓGICO DA PESQUISA...............................................36

3.1 Coleta de dados .......................................................................................................................................37

3.1.1 Dados provenientes da disciplina Química Ambiental II ...............................................37

3.1.2 Dados provenientes da disciplina Química e Sociedade ........................................................39

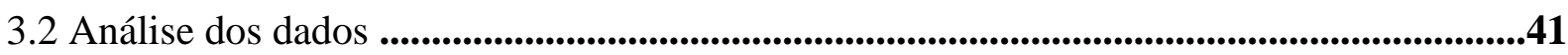

3.2.1 Utilização do programa ALA-Reader para a obtenção de matrizes .......................................42

3.2.2 Utilização do programa Hamlet para a obtenção de matrizes ..........................................47

3.2.3 Definição das possíveis estruturas dos textos a serem analisados pelo programa Hamlet

3.2.4 Obtenção de redes de conceitos .................................................................................58

3.2.5 Obtenção de mapas conceituais ....................................................................................................64 
4.1 Análises referentes à disciplina Química Ambiental II ....................................................68

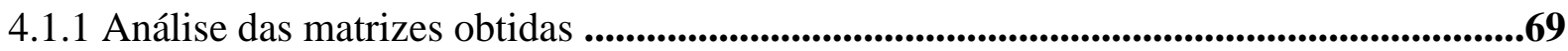

4.1.2 Análise das redes de conceitos obtidas ............................................................................71

4.1.3 Análise dos mapas conceituais obtidos ...........................................................................82

4.1.4 Análise geral das estruturas gráficas obtidas no contexto da Química Verde .................87

4.2 Análises referentes à disciplina Química e Sociedade ...................................................89

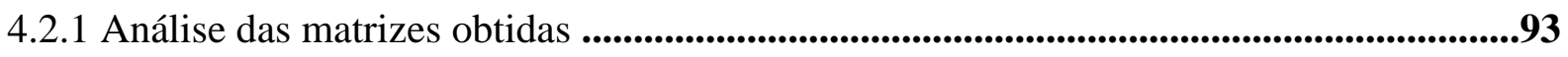

4.2.2 Análise das redes de conceitos obtidas .................................................................95

4.2.3 Análise dos mapas conceituais obtidos ..........................................................................113

4.2.4 Análise geral das estruturas gráficas obtidas no contexto da Natureza da Ciência .......122

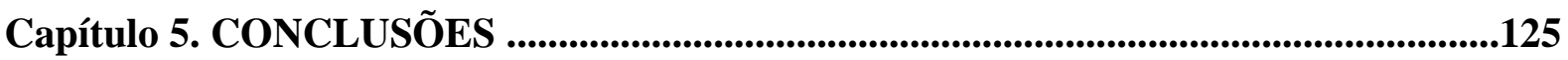

REFERÊNCIAS ..........................................................................................................132 
Autorizo a reprodução e divulgação total ou parcial deste trabalho, por qualquer meio convencional ou eletrônico, para fins de estudo e pesquisa, desde que citada a fonte.

\section{FICHA CATALOGRÁFICA \\ Preparada pelo Serviço de Biblioteca e Informação do Instituto de Física da Universidade de São Paulo}

\section{Silva, Patricia Andrade}

Mapas e redes conceituais: uma proposta metodológica para a sua construção a partir de textos. - São Paulo, 2012.

Dissertação (Mestrado) - Universidade de São Paulo. Faculdade de Educação, Instituto de Física, Instituto de Química e Instituto de Biociências.

Orientador: Prof. Dr. Flávio Antonio Maximiano

Área de Concentração: Química

Unitermos: 1.Mapas conceituais; 2.Conceitos (Processos cognitivos); 3. Conhecimento.

USP/IF/SBI-058/2012 


\section{APRESENTAÇÃO}

Acreditando na importância de se analisarem diferentes tipos de produções dos alunos no decorrer de seu aprendizado, o presente trabalho preocupa-se em mostrar o uso de uma metodologia em que textos produzidos por alunos são analisados com o auxílio de ferramentas computacionais, gerando estruturas gráficas como mapas e redes que relacionam conceitos e procuram representar de maneira clara e objetiva a estrutura de conhecimento dos alunos.

A pesquisa foi desenvolvida a partir de dados coletados em duas disciplinas distintas de cursos de graduação do Instituto de Química da Universidade de São Paulo denominadas QFL3502 Química Ambiental II e 4603000 Química e Sociedade; a primeira pertencente ao curso de Bacharelado em Química Ambiental (período noturno) e a segunda pertencente ao curso de Licenciatura em Química (período integral). Durante a leitura deste trabalho, o leitor perceberá que o foco da pesquisa permaneceu no desenvolvimento de uma metodologia para a obtenção de estruturas gráficas representativas do grupo de alunos de cada uma das disciplinas citadas e não de cada estudante.

O texto encontra-se organizado em cinco capítulos, a começar pela introdução, em que se pretende apresentar ao leitor os objetivos, as perguntas e hipóteses da pesquisa.

No capítulo dois é apresentada a fundamentação teórica do trabalho, onde a presente pesquisa é contextualizada no âmbito da avaliação da aprendizagem, além de se descreverem ideias a respeito da organização do conhecimento, bem como a importância de suas formas de representação, o que compreende os chamados mapas conceituais e as redes de conceitos.

O capítulo três pode ser considerado a essência do trabalho, uma vez que é dedicado aos aspectos metodológicos da pesquisa propriamente dita, explicitando os instrumentos de coleta e análise de dados. Neste capítulo, procura-se esclarecer para o leitor de que forma textos produzidos por alunos podem ser analisados por ferramentas computacionais e como é possível construir estruturas gráficas a partir desta análise.

No capítulo quatro são apresentados os resultados $e$ discussão, onde o leitor encontrará análises específicas dentro do contexto de cada disciplina citada anteriormente. No capítulo cinco são apresentadas as conclusões e implicações deste trabalho. 
Capítulo 1.

INTRODUÇÃO 


\section{Capítulo 1. INTRODUÇÃO}

A elaboração de textos por alunos em resposta a questões dissertativas dentro do contexto escolar parece ser a forma mais convencional de se tentar avaliar o que os alunos sabem, uma vez que o texto que um indivíduo produz procura refletir de forma aproximada a sua estrutura de conhecimentos sobre determinado tema. Ao escrever um texto, o aluno resgata informações sobre um assunto, seleciona as informações importantes para responder à questão que lhe foi proposta e depois organiza suas ideias para construir um texto lógico e coerente.

Independentemente do contexto, é inevitável que a leitura e análise de textos sejam tarefas que exigem um tempo considerável no dia-a-dia de um professor ou pesquisador, de forma que quando se tem o interesse em conhecer as ideias mais relevantes sobre determinado tema para um grupo de alunos, a tarefa se torna ainda mais trabalhosa. A análise de muitos textos pode ser exaustiva, dificultando a seleção e organização das ideias principais dos alunos por parte do professor ou pesquisador.

O objetivo geral da presente pesquisa consiste em desenvolver uma metodologia que faz uso de ferramentas computacionais para transformar textos escritos por alunos em estruturas gráficas como mapas e redes de conceitos. No entanto, para atingir o objetivo geral deste trabalho, alguns objetivos específicos podem ser citados por direcionarem a pesquisa como um todo.

O primeiro objetivo específico consiste em testar duas diferentes ferramentas computacionais (softwares de análise de textos), ALA-Reader ${ }^{\circledR}$ e Hamlet ${ }^{\circledR}$, que são utilizadas para quantificar relações entre conceitos presentes em um texto. Além disso, pretende-se analisar as diferenças na quantificação das relações entre conceitos realizada pelos programas citados, partindo-se de um texto na forma como foi escrito pelo aluno (o que será chamado de texto bruto) e de um texto em que são extraídas as proposições presentes no texto original (o que será chamado de texto modificado). Uma vez quantificadas as relações entre conceitos presentes em um texto, outro objetivo específico do trabalho consiste em mostrar e comparar algumas possibilidades de estruturas gráficas capazes de representar essas relações entre conceitos. Finalmente, diante da análise das diferentes estruturas gráficas obtidas, pretende-se fazer inferências quanto à estrutura de conhecimento dos grupos de alunos sobre os temas abordados nas disciplinas Química Ambiental II e Química e Sociedade, de forma a 
demonstrar ao leitor a possível utilidade da metodologia desenvolvida neste trabalho dentro do contexto da pesquisa em ensino e da avaliação da aprendizagem de alunos.

Diante dos objetivos apresentados e da breve introdução ao que se pretende trabalhar na presente pesquisa, tem-se a seguinte pergunta fundamental: De que forma é possível transformar um texto escrito em uma estrutura gráfica capaz de mostrar relações estabelecidas entre conceitos?

A partir desta pergunta fundamental, o desenvolvimento da pesquisa e a construção do presente trabalho ocorreram de forma a responder outras perguntas específicas apresentadas a seguir:

- Em qual contexto e a partir de quais questionamentos os textos dos alunos podem ser escritos?

- De que forma é possível quantificar as relações entre conceitos estabelecidas em um texto?

- Uma vez quantificadas as relações entre conceitos presentes em um texto, que critérios utilizar para escolher quais relações devem ser representadas graficamente?

- Que tipos de informações se podem obter a partir de uma estrutura gráfica em que conceitos estão relacionados?

- O que define a escolha por determinado tipo de estrutura gráfica?

Acredita-se que a metodologia utilizada e descrita neste trabalho possa trazer uma possibilidade de quantificação de relações entre conceitos estabelecidas por um grupo de alunos para determinado tema, viabilizando a construção de uma estrutura gráfica que represente de maneira objetiva e clara essas relações entre conceitos. A utilidade desta metodologia se dá tanto no contexto da pesquisa em ensino quanto na própria prática docente, uma vez que a estrutura gráfica resultante, ou seja, o produto final da aplicação da metodologia descrita pode permitir estabelecer inferências quanto à estrutura de conhecimento de um grupo de alunos.

Conseqüentemente, diante das estruturas gráficas obtidas com a proposta deste trabalho, identifica-se a possibilidade de um pesquisador estabelecer diferentes comparações no decorrer de sua pesquisa ou de um professor conhecer as relações entre conceitos mais relevantes para um grupo de alunos (estejam elas corretas ou não) podendo, desta forma, planejar e direcionar seu curso a partir do que é observado. 


\section{Capítulo 2.}

\section{FUNDAMENTAÇÃO TEÓRICA}




\section{Capítulo 2. FUNDAMENTAÇÃO TEÓRICA}

\subsection{Contextualização da pesquisa no âmbito da avaliação da aprendizagem}

$\mathrm{Na}$ introdução ao presente trabalho propõe-se a indagação sobre 'como é possível transformar um texto escrito em uma estrutura gráfica capaz de mostrar relações estabelecidas entre conceitos?'. Considerando-se que o ponto de partida para o desenvolvimento deste trabalho de pesquisa consistiu justamente em ações avaliativas que possibilitassem aos alunos expressar relações entre conceitos por meio de textos, antes de apresentar a metodologia para a obtenção das estruturas gráficas e apresentar os resultados obtidos com a presente pesquisa, mostra-se imprescindível situar de que forma atividades que solicitam aos alunos a elaboração de textos em resposta a questões dissertativas, bem como os mapas e as redes de conceitos se enquadram dentro do contexto da avaliação da aprendizagem.

Conforme se observará nos tópicos seguintes, as informações que podem estar presentes em mapas ou redes de conceitos fazem dessas estruturas gráficas valiosos instrumentos de avaliação que permitem aos pesquisadores e professores desenvolverem um trabalho avaliativo contínuo. Neste sentido, esses instrumentos possibilitam não somente avaliar os conhecimentos dos alunos após o término do processo de ensino-aprendizagem de determinado conjunto de conteúdos, como também permite o planejamento de todo esse processo desde o seu princípio: (i) compreendendo o entendimento prévio dos alunos acerca dos assuntos a serem trabalhados pelos professores; (ii) observando sua evolução ao longo dos estudos e, finalmente, (iii) permitindo o replanejamento do processo de ensino com base nesses dados.

Desta forma, embora os objetivos desta pesquisa não contemplem aspectos mais profundos do tema avaliação, a seguir são apresentados alguns tópicos gerais com o objetivo de evidenciar ao leitor as perspectivas de aplicação da presente pesquisa e de seus resultados por professores e pesquisadores no contexto da avaliação da aprendizagem dos alunos. 


\subsubsection{O processo avaliativo}

Tradicionalmente, a avaliação é uma das atividades presentes no cotidiano de professores e alunos, sendo parte integrante da prática escolar. Aluno e professor, ao iniciarem suas atividades em uma instituição de ensino, imediatamente e naturalmente procuram se informar e se apropriar devidamente do sistema de avaliação. Tal preocupação tem sentido quando se pensa na visão mais comum que se tem da avaliação pela sociedade, como algo que não faz parte do dia-a-dia das disciplinas envolvidas, representando um momento tenso e de confronto entre professores e estudantes, que é a hora da prova (SILVA; MORADILLO, 2002).

Neste sentido, Luckesi (2003, p. 17) afirma que "nossa prática educativa escolar passou a ser direcionada por uma "pedagogia do exame",, ao falar sobre a relevância adquirida pela avaliação da aprendizagem nos processos de ensino. Com a prática pedagógica polarizada simplesmente pelas provas e exames e com os alunos motivados na escola apenas pelas notas, percebe-se que o ato de avaliar passa bem distante do que Silva $(2003$, p. 9) defende como o papel da avaliação: "acompanhar a relação ensino e aprendizagem para possibilitar as informações necessárias para manter o diálogo entre as intervenções dos docentes e dos educandos". Ou seja, a chamada pedagogia do exame, bem como a avaliação puramente classificatória, são opostas à ideia de avaliação como uma atividade cotidiana de colaboração entre professores e alunos na busca pelo conhecimento, destinada a orientar o ensino e facilitar a aprendizagem.

De acordo com Sanmartí (2009, p. 18), o processo avaliativo é caracterizado "pela coleta e pela análise de informação, pela emissão de um juízo sobre ela e pela tomada de decisões de caráter social ou pedagógico, conforme o juízo emitido". Da mesma forma, Luckesi (2003, p. 33) caracteriza a avaliação "como uma forma de ajuizamento da qualidade do objeto avaliado, fator que implica uma tomada de decisão a respeito do mesmo, para aceitá-lo ou para transformá-lo".

A partir dessas definições, é possível perceber uma responsabilidade considerável por parte do professor não apenas no que diz respeito à aplicação de uma atividade avaliativa para obter informações, mas principalmente em seu papel de julgar a qualidade da produção do aluno e de tomar decisões frente ao que foi analisado, possibilitando o melhor caminho possível para o processo de aprendizagem do estudante. Tais responsabilidades do professor, 
dentro do contexto e da dinâmica escolar, encontram inúmeras barreiras, sendo que a primeira delas relaciona-se à subjetividade envolvida na análise das respostas dos alunos ao que foi solicitado na avaliação. Para não se depararem com tal dificuldade, é comum professores utilizarem avaliações mais objetivas, que tenham como produto final respostas que não dão margem para interpretações diversas.

No ensino de química, por exemplo, verifica-se que a avaliação tradicionalmente se dá por meio de atividades bastante objetivas e algorítmicas, como a resolução de exercícios repetitivos ou problemas em que as respostas dos alunos consistem, na maior parte das vezes, em determinar fórmulas, montar equações químicas, dar a nomenclatura de compostos ou efetuar cálculos matemáticos. Tais formas de avaliação dificilmente são capazes de representar a aproximada estrutura de conhecimentos de um aluno sobre determinado assunto ou de mostrar as relações entre conceitos percebidas pelo mesmo. A ideia da atividade avaliativa caracterizada por ser o ponto de partida da presente pesquisa é justamente uma tentativa de se opor a isso, permitindo ao aluno expor seu entendimento sobre determinado assunto, deixando claro para o professor quais são as relações estabelecidas entre os conceitos considerados, bem como a natureza dessas relações.

A queixa sobre o tempo disponível para que os professores se apropriem de processos avaliativos mais significativos para si mesmos e para os alunos, tomando decisões eficazes frente ao resultado de uma avaliação, também é uma realidade e uma grande barreira a ser vencida. Normalmente, os professores optam pela simples aceitação do resultado de uma avaliação, independente deste ser satisfatório ou não, uma vez que se preocupam extremamente em cumprir o conteúdo planejado e não têm tempo suficiente para trabalhar as dificuldades dos alunos individualmente, possibilitando uma aprendizagem mais significativa. Com esta dinâmica, o professor aplica uma avaliação, atribui uma nota ao que foi produzido pelo aluno pela comparação com um padrão, este resultado é publicado e é dada continuidade ao conteúdo, sem se preocupar com os erros e concepções alternativas que fizeram parte do processo avaliativo.

Neste aspecto, Sanmartí discute a respeito do dilema eterno do professor entre o trabalho lento, com profundidade, com resultados imediatos e muito eficazes em longo prazo e o trabalho superficial, rápido, que em muitas ocasiões já se mostrou sem futuro e pouco eficiente (SANMARTÍ, 2009). Na prática, o professor realmente se encontra diante do grande desafio de "selecionar os conteúdos que lhe parecem mais significativos e utilizar uma avaliação que seja: útil para o professor em sua atuação docente, gratificante para os alunos 
em sua aprendizagem e orientadora para ambos em suas atuações" (SANMARTÍ, 2009, p. 20).

A escolha por uma perspectiva de avaliação que se opõe ao modelo que segue a simples seqüência de transmitir; verificar e avaliar exige que o professor tenha a possibilidade e a disponibilidade de prestar muita atenção em seus alunos, conhecendo-os melhor, ouvindo suas falas, argumentos e questionamentos, instigando-os por meio de desafios, favorecendo, desta maneira, a autonomia moral e intelectual desses alunos (HOFFMANN, 1993).

\subsubsection{Influências no processo avaliativo}

A prática da avaliação dentro do contexto escolar, no entanto, sofre a influência de diversos fatores, não apenas da concepção de avaliação do professor, bem como de sua disponibilidade e comprometimento. Alguns aspectos pessoais estão envolvidos na realização da avaliação, tais como a relação existente entre professores e alunos, a disciplina idealizada para o ambiente de aprendizagem, bem como as expectativas dos alunos, professores e pais no que diz respeito à avaliação. Referindo-se à prática da avaliação da aprendizagem na escola brasileira, Luckesi (2003, p. 18) aponta que:

\footnotetext{
O sistema de ensino está interessado nos percentuais de aprovação / reprovação do total dos educandos; os pais estão desejosos de que seus filhos avancem nas séries de escolaridade; os professores se utilizam permanentemente dos procedimentos de avaliação como elementos motivadores dos estudantes, por meio da ameaça; os estudantes estão sempre na expectativa de virem a ser aprovados ou reprovados e, para isso, servem-se dos mais variados expedientes.
}

Assim, a conseqüência natural de um ambiente escolar com a atenção centraliza nas provas é que a relação professor-aluno seja prejudicada, com professores elaborando suas provas pensando nas prováveis reprovações, na negociação de pontos e no uso da avaliação como uma maneira de disciplinar os alunos (LUCKESI, 2003).

Além disso, o processo avaliativo é influenciado e se desenvolve frente aos cenários educativos que se constituem a partir de diferentes concepções de aprendizagem e de diferentes abordagens dos temas de estudo e conteúdos selecionados (HOFFMANN, 2003). Neste sentido, Hoffmann (2003, p. 49) expõe que: 
[...] um cenário educativo desafiador, onde os alunos deixam de ser apenas receptores de informações, fazedores de exercícios e leitores de livros didáticos, implica um processo avaliativo adequado à tal concepção e desafiador para o docente da disciplina. Uma prática avaliativa tradicional, portanto, será totalmente incoerente para responder sobre a aprendizagem do aluno que vivenciou experiências educativas de pesquisa, de questionamento, de experimentação ativa ou de desenvolvimento de projetos.

De fato, muitos dos pressupostos da avaliação mudam dependendo de qual é a principal finalidade do ensino numa escola. A escolha por uma concepção de ensino centrado na seleção de alunos bem preparados para os exames vestibulares, por exemplo, fatalmente significa restringir a avaliação aos conteúdos necessários para tais exames, ao passo que quando se pensa na formação integral do sujeito, o objetivo é o desenvolvimento da pessoa como um todo e as avaliações vão além dos conteúdos necessários para o caminho até a universidade, levando em consideração conteúdos conceituais, procedimentais e atitudinais (ZABALA, 1998).

Portanto, o processo avaliativo deve procurar ser coerente com o cenário e contexto educacional, sendo que o ideal é que a reflexão sobre o que se quer com a avaliação, quais devem ser seus objetivos e para quê deve servir, seja uma constante nas escolas e entre seus educadores para que exista tal coerência.

\subsubsection{Propósitos da avaliação}

Pode-se dizer que a discussão sobre como fazer uma avaliação e até mesmo a busca por um instrumento avaliativo seguro e, muitas vezes, padronizado, é algo comum no dia-adia de professores, sendo esta uma característica que, ironicamente, até costuma se destacar em relação ao questionamento do verdadeiro significado da prática avaliativa e do sentido da avaliação na escola (HOFFMANN, 1993).

Luckesi (2003, p. 81) defende que a avaliação deve ser considerada "um instrumento de compreensão do estágio de aprendizagem em que se encontra o aluno" e, assim, entende-se que a avaliação adquire uma importante função de diagnosticar e de deixar claro para o professor a dimensão do entendimento do aluno, possibilitando a atuação do educador no sentido de ajudar este aluno a superar suas dificuldades e progredir em seu aprendizado. 
Desta forma, cabe a reflexão sobre a forma mais convencional de avaliação existente, aquela que é realizada ao final de bimestres ou trimestres, onde um número excessivo de conteúdos é cobrado, muitas vezes na forma de questões que exigem do aluno a simples memorização de conceitos, os quais são esquecidos em pouquíssimo tempo. Este tipo de avaliação, por ocorrer em um momento específico, após um grande número de aulas, se distancia bastante da chamada avaliação diagnóstica e se aproxima da avaliação com função classificatória que, segundo Luckesi (2003, p. 34), "não auxilia em nada o avanço e o crescimento".

O sistema de avaliação classificatório cada vez mais se mostra insuficiente no sentido de apontar as falhas certamente presentes ao longo do processo de ensino e aprendizagem, passando por cima das dificuldades dos alunos, uma vez que sua prioridade é a seleção dos que mais se adéquam a tal sistema. "As notas e as provas funcionam como redes de segurança em termos do controle exercido pelos professores sobre seus alunos, das escolas e dos pais sobre os professores, do sistema sobre suas escolas" (HOFFMANN, 1993, p. 26).

De acordo com Luckesi, não só para professores e alunos, mas para a sociedade em geral, o que parece importar realmente é a nota, a média final, sendo que tudo o que ocorreu ao longo do processo de aprendizagem, as dificuldades e os êxitos, os caminhos percorridos para superar as dificuldades, pouco são valorizados. “O que predomina é a nota: não importa como elas foram obtidas nem por quais caminhos. São operadas e manipuladas como se nada tivessem a ver com o percurso ativo do processo de aprendizagem" (LUCKESI, 2003, p. 18, grifo do autor).

Fatalmente, como se pode perceber, um processo avaliativo baseado na classificação traz consequiências para professores e alunos, tanto no âmbito pedagógico quanto psicológico. Luckesi (2003, p. 25) afirma que, psicologicamente, a pedagogia do exame "é útil para desenvolver personalidades submissas", formando alunos que se conformam com a maneira como tudo é conduzido dentro do sistema de ensino; já no âmbito pedagógico, defende que enquanto a avaliação da aprendizagem estiver polarizada pelos exames, "não cumprirá sua função de subsidiar a decisão da melhoria da aprendizagem".

É possível dizer que, ao considerar somente os números, as médias obtidas pelos alunos ao longo de um ano letivo, o professor tem apenas uma noção superficial acerca dos conhecimentos de seus alunos. Desconhece, de fato, as deficiências, dificuldades e eventuais lacunas que fizeram parte do processo de aprendizagem que, ao final, se resumiu a uma nota. 
Em relação a esta "falsa" noção sobre o que o aluno realmente sabe, Zabala (1998, p. 209) comenta que:

Devemos levar em conta que se o objetivo fundamental da avaliação é conhecer para ajudar, a forma como tradicionalmente as provas escritas foram desenvolvidas, pelo fato de terem caráter sancionador, estabeleceu uma dinâmica que faz com que o objetivo básico do aluno não seja dar a conhecer suas deficiências para que o professor ou a professora ajudem-no, mas, ao contrário, demonstrar ou aparentar que sabe muito mais.

A necessidade de superação da prática tradicional baseada somente na ação avaliativa classificatória se faz cada vez mais presente, quando se pensa numa pedagogia preocupada com a transformação dos alunos e também com um aprendizado mais profundo e coerente com o conhecimento estabelecido. Para refletir sobre o que, possivelmente, poderia ser considerado como o ideal em termos de avaliação, convém retomar a própria definição de Sanmartí para uma ação avaliativa, em que é possível identificar a seguinte seqüência: coleta e análise de informação, seguida da emissão de um juízo e a posterior tomada de decisão diante do juízo emitido.

Segundo Sanmartí, dependendo do tipo de decisão tomada após a emissão de um juízo sobre a produção do aluno, as funções da avaliação podem ter um caráter social ou pedagógico / regulador. A função de caráter social é característica de avaliações orientadas a certificar, constatar e tornar público o nível de conhecimento de um aluno, sendo chamadas de avaliações somativas ou qualificativas. Este tipo de avaliação pode ser utilizado tanto para selecionar os alunos quanto para orientá-los. Já a função de caráter pedagógico ou regulador é orientada a identificar mudanças cabíveis na atuação do professor e do aluno para que a aprendizagem seja significativa, ou seja, visa à regulação do processo de ensinoaprendizagem, ocorrendo por meio das chamadas avaliações formativas (SANMARTÍ, 2009).

A avaliação formativa, com sua função reguladora, pode ser considerada como uma modalidade de avaliação que é realizada durante o processo de ensino-aprendizagem e, de acordo com o momento em que aparece, apresenta as seguintes finalidades específicas: avaliação inicial, avaliação ao longo do processo e avaliação final. A avaliação inicial ou diagnóstica busca conhecer as concepções prévias dos alunos sobre o que se pretende ensinar e, assim, permite ao professor a identificação de qual pode ser seu ponto de partida, bem como a adaptação de seu planejamento diante das informações obtidas. 
Já as avaliações que ocorrem ao longo do processo de ensino-aprendizagem trazem "as informações para fazer as regulações no trabalho do professor e da professora em função do desenvolvimento dos aprendentes, conscientizando-os de seus percursos de aprendizagens" (SILVA, 2003, p. 17). Sanmartí defende que esta é a avaliação mais importante, uma vez que "a qualidade de um processo de ensino depende, em boa parte, de se conseguir ajudar os alunos a superarem os obstáculos em espaços de tempo pequenos no momento em que são detectados" (SANMARTÍ, 2009, p. 33).

Finalmente, a avaliação final ocorre com o término do processo de ensinoaprendizagem de determinado conjunto de conteúdos, tendo uma finalidade formativa quando seus resultados são utilizados para orientar e conscientizar os alunos de sua aprendizagem ou, por outro lado, uma finalidade seletiva quando seus resultados servem simplesmente para qualificar os alunos.

Ao se pensar no ensino e na avaliação tradicional, é possível dizer que as chamadas avaliações somativas, como as avaliações finais destinadas à seleção, são as mais valorizadas e as mais presentes no dia-a-dia escolar, em que a função selecionadora aparece como mais relevante perante a função orientadora que também possui. No entanto, é importante ressaltar justamente que a avaliação somativa pode fazer parte de uma perspectiva de avaliação formativa, no sentido de orientar os alunos sobre os caminhos que devem ser seguidos diante dos resultados obtidos ou das certificações alcançadas. O que não parece ser o ideal é fixar o processo avaliativo apenas na avaliação somativa com a função selecionadora, dando importância apenas para as notas obtidas nas avaliações finais.

\subsubsection{A importância do erro no processo avaliativo}

Segundo Silva (2003, p. 8), a avaliação formativa se preocupa em superar "a crise do paradigma educacional centrado no ensino, onde a escola apenas se responsabiliza por ensinar de forma linear e uniforme, ficando à sorte dos alunos aprenderem". Tal afirmação é coerente com uma característica fundamental da avaliação formativa que é a importância e a visão sadia atribuída aos erros, de forma que estes são reconhecidos como o caminho e o avanço para o crescimento, ou seja, o erro é algo dinâmico (LUCKESI, 2003).

Normalmente, o erro é visto como algo ruim e até mesmo como fonte para castigo, sendo que os processos mais tradicionais de avaliação da aprendizagem se revelam de pouca 
utilidade, pois a preocupação maior do professor que corrige a prova parece ser mais o desconto de pontos do que a verdadeira análise dos erros cometidos, ou seja, a classificação dos alunos é mais importante do que a identificação do nível de domínio de cada um. Com esta perspectiva, a avaliação escolar consiste em uma simples verificação de aprendizagem, em que os erros são admitidos e não se buscam meios para compreendê-los e trabalhá-los (PERRENOUD, 1999).

No âmbito da avaliação formativa, o erro aparece como algo que permite ao professor identificar as dificuldades dos alunos quando estes são questionados, além de possibilitar uma aprendizagem em que os conhecimentos iniciais do aluno são constantemente reconstruídos e revisados. A importância do erro, bem como os objetivos da avaliação formativa ficam claros na seguinte fala de Sanmartí (2009, p. 30):

[...] do ponto de vista cognitivista, a avaliação formativa centra-se na compreensão do funcionamento cognitivo do estudante frente às tarefas que lhe são propostas. A informação que se busca refere-se às representações mentais dos alunos e às estratégias que utiliza para chegar a um resultado determinado, quer dizer, a finalidade é chegar a compreender por que um aluno não entende um conceito ou não sabe fazer uma determinada tarefa. Os erros são objetos de estudo na medida em que são reveladores da natureza das representações ou das estratégias elaboradas pelo estudante.

Avaliar as aprendizagens dentro da perspectiva da avaliação formativa parece ser algo extremamente eficaz no que se refere à possibilidade de um ensino em que o professor realmente conhece seu aluno, suas dificuldades e seus meios para enfrentá-las. Além disso, a aprendizagem do aluno tende a ocorrer dentro de uma seqüência de atividades que são utilizadas constantemente com o objetivo de regular o processo, ou seja, a cada oportunidade que o aluno tem de expor seu conhecimento, o professor repensa seu planejamento e o adéqua às necessidades dos alunos percebidas. No entanto, ao buscar ações avaliativas eficazes e significativas para professores e alunos é inevitável que se pergunte justamente 'o que se deve oportunizar aos alunos em uma avaliação e quais instrumentos devem ser utilizados?'.

\subsubsection{Como deve ser a avaliação?}

Inserir uma avaliação ao longo do processo de ensino-aprendizagem não quer dizer que a aprendizagem de certos conceitos esteja concluída, mas que um determinado nível de 
profundidade e compreensão acerca destes conceitos foi atingido pelos alunos (ZABALA, 1998). Assim, as atividades avaliativas devem procurar favorecer ao máximo a demonstração dos conhecimentos dos alunos de maneiras diversas, possibilitando aos alunos registrar aquilo que entenderam acerca de determinado assunto, além de estimulá-los a utilizar conceitos importantes para a resolução de conflitos e problemas.

Neste aspecto, nos processos avaliativos o ideal é que o aluno seja acompanhado por meio de tarefas que permitam a expressão de suas próprias ideias e vivências, o que preferencialmente deve ocorrer com propostas de atividades dissertativas, como a produção de narrativas e textos (HOFFMANN, 2003). Por isso, a elaboração de atividades avaliativas comprometidas com a aprendizagem do aluno deve procurar estar sempre articulada com as propostas pedagógicas escolhidas e, se o objetivo é possibilitar ao aluno que demonstre e exponha seus saberes, o natural é que a avaliação se afaste de atividades baseadas apenas na repetição de definições ou testes objetivos, por exemplo.

A reflexão sobre a escolha do instrumento avaliativo é de fundamental importância dentro do contexto escolar. No dia-a-dia, professores utilizam diversos instrumentos para coletar as informações necessárias acerca das aprendizagens dos alunos, desde a simples observação até a realização de simulados ou testes padronizados. Esta diversificação é importante e vantajosa, uma vez que possibilita um maior número e variedade de informações sobre o processo de ensino-aprendizagem, enquanto a limitação da prática avaliativa a um único instrumento pode significar desperdício de uma diversidade de informações úteis principalmente para a tomada de decisão sobre eventuais mudanças necessárias (SILVA, 2003). Sanmartí (2009, p. 97) também defende que a utilização de diferentes instrumentos pode melhorar a avaliação da aprendizagem e, neste aspecto, faz a seguinte colocação:

\footnotetext{
Um mesmo tipo de instrumento pode ser útil em diferentes momentos de aprendizagem e para diferentes propósitos, embora as decisões que são tomadas em função dos dados recolhidos possam ser diferentes. Tende-se a pensar que apenas uma prova tradicional revela o que os alunos sabem e quais são seus erros e suas dificuldades, quando de fato pode-se utilizar múltiplas fontes de informação e aplicar instrumentos variados que se adaptem à diversidade de estilos motivacionais e de aprendizagens dos estudantes, e igualmente às formas de ensino dos professores, que também são diferentes.
}

A escolha do instrumento avaliativo é um entre os vários aspectos envolvidos com o complexo tema avaliação e, como ocorre com praticamente tudo que envolve educação, não 
há uma receita infalível a ser seguida. A proposta de atividade avaliativa utilizada nesta pesquisa como uma forma de se obterem textos escritos por alunos expressando seu entendimento sobre determinados assuntos, bem como os mapas e as redes de conceitos construídas a partir desses textos são apenas algumas possibilidades dentre os inúmeros instrumentos avaliativos possíveis. O aspecto principal dessa proposta dentro do contexto da avaliação da aprendizagem dos alunos é justamente o de poder ser utilizado em diferentes momentos do processo de ensino-aprendizagem, permitindo sua regulação.

Certamente, a escolha do instrumento se aproximará de um ideal na medida em que o professor estabelecer uma coerência entre sua escolha e os objetivos didáticos, além de realmente enxergar a atividade avaliativa como um instrumento de aprendizagem. Acima de tudo, uma vez que a prática avaliativa é uma realidade na vida escolar, a reflexão sobre o verdadeiro significado da avaliação deve ser uma constante, justamente para que toda a prática e toda a energia despendida em sua elaboração tenha sentido para todos os envolvidos.

\subsection{A importância de se tentar conhecer a organização do conhecimento}

Conforme mencionado anteriormente, a proposta de atividade avaliativa utilizada como ponto de partida para o desenvolvimento deste trabalho teve o objetivo de possibilitar aos alunos o estabelecimento de relações entre conceitos por meio de textos, de forma que pudessem expressar seu entendimento sobre determinados assuntos. A partir dos textos escritos pelos alunos, a presente pesquisa se desenvolveu focada na metodologia utilizada para transformar os referidos textos em estruturas gráficas, como mapas e redes de conceitos. No entanto, é possível dizer que o ato de solicitar que os alunos expressassem seu entendimento sobre determinado assunto por meio de textos esteve diretamente relacionado com o interesse em conhecer a aproximada organização da estrutura de conhecimento desses alunos sobre os temas específicos das disciplinas em que os dados desta pesquisa foram coletados.

Neste sentido, de acordo com a psicologia cognitiva, a essência do conhecimento encontra-se justamente em sua estrutura, sendo uma forma de expressão da rede neural de um indivíduo, que é única para cada um e está no nível mais fundamental da memória (CLARIANA; WALLACE, 2007). A estrutura do conhecimento se refere a como as informações estão organizadas na mente humana, informações estas referentes a relações 
significativas entre conceitos, ou seja, relações de peso entre conceitos que são utilizadas pelo indivíduo para expressar significados (CLARIANA, 2010; SHAVELSON; RUIZ-PRIMO; WILEY, 2005).

De acordo com essa perspectiva, o conhecimento sobre determinado assunto cresce por meio do aprendizado, treino e/ou experiência e, assim, os conceitos referentes ao conhecimento sobre determinado assunto se tornam cada vez mais interligados. Ou seja, conhecer determinado assunto implica possuir uma estrutura de conhecimento altamente integrada dentre os conceitos envolvidos. Por isso, é possível dizer que especialistas sobre determinados assuntos possuem uma grande base de conhecimentos que é organizada numa estrutura elaborada e integrada, ao passo que leigos ou aprendizes sobre determinados assuntos tendem a possuir um domínio menor de conhecimento e uma organização deste bem menos coerente (SHAVELSON; RUIZ-PRIMO; WILEY, 2005).

Partindo-se da ideia geral de que aprender envolve uma reorganização de relações significativas entre conceitos na mente de um indivíduo, onde novos conceitos se relacionam com os já existentes constituindo uma estrutura cognitiva mais coerente e abrangente, pode-se dizer que a ideia de uma estrutura de conhecimento organizada sobre determinado assunto está relaciona com a aprendizagem proposicional proposta por David Ausubel (MOREIRA, 1999).

De acordo com a teoria da aprendizagem significativa de David Ausubel, aprender é um processo contínuo em que novos conceitos ganham maiores significados conforme novas relações são adquiridas. Assim, os conceitos são constantemente aprendidos, modificados, tornando-se mais explícitos e mais inclusivos conforme se tornam progressivamente mais diferenciados (NOVAK; GOWIN, 1984). A chamada aprendizagem proposicional, por sua vez, pode ser considerada a mais complexa no contexto da aprendizagem significativa, estando relacionada ao entendimento das ideias expressas por conjuntos de palavras combinadas (MOREIRA, 1999).

Como se pode perceber, conhecer a estrutura de conhecimento dos alunos pode fornecer informações valiosas, mostrando-se como algo fundamental principalmente no contexto do processo de ensino-aprendizagem. Devido a esta importância, é essencial a reflexão sobre as diferentes formas para tentar conhecer tal estrutura de conhecimento, ou seja, 'como medir ou avaliar a estrutura de conhecimentos dos alunos da forma mais próxima possível?'. Neste sentido, a construção de estruturas gráficas como mapas e redes de conceitos, bem como sua obtenção a partir de textos escritos consistem em maneiras variadas 
e eficazes para avaliar a estrutura de conhecimentos dos alunos (CLARIANA; WALLACE, 2007; SHAVELSON; RUIZ-PRIMO; WILEY, 2005).

Escrever textos em resposta a questões dissertativas pode ser considerado a forma mais convencional para tentar avaliar o entendimento dos alunos sobre as relações significativas reconhecidas pelos mesmos entre determinados conceitos (CLARIANA; WALLACE; GODSHALK, 2009). Ao escrever um texto, o aluno resgata e seleciona as informações mais importantes sobre o assunto em questão e depois organiza suas ideias para construir um texto lógico e coerente. Por isso, é possível dizer que um texto contém muitos aspectos da estrutura de conhecimento de um indivíduo, porém, sua análise por um professor ou pesquisador não se mostra uma tarefa simples e prática, quando o objetivo é compreender as relações mais significativas entre conceitos estabelecidas no texto do aluno (CLARIANA; WALLACE, 2007).

Alguns dos trabalhos produzidos pelo grupo de pesquisa do qual a autora deste trabalho participa têm se desenvolvido justamente a partir da percepção sobre as informações que podem ser extraídas de textos escritos por alunos de forma a se obterem estruturas gráficas que as representem de forma mais prática, clara e objetiva.

No referido grupo de pesquisa, a relação considerada entre textos escritos e estruturas gráficas foi iniciada a partir do trabalho desenvolvido por Martins e Maximiano (2008a), no qual mapas conceituais foram construídos a partir de textos escritos por alunos em resposta a uma questão que fornecia uma lista de conceitos pré-estabelecida. Neste trabalho, as relações de caráter proposicional entre conceitos presentes nos textos dos alunos foram quantificadas manualmente em uma matriz de similaridade. Esta matriz referente à turma de alunos foi utilizada para a elaboração de um mapa conceitual que representava, em termos de proposições, as relações entre os conceitos que mais apareceram em todos os textos dos alunos.

Desde então, os trabalhos deste grupo de pesquisa vêm sendo aprimorados principalmente pelos diversos trabalhos desenvolvidos pelo grupo da Penn State University, liderado por Roy Clariana. Este grupo trabalha na mesma linha de investigação, tendo desenvolvido um programa computacional denominado ALA-Reader ${ }^{\circledR}$ que converte diretamente textos em matrizes de similaridade que podem ser lidas por outros programas computacionais para fornecer estruturas gráficas como mapas e redes de conceitos (CLARIANA; WALLACE, 2007). Além disso, a obtenção de matrizes de similaridade que quantificam relações entre conceitos presentes em textos escritos também vem sendo aprimorada pelo programa computacional Hamlet $^{\circledR}$, desenvolvido por Alan Brier, membro do 
National Centre for Research Methods, de Southampton. Este programa realiza uma busca por palavras em arquivos de texto, tendo como referência uma lista de vocabulário elaborada previamente, fornecendo a frequência com que essas palavras aparecem ao longo de todo o texto, de frases ou de qualquer unidade de contexto especificada.

A partir do conhecimento sobre os programas computacionais citados, os trabalhos do grupo de pesquisa do qual a autora deste trabalho participa começaram a usar e testar os

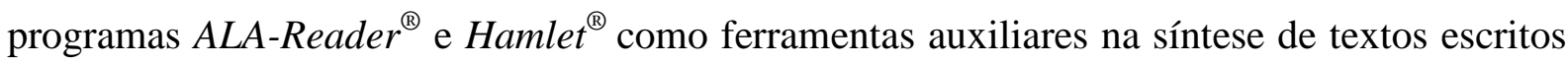
por estudantes em matrizes de similaridade, de forma a facilitar a construção de estruturas gráficas que procuram representar a estrutura de conhecimento desses estudantes (SILVA; JUNQUEIRA; MAXIMIANO, 2010; JUNQUEIRA; SILVA; MAXIMIANO， 2010; JUNQUEIRA; MAXIMIANO, 2011).

Partindo-se da ideia de aprendizagem proposicional acima descrita, a seguir são apresentadas duas técnicas de mapeamento cognitivo, em que as estruturas gráficas denominadas mapas conceituais e redes de conceitos explicitam relações estabelecidas entre conceitos.

\subsection{Técnicas de mapeamento das redes de conhecimento}

Mapa é uma das formas mais antigas que o homem conhece para a representação e a comunicação gráfica, sendo anterior ao surgimento da escrita e do sistema numérico, conhecido e utilizado principalmente na representação de territórios geográficos. Além disso, mapas também são extremamente úteis na tentativa de representar o espaço mental, ou seja, o pensamento humano e sua rede de múltiplas conexões, denominando-se "mapa cognitivo" quando encerra esta função (OKADA, 2008).

Do ponto de vista da aprendizagem, a experiência de mapear se relaciona a um processo de representação gráfica em que é necessário desconstruir, ressignificar, reconectar e construir conhecimentos explícitos, explorando espaços desconhecidos. As técnicas para o mapeamento de redes do conhecimento podem propiciar a organização do saber, além do registro da aprendizagem, favorecendo a reconstrução e a troca de novos significados (OKADA, 2008), além de poderem desenvolver a aprendizagem significativa através de associações de conhecimentos prévios com os novos conhecimentos (NOVAK, 1998). 
Neste sentido, algumas pesquisas são reconhecidas por terem utilizado diferentes abordagens na tentativa de capturar a organização do conhecimento (GOLDSMITH; JOHNSON; ACTON, 1991; NOVAK; GOWIN, 1984; WHITE; GUNSTONE, 1992), sendo comum entre essas pesquisas a ideia de que a estrutura do conhecimento pode ser modelada como redes associativas com nós ou conceitos ligados entre si. A força da ligação entre os nós depende, por exemplo, da frequência com que a ligação é estabelecida (SHAVELSON; RUIZ-PRIMO; WILEY, 2005). As referidas técnicas de mapeamento das redes de conhecimento são os chamados mapas conceituais e as redes de conceitos.

\subsubsection{Mapas conceituais}

Os mapas conceituais consistem em estruturas gráficas que indicam relações significativas entre conceitos específicos, os quais normalmente encontram-se organizados de maneira hierárquica, do mais inclusivo para o mais específico. A técnica dos mapas conceituais foi desenvolvida em meados da década de setenta por Joseph Novak e seus colaboradores na Universidade de Cornell, nos Estados Unidos. Os mapas conceituais são planejados para representar significativamente relacionamentos entre rótulos conceituais em forma de proposições (NOVAK; GOWIN, 1984), sendo estas as unidades fundamentais dos mapas conceituais, tendo a estrutura indicada na figura a seguir.

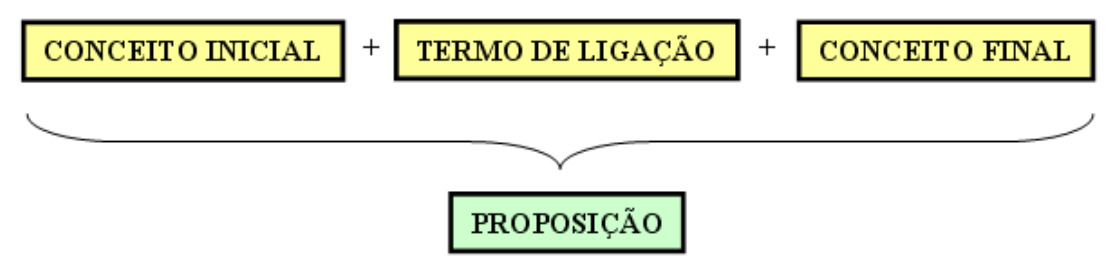

Figura 2.1 - Estrutura de uma proposição

Deve-se ressaltar a importância do termo de ligação na proposição, pois sua inclusão é justamente o que confere ao mapeamento conceitual sua característica fundamental da busca pelo significado. O termo de ligação indica a relação entre conceitos presente na estrutura cognitiva do indivíduo, sendo este um aspecto fundamental na verificação da aprendizagem. Inclusive, erros conceituais podem ser evidenciados pelos mapas, uma vez que a aprendizagem significativa não implica necessariamente o estabelecimento de relações 
conceituais corretas. Apesar de significativa, a aprendizagem pode apresentar incorreções passíveis de revisão (NOVAK, 2002). A figura 2.2, a seguir, apresenta um exemplo de mapa conceitual.

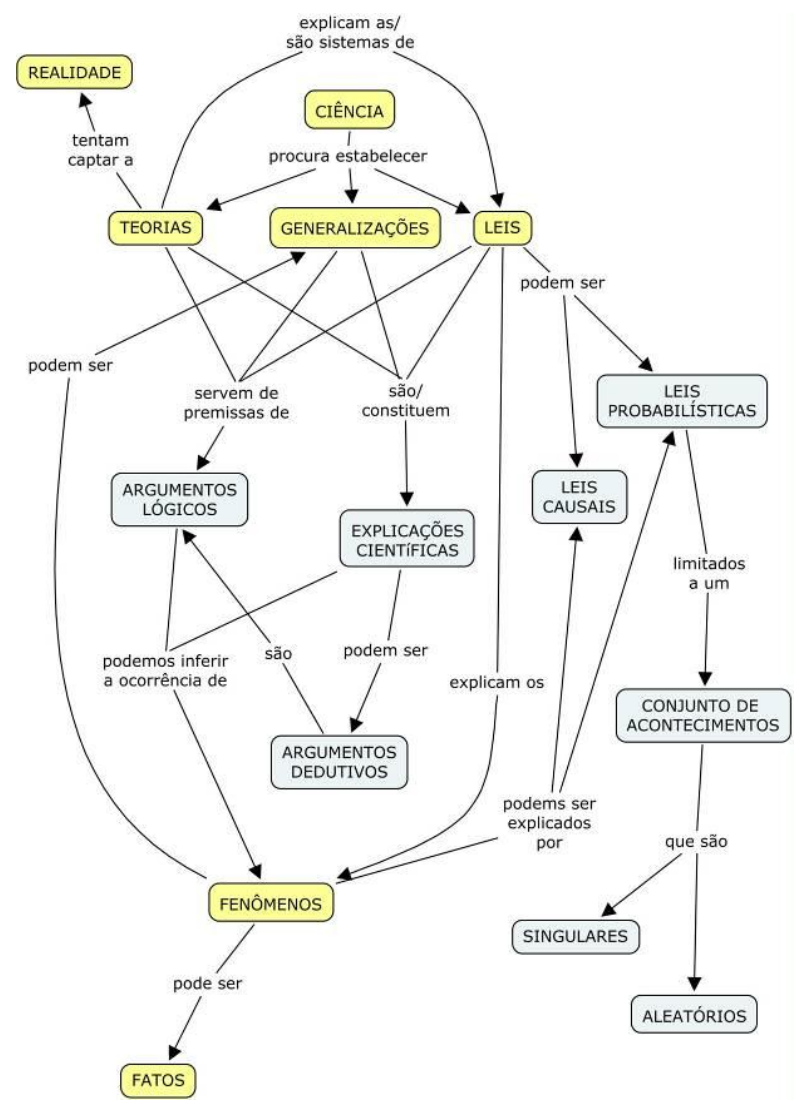

Figura 2.2 - Exemplo de mapa conceitual elaborado a partir da leitura do livro "O método nas ciências naturais e sociais” (ALVES-MAZZOTTI; GEWANDSZNAJDER, 2004).

Os mapas conceituais podem ser elaborados de diversas formas, por exemplo, a partir de uma solicitação para construir a estrutura gráfica diante de uma lista de conceitos prédefinida, ou a partir da requisição para completar conceitos faltantes ou preencher as frases de ligação em uma estrutura previamente elaborada (SHAVELSON; RUIZ-PRIMO; WILEY, 2005). Especialmente no caso de o mapa conceitual ser construído a partir de uma lista prédefinida de palavras ou de forma livre em resposta a um questionamento, é possível considerar os mapas conceituais como estruturadores do conhecimento, uma vez que são capazes de evidenciar como o conhecimento sobre determinado assunto encontra-se organizado na estrutura cognitiva de seu autor e como o mesmo entende as relações entre os conceitos. 
Neste sentido, vale ressaltar que mesmo tratando-se do mesmo assunto e utilizando os mesmos conceitos, dois indivíduos podem construir mapas conceituais distintos, que refletirão a maneira como os conceitos em questão encontram-se organizados e relacionados na mente de cada um (KINCHIN; HAY; ADAMS, 2000). Para um determinado conjunto de conceitos, não há apenas um mapa conceitual possível e correto, mas diversas representações possíveis de determinada estrutura conceitual (MOREIRA, 2003).

Conforme citado anteriormente, uma característica fundamental na elaboração de mapas conceituais é a busca pelo significado, que se concretiza no estabelecimento de relações significativas entre conceitos. A teoria em que se baseia a técnica de mapeamento conceitual de Novak é a da aprendizagem significativa de David Ausubel, que propõe uma explicação teórica para o processo de aprendizagem segundo o ponto de vista cognitivista. De acordo com esta teoria, a aprendizagem consiste no armazenamento organizado e na integração de informações na mente do ser que aprende, sendo esta organização um complexo conhecido como estrutura cognitiva (MOREIRA, 1999). A estrutura cognitiva de um indivíduo nada mais é do que o conteúdo e organização de suas ideias em uma área particular de conhecimentos e, para Ausubel, o fator que mais influencia a aprendizagem é aquilo que o aluno já sabe.

Segundo a teoria de Ausubel, a aprendizagem ocorre conforme novas informações adquirem significados para o aprendiz por meio de uma espécie de ancoragem nos aspectos relevantes da estrutura cognitiva do indivíduo, os chamados subsunçores (MOREIRA, 1999; KINCHIN; HAY; ADAMS, 2000). Ou seja, com a aprendizagem significativa, o novo conhecimento e o já existente (conhecimento prévio) interagem de tal forma que ambos se modificam; os subsunçores adquirem novos significados, se tornando mais diferenciados e estáveis.

A aprendizagem sem atribuição de significados pessoais (caráter idiossincrático) e sem relação com os conhecimentos prévios, por sua vez, ocorre de forma mecânica e não significativa (NOVAK, 2002). Na aprendizagem mecânica, o novo conhecimento é armazenado de maneira arbitrária e literal na mente do indivíduo, sendo possível dizer que ao elaborar um mapa conceitual o aluno é estimulado a buscar relações significativas entre conceitos, diminuindo a chance de ocorrer uma aprendizagem mecânica.

A utilização de mapas conceituais pode atender diferentes necessidades no meio escolar, tais como: analisar o currículo, estruturar o conteúdo de uma disciplina, organizar os conceitos de uma aula e avaliar a aprendizagem (MOREIRA, 2003). O uso de mapas 
conceituais como ferramenta de avaliação da aprendizagem pode ajudar a modificar a ideia geral que se tem da prova como instrumento quase exclusivo para essa finalidade.

Como forma de avaliação, apesar de se tratar de uma técnica não tradicional, os mapas conceituais apresentam-se como bons instrumentos para a verificação da estrutura cognitiva dos estudantes, uma vez que mostram aspectos importantes da organização dos conceitos na estrutura cognitiva do indivíduo. De acordo com Piconez (2012, p. 4) o uso dos mapas conceituais como recurso de avaliação em situações de ensino-aprendizagem pode auxiliar o professor quando sua intenção é "investigar como o estudante compreende as articulações adequadas entre conceitos dentro de um tema ou assunto, documentar a natureza e a freqüência dos conhecimentos anteriores e acompanhar sistematicamente o desenvolvimento do estudante".

A utilização do mapa conceitual como uma técnica de avaliação fornece de forma mais direta a percepção dos estudantes a respeito de conceitos relacionados entre si, mostrando, inclusive, a natureza das relações entre os conceitos considerados. Além disso, a partir do momento em que os alunos compreendem a forma como deve ser realizada a avaliação produzindo mapas conceituais, esta técnica pode ser utilizada com um grande número de alunos, em um curto período de tempo e com poucas intervenções do professor.

No entanto, ressalta-se novamente que ao desenvolver uma atividade avaliativa com mapas conceituais deve-se atentar para o fato de não existir um mapa conceitual "correto" e que todos eles possuem componentes idiossincráticos. A avaliação com mapa conceitual se diferencia quase completamente das tradicionais provas, pois o objetivo não é simplesmente testar conhecimentos e atribuir uma nota ao aluno, a fim de classificá-lo de alguma maneira. A ideia é obter informações sobre o tipo de estrutura que o aluno vê para um dado conjunto de conceitos. Desta forma, a análise de mapas conceituais deve ser essencialmente qualitativa, sendo que o mais importante é obter evidências de aprendizagem significativa (MOREIRA, 1999).

Assim, a utilização dos mapas conceituais como ferramenta de avaliação aponta a necessidade de uma postura diferente da usual por parte dos professores e dos alunos. Conforme citado anteriormente, os mapas conceituais foram desenvolvidos para promover a aprendizagem significativa, portanto, professores que preferem a segurança de ensinar conteúdos sem margem para interpretações pessoais e alunos habituados a memorizar conteúdos para reproduzi-los nas avaliações dificilmente se adaptarão a esta técnica para finalidades avaliativas. 


\subsubsection{Redes de conceitos}

Além dos mapas conceituais, destaca-se também a técnica de representação da organização do conhecimento chamada de rede de conceitos. As redes de conceitos consistem em modelos espaciais que derivam da teoria de grafos e, por isso, possuem fundamentos matemáticos na geometria (SCHVANEVELDT; DURSO; DEARHOLT, 1988). A teoria de grafos, por sua vez, é um estudo matemático de estruturas formadas por dois conjuntos: um deles é chamado de $\mathrm{V}$ por ser o conjunto dos vértices e o outro é chamado de $\mathrm{E}$, referente ao conjunto das arestas (BOAVENTURA NETTO; JURKIEWICZ, 2009).

De forma mais simplificada, os vértices da teoria de grafos podem ser chamados de nós e as arestas podem ser chamadas de ligações que conectam alguns pares de nós, sendo que os valores atribuídos às ligações entre nós presentes no grafo (de distância, por exemplo) fornecem informações quantitativas que acompanham a estrutura gráfica, além de caracterizarem esta estrutura como uma rede.

Para a construção de redes de conceitos, algumas abordagens relacionadas a matrizes são conhecidas. Neste contexto, uma rede de conceitos nada mais é do que uma representação bidimensional de uma matriz de dados relacionados, em que os conceitos são representados pelos chamados nós e as relações são evidenciadas como ligações com certo valor associado conectando esses nós (CLARIANA, 2010). Logo, uma das maneiras de se construírem redes de conceitos é justamente a partir de uma matriz de correlação entre conceitos, que apresenta, para cada par de conceitos, um valor numérico que simboliza o quanto esses conceitos estão relacionados.

Para obter essas matrizes de correlação, diversas abordagens podem ser utilizadas com o objetivo de verificar o quanto determinados conceitos estão relacionados. Algumas abordagens mais comuns e de simples aplicação referem-se ao julgamento de similaridade entre conceitos, o que pode ser feito, por exemplo, por meio de testes em que indivíduos são requisitados a indicar o quanto dois conceitos estão relacionados por meio de uma escala (CLARIANA, 2010). A partir dos dados provenientes dos resultados desses testes, matrizes de similaridade podem ser construídas, possibilitando assim a posterior elaboração de redes de conceitos.

Conforme mencionado anteriormente, o foco da presente pesquisa encontra-se na metodologia utilizada para se obterem estruturas gráficas como mapas e redes de conceitos a 
partir de textos escritos por alunos. Estes textos contêm muitos aspectos da estrutura de conhecimento de seus autores, uma vez que neles são encontradas relações entre conceitos estabelecidas pelos mesmos. Neste sentido, verifica-se que a elaboração de textos também consiste em uma dentre as diversas abordagens para se descobrir como e o quanto determinados conceitos estão relacionados, de forma a se obter uma matriz que, posteriormente, permitirá a construção de uma rede de conceitos.

Como representações da estrutura cognitiva, as chamadas redes de conceitos são uma ótima alternativa, identificando-se com a psicologia cognitiva (SCHVANEVELDT; DURSO; DEARHOLT, 1988). Neste sentido, como modelos psicológicos, a utilização das redes implica a suposição de que conceitos e suas relações podem ser representados por uma estrutura formada por nós (que seriam os conceitos) e por ligações (que seriam as relações entre os conceitos). A força das relações entre os conceitos é refletida pelos valores associados às ligações e o significado relacional de um conceito é determinado por suas conexões com outros conceitos (SCHVANEVELDT; DURSO; DEARHOLT, 1989). Na figura 2.3, a seguir, é apresentado um exemplo de rede de conceitos.

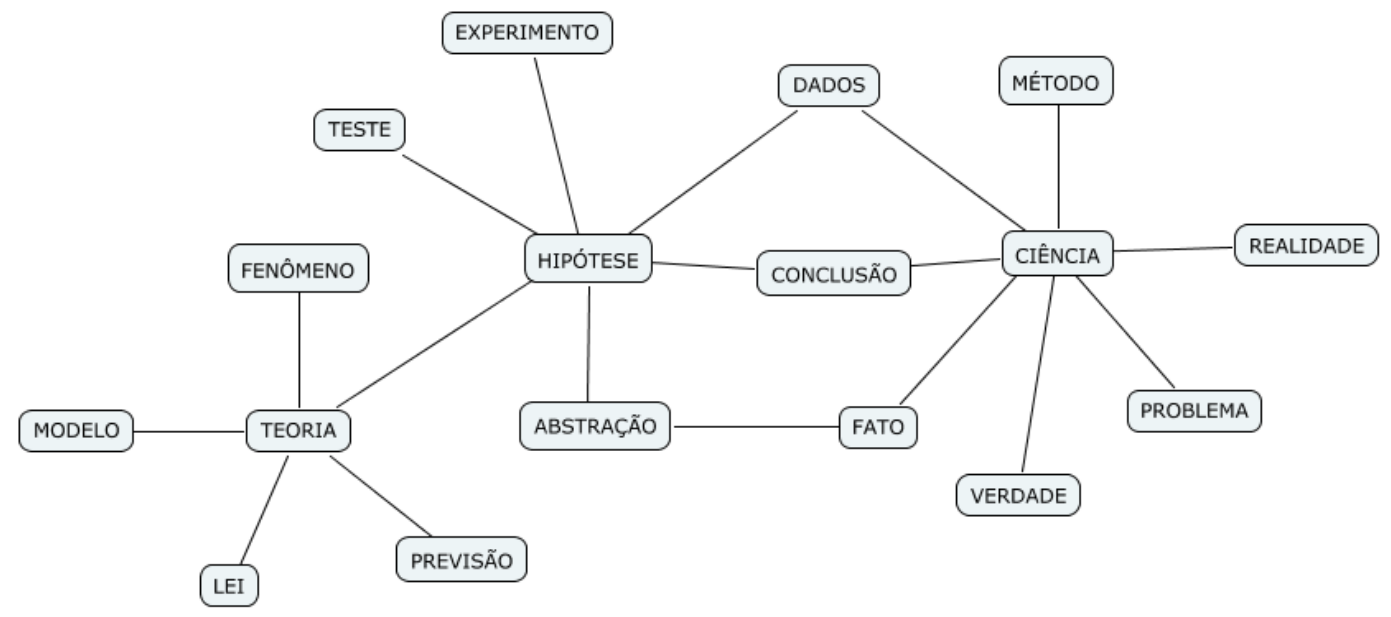

Figura 2.3 - Exemplo de rede de conceitos sobre o tema como se faz ciência

As redes de conceitos se assemelham aos mapas conceituais em sua aparência, porém não possuem os rótulos que esclarecem a natureza e o significado das ligações entre os conceitos (CLARIANA, 2010). O uso das redes sem interpretação semântica das ligações admite que a estrutura da rede corresponde a estruturas psicologicamente significativas, mostrando as associações de maior destaque e relevância entre os conceitos na mente de um indivíduo (SCHVANEVELDT; DURSO; DEARHOLT, 1989). Desta forma, o que é 
representado nas redes possibilita identificar aspectos estruturais da representação conceitual que estão relacionados à organização da memória, ao estabelecimento de categorias, dentre outras informações referentes ao processamento de certos fenômenos na mente humana (SCHVANEVELDT; DURSO; DEARHOLT, 1989).

Como se pode perceber, as redes oferecem uma maneira, dentre muitas que são possíveis, para extrair e representar uma estrutura a partir de dados que relacionam conceitos, de forma a mostrar o quanto esses conceitos estão relacionados (SCHVANEVELDT; DURSO; DEARHOLT, 1988). A ideia fundamental da utilização de redes é que a representação da estrutura de conhecimentos de um indivíduo por meio dessas estruturas gráficas possa simplificar dados coletados de modo mais convencional, por meio de textos, por exemplo, revelando padrões que levam a interpretações relevantes e úteis sobre as relações reconhecidas e identificadas entre conceitos. 


\section{Capítulo 3.}

\section{PERCURSO METODOLÓGICO DA}

PESQUISA 


\section{Capítulo 3. PERCURSO METODOLÓGICO DA PESQUISA}

Neste capítulo serão discutidos os procedimentos metodológicos empregados na pesquisa, bem como uma breve descrição do contexto em que ela se desenvolveu. Assim, serão descritas as atividades desenvolvidas durante o trabalho, contemplando a coleta e o tratamento dos dados.

Tendo em vista que o objetivo geral desta pesquisa é desenvolver uma metodologia para transformar textos escritos por alunos em estruturas gráficas como mapas e redes de conceitos, uma das primeiras ações de todo o percurso foi a elaboração de questões que seriam respondidas por alunos dos cursos de graduação do Instituto de Química da Universidade de São Paulo.

Os dados coletados nesta pesquisa referem-se a produções textuais de 42 estudantes de duas disciplinas distintas, denominadas QFL3502 Química Ambiental II e 4603000 Química e Sociedade; a primeira pertencente ao curso de Bacharelado em Química Ambiental (período noturno) e a segunda pertencente ao curso de Licenciatura em Química (período integral). A seguir é explicado o contexto em que os textos dos alunos das referidas disciplinas foram produzidos, bem como a questão orientadora para a elaboração dos mesmos em cada disciplina.

\subsection{Coleta de dados}

\subsubsection{Dados provenientes da disciplina Química Ambiental II}

Os primeiros dados deste trabalho foram coletados durante o ano de 2007 no âmbito da disciplina Química Ambiental II do curso noturno de Bacharelado em Química Ambiental.

Durante esta disciplina, foram abordadas diferentes questões relacionadas às implicações da atividade química no meio ambiente, tendo como orientação os seguintes temas centrais:

- Métodos alternativos de fabricação; 
- Possibilidades na escolha de: matérias-primas, reagentes, solventes, condições reacionais, tipos de reações e etapas de purificação;

- Implicações do uso de reações catalíticas ou estequiométricas;

- Catálise química e biocatálise;

- Matérias-primas renováveis, reagentes e solventes não-poluentes;

- Biodegradabilidade do produto final.

Referente à disciplina Química Ambiental II, o presente trabalho versa sobre a análise de textos produzidos pelos 16 alunos matriculados em resposta a uma pergunta inserida em uma avaliação somativa (prova final da disciplina), na qual o enunciado apresentado no quadro a seguir estava presente:

Dado o seguinte conjunto de palavras:

\begin{tabular}{|c|c|c|c|c|}
\hline matérias-primas & resíduos & solventes & $\begin{array}{l}\text { catálise ou } \\
\text { catalisador }\end{array}$ & reagentes \\
\hline sais inorgânicos & gás hidrogênio & gás oxigênio & dióxido de carbono & síntese orgânica \\
\hline petroquímica & eficiência atômica & $\begin{array}{c}\text { matérias-primas } \\
\text { renováveis }\end{array}$ & indústria química & $\begin{array}{c}\text { indústria } \\
\text { farmacêutica }\end{array}$ \\
\hline efluentes aquosos & estequiométricas(os) & pressão de vapor & seletividade & emissões \\
\hline minimizar & condições reacionais & & & \\
\hline
\end{tabular}

Utilizando estas palavras (todas, ou apenas algumas delas, ou palavras derivadas dessas, ou outras que julgue necessário) escreva um parágrafo explicando a relação entre elas no contexto da atividade química e seus efeitos no meio ambiente e saúde humana.

Quadro 3.1 - Pergunta respondida pelos alunos da disciplina Química Ambiental II

Como se pode perceber pelo enunciado acima, a ideia fundamental foi possibilitar que o aluno escrevesse um texto sobre o tema proposto a partir de palavras fornecidas (também chamadas de termos indutores), de forma que fosse possível identificar neste texto a presença de relações entre essas palavras ou variações das mesmas. Essas palavras ou termos indutores fornecidos foram pré-estabelecidos a partir de sua importância dentro do contexto da atividade, tendo como objetivo justamente promover a reflexão dos alunos sobre as possíveis relações existentes entre essas palavras durante a elaboração de seus textos. 


\subsubsection{Dados provenientes da disciplina Química e Sociedade}

Neste trabalho, também foram estudados e analisados dados coletados no início e no final da disciplina Química e Sociedade, a qual faz parte da grade de disciplinas do curso de Licenciatura em Química, do período integral.

Os dados são referentes a uma turma de 26 alunos do ano de 2009 que, no decorrer da disciplina, tiveram a oportunidade de estudar e discutir textos que abordavam as diferentes concepções de ciência, além de episódios da história da ciência. Durante a disciplina, foram abordados diferentes temas com o objetivo de proporcionar aos alunos a reflexão e a compreensão: (i) sobre as relações entre a química, seu desenvolvimento científico, suas aplicações tecnológicas e a sociedade; (ii) sobre o desenvolvimento científico como um processo de produção histórico/social e (iii) sobre o papel da educação científica frente às atuais necessidades e complexidade da sociedade moderna.

Neste contexto, o programa da disciplina foi orientado de acordo com os seguintes temas centrais:

- Ciência e sociedade;

- A produção científica na atualidade;

- Educação científica;

- Química e sociedade;

- O que é ciência;

- Pesquisa científica e metodologia científica;

- Estudo de casos ilustrativos do "fazer ciência";

- A natureza da Química;

- Percepção pública da ciência;

- Ciências, técnicas e sociedade: o papel da ciência e da tecnologia no cotidiano;

- Educação em Ciências/ Química.

A atividade solicitada à turma, antes e após a instrução, ou seja, no início e no final da disciplina, consistia em escrever um texto explicando como se faz ciência, a partir de uma lista de 18 conceitos pré-estabelecidos, conforme o enunciado apresentado no quadro a seguir: 
Pense no significado das seguintes palavras:

\begin{tabular}{|c|c|c|c|c|c|}
\hline abstração & ciência & conclusão & dado & experimento & fato \\
\hline fenômeno & hipótese & lei & método & modelo & observação \\
\hline previsão & problema & realidade & teoria & teste & verdade \\
\hline
\end{tabular}

Utilizando estas palavras (todas, ou apenas algumas delas, ou palavras derivadas dessas, ou outras que julgue necessário) escreva um parágrafo explicando para uma pessoa como se faz ciência. Se você preferir, escreva seu texto na forma de proposições (frases) simples que relacionem as palavras acima.

Quadro 3.2 - Pergunta respondida pelos alunos da disciplina Química e Sociedade

Conforme exposto, a origem dos textos escritos pelos alunos que constituem os dados desta pesquisa está em uma pergunta inserida em um tipo de atividade avaliativa. Em ambos os casos apresentados, a pergunta realizada pode ser considerada de caráter geral, em que são fornecidos termos indutores previamente estabelecidos, de acordo com sua importância dentro do contexto de estudo. Além disso, verifica-se que o uso dos termos indutores é livre, tendo sido utilizados nas atividades avaliativas com o objetivo de promover a reflexão sobre as possíveis relações entre os conceitos fornecidos.

Um aspecto relevante das perguntas realizadas refere-se à clareza necessária no enunciado, uma vez que o aluno deve compreender o comando principal - expressar as relações existentes entre os conceitos fornecidos por meio de um texto - de tal forma que, posteriormente, seja possível para o professor verificar as relações estabelecidas, bem como a natureza das mesmas.

As perguntas realizadas poderiam ser classificadas como questões abertas, as quais possibilitam uma grande reflexão entre os alunos sobre o assunto definido na questão. Tratase de uma atividade em que o aluno recorre às próprias ideias, pensa em seus significados e, desta forma, chega o mais próximo possível do que se espera dele com este tipo de proposta: o estabelecimento de relações significativas entre conceitos.

No entanto, deve-se ressaltar que algumas dificuldades podem surgir no uso didático de questões abertas como as que fizeram parte deste trabalho, principalmente pelo caráter geral ou aberto que possuem e que pode permitir diversas formas de resolução ou linhas de raciocínio. Devido a estas características, eventualmente este tipo de problema pode parecer 
vago demais para os alunos, que podem não saber exatamente o que devem fazer ou por onde começar. Por isso, os momentos em que os textos que constituem os dados desta pesquisa foram desenvolvidos contaram com o apoio do professor da disciplina no que diz respeito à explicação prévia do que se deveria fazer, ou seja, antes do momento da avaliação foi extremamente importante deixar claro os objetivos da atividade para os alunos.

\subsection{Análise dos dados}

Uma vez produzidos os textos pelos alunos em resposta às perguntas realizadas, sabese que esses textos podem ser analisados de diferentes maneiras, por exemplo, por meio de uma correção padrão da resposta comparativa ao desejado, bem como por análise de conteúdo.

No entanto, o presente trabalho pretende mostrar algumas maneiras de se chegar a uma estrutura gráfica que demonstre, da forma mais próxima possível, a estrutura de conhecimentos de um grupo de alunos a partir de suas produções textuais, tornando explícitas as ideias mais relevantes e fundamentais para os alunos em suas produções. Na figura a seguir são apresentadas as etapas básicas envolvidas no processo de transformação de textos em estruturas gráficas (mapas e redes de conceitos) que fazem parte da presente pesquisa:
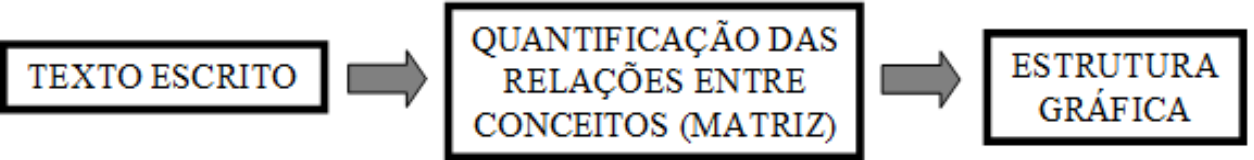

Figura 3.1 - Etapas básicas do processo de transformação de textos em estruturas gráficas

O processo indicado na figura 3.1 foi desenvolvido durante a presente pesquisa tendo como referência outros trabalhos científicos que procuram desenvolver ferramentas e metodologias na tentativa de capturar a estrutura de conhecimentos a partir de textos escritos. Neste sentido, destacam-se os trabalhos produzidos pelo grupo de pesquisa do qual a autora deste trabalho participa (MARTINS; MAXIMIANO, 2008a, 2008b; SILVA; JUNQUEIRA; MAXIMIANO, 2010; JUNQUEIRA; SILVA; MAXIMIANO, 2010), entre outros 
(CLARIANA; KOUL, 2004; NUUTILA; TORMA, 2004; KOWATA; CURY; BOERES, 2010; VILLALON; CALVO; MONTENEGRO, 2010).

Como se pode perceber pelo que se encontra esquematizado na figura 3.1, todo o processo de transformação de textos em estruturas gráficas se baseia em duas etapas principais: i) quantificação das relações entre conceitos presentes no texto na forma de uma matriz e ii) elaboração da estrutura gráfica a partir da matriz gerada anteriormente.

No decorrer da presente pesquisa, duas ferramentas computacionais denominadas ALA-Reader ${ }^{\circledR}$ e Hamlet $^{\circledR}$ foram utilizadas com o mesmo objetivo: quantificar as relações entre conceitos presentes em um texto. A escolha por utilizar ferramentas computacionais para este fim se deu justamente por se tratar de uma tarefa que, caso fosse realizada de forma manual, seria algo extremamente cansativo e pouco prático. No entanto, para a utilização dos programas citados, inicialmente todos os textos dos alunos foram digitados na íntegra.

A análise de textos possível de se realizar com auxílio dos dois programas acima mencionados gera, de formas diferentes, uma matriz de similaridade que relaciona todos os conceitos previamente fornecidos entre si, sendo que os valores mostrados nessa matriz referem-se à simples ocorrência ou ao número de vezes que cada relação entre conceitos foi estabelecida. As diferenças entre o funcionamento, bem como das matrizes produzidas pelos programas ALA-Reader ${ }^{\circledR}$ e Hamlet $^{\circledR}$ para quantificar relações entre conceitos presentes em um texto são explicadas a seguir.

\subsubsection{Utilização do programa $A L A-$ Reader $^{\circledR}$ para a obtenção de matrizes}

O programa denominado ALA-Reader ${ }^{\circledR}$ (ALA, analysis of lexical aggregates) foi desenvolvido por Roy B. Clariana para transformar textos em arquivos que podem ser convertidos em mapas ou redes de conceitos (CLARIANA; WALLACE, 2007). Para analisar os textos, o programa utiliza uma lista de conceitos formada por até trinta palavras que tem a função de auxiliar a busca pela ocorrência dos conceitos presentes nesta lista no texto a ser analisado. Os conceitos que compõem essa lista são selecionados previamente pelo professor / pesquisador, tendo como base a importância desses conceitos dentro do tema ou da pergunta que originou o texto do aluno (CLARIANA; KOUL, 2004). No presente caso, as listas de conceitos utilizadas pelo programa coincidem com as listas prévias de conceitos fornecidas nos enunciados das questões apresentadas nos itens 3.1.1 e 3.1.2. 
Para que o programa possa reconhecer nos textos dos alunos certas variações na escrita ou possíveis sinônimos para os conceitos pré-estabelecidos, a lista de conceitos em que se baseia deve ser organizada de uma maneira específica. Desta forma, elabora-se um arquivo em que os conceitos pré-estabelecidos são escritos um em cada linha, seguindo o seguinte formato para cada uma dessas linhas: primeiro se escreve o conceito em sua forma original; a seguir, o radical da palavra que expressa o conceito; na sequência, alguma variação semântica do conceito ou sinônimo; e, finalmente, outra variação semântica do conceito ou sinônimo. Para o conceito abstração, por exemplo, a seguinte sequência seria necessária: abstração abstra abstrato abstrata.

Após a elaboração da lista de conceitos, pode-se prosseguir com a análise de um ou mais textos de duas maneiras diferentes, que são os chamados modo $\mathrm{S}$ e modo L. O modo $\mathrm{S}$ do programa $A L A-$ Reader $^{\circledR}$ significa abordagem de agregação por sentença e consiste na busca de relações entre conceitos dentro de uma sentença, a qual é considerada uma importante unidade na organização de um texto (CLARIANA, 2010).

Independentemente da escolha pelo modo $\mathrm{S}$ ou $\mathrm{L}$, a análise de um texto pelo ALAReader $^{\circledR}$ inicia-se pela identificação das ocorrências dos conceitos pré-estabelecidos ao longo do texto. Desta forma, no quadro 3.3 observa-se um exemplo de um texto constituído por três sentenças e as ocorrências de determinados conceitos identificadas pelo programa ALAReader $^{\circledR}$, onde o valor 1 significa a ocorrência e o valor 0 significa a não ocorrência de determinado conceito.

\begin{tabular}{|l|l|l|l|l|l|}
\hline Ciência & Método & Problema & Fenômeno & Experimento & Conclusão \\
\hline
\end{tabular}

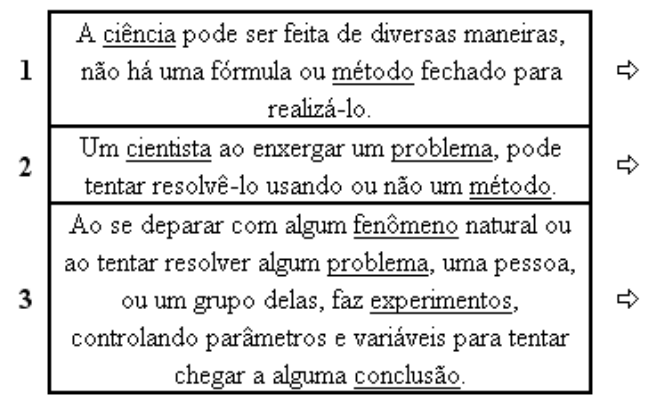

$\Rightarrow$\begin{tabular}{c|c|c|c|c|c|}
\hline 1 & 1 & 0 & 0 & 0 & 0 \\
\hline 1 & 1 & 1 & 0 & 0 & 0 \\
\hline 0 & 0 & 1 & 1 & 1 & 1 \\
\hline
\end{tabular}

Quadro 3.3 - Exemplo de identificação de ocorrências de conceitos em um texto pelo programa $A L A$ Reader $^{\circledR}$

A seguir, o modo $\mathrm{S}$ do programa ALA-Reader ${ }^{\circledR}$ transforma essas ocorrências de conceitos que foram identificadas ao longo do texto em matrizes de similaridade que 
demonstram todas as relações possíveis entre conceitos presentes em uma mesma sentença. Nessas matrizes, para cada relação entre conceitos presente é atribuído o valor numérico 1, ao passo que o valor 0 significa uma relação inexistente entre um par de conceitos.

Desta forma, para a primeira sentença do texto acima utilizado como exemplo, verifica-se a existência de apenas uma relação entre os conceitos ciência e método, sendo que nas duas outras sentenças um número maior de relações entre conceitos é verificado justamente por se tratarem de sentenças em que mais conceitos estão presentes. Para um maior esclarecimento, as figuras 3.2, 3.3 e 3.4 mostram as matrizes obtidas para cada uma das três sentenças que compõem o pequeno texto utilizado como exemplo anteriormente:

\begin{tabular}{|c|c|c|c|c|c|c|}
\multicolumn{1}{c|}{ Sentença 1 } \\
\cline { 2 - 8 } \multicolumn{1}{c|}{} & Ciência & Método & Problema & Fenômeno & Experimento & Conclusão \\
\hline Ciência & & & & & & \\
\hline Método & 1 & & & & & \\
\hline Problema & 0 & 0 & & & & \\
\hline Fenômeno & 0 & 0 & 0 & & & \\
\hline Experimento & 0 & 0 & 0 & 0 & & \\
\hline Conclusão & 0 & 0 & 0 & 0 & 0 & \\
\hline
\end{tabular}

Figura 3.2 - Matriz obtida pelo modo S do programa ALA-Reader ${ }^{\circledR}$ para a sentença 1 do quadro 3.3

\begin{tabular}{|c|c|c|c|c|c|c|}
\cline { 2 - 7 } \multicolumn{1}{c|}{} & Ciência & Método & Problema & Fenômeno & Experimento & Conclusão \\
\hline Ciência & & & & & & \\
\hline Método & 1 & & & & & \\
\hline Problema & 1 & 1 & & & & \\
\hline Fenômeno & 0 & 0 & 0 & & & \\
\hline Experimento & 0 & 0 & 0 & 0 & & \\
\hline Conclusão & 0 & 0 & 0 & 0 & 0 & \\
\hline
\end{tabular}

Figura 3.3 - Matriz obtida pelo modo S do programa ALA-Reader ${ }^{\circledR}$ para a sentença 2 do quadro 3.3

\begin{tabular}{|c|c|c|c|c|c|c|}
\cline { 2 - 7 } \multicolumn{1}{c|}{ Sentença 3 } \\
\hline Ciência & Ciência & Método & Problema & Fenômeno & Experimento & Conclusão \\
\hline Método & 0 & & & & & \\
\hline Problema & 0 & 0 & & & & \\
\hline Fenômeno & 0 & 0 & 1 & & & \\
\hline Experimento & 0 & 0 & 1 & 1 & & \\
\hline Conclusão & 0 & 0 & 1 & 1 & 1 & \\
\hline
\end{tabular}

Figura 3.4 - Matriz obtida pelo modo S do programa ALA-Reader ${ }^{\circledR}$ para a sentença 3 do quadro 3.3

Finalmente, as matrizes de similaridade obtidas pelo modo S do programa ALA-Reader ${ }^{\circledR}$ para cada sentença são agregadas e não somadas, sendo obtida uma matriz de similaridade que representa o texto como um todo (CLARIANA, WALLACE, GODSHALK, 2009). Assim, considerando-se ainda o texto utilizado como exemplo anteriormente, verifica-se que os conceitos ciência e método, por exemplo, apresentam uma relação entre eles tanto na primeira quanto na segunda sentença, porém, a matriz obtida com a agregação das matrizes de 
cada sentença não mostra o valor total das relações encontradas entre os referidos conceitos, que seria 2, mas sim o valor 1, que indica que a relação apareceu ao longo do texto pelo menos uma vez. A figura 3.5 mostra a matriz obtida com a agregação das matrizes presentes nas figuras 3.2, 3.3 e 3.4 .

\begin{tabular}{|c|c|c|c|c|c|c|}
\cline { 2 - 8 } \multicolumn{1}{c|}{} & Ciência & Método & Problema & Fenômeno & Experimento & Conclusão \\
\hline Ciência & & & & & & \\
\hline Método & 1 & & & & & \\
\hline Problema & 1 & 1 & & & & \\
\hline Fenômeno & 0 & 0 & 1 & & & \\
\hline Experimento & 0 & 0 & 1 & 1 & & \\
\hline Conclusão & 0 & 0 & 1 & 1 & 1 & \\
\hline
\end{tabular}

Figura 3.5 - Matriz obtida pelo modo $\mathrm{S}$ do programa ALA-Reader ${ }^{\circledR}$ por agregação das matrizes das figuras 3.2, 3.3 e 3.4

O modo L do programa ALA-Reader ${ }^{\circledR}$ é denominado abordagem de agregação linear e nele as sentenças que compõem o texto não têm a mesma importância que no modo $\mathrm{S}$. A análise pelo modo L funciona fazendo a busca pelas relações entre os conceitos préestabelecidos de acordo com a sequência linear em que aparecem nas sentenças que compõem o texto (CLARIANA; WALLACE, 2007; CLARIANA, WALLACE, GODSHALK, 2009).

Assim, para o texto exemplificado no quadro 3.3, uma matriz diferente da que é mostrada na figura 3.5 (referente ao modo S) é obtida quando a análise é realizada pelo modo L. Na matriz apresentada na figura 3.6 fica evidente a abordagem de agregação linear característica do modo L ao se observar a relação identificada entre os conceitos método e fenômeno, os quais se encontram em sentenças diferentes do texto, porém, por aparecerem de forma sequencial entre uma sentença e outra, o programa identifica uma relação entre os referidos conceitos.

\begin{tabular}{|c|c|c|c|c|c|c|}
\cline { 2 - 8 } \multicolumn{1}{c|}{} & Ciência & Método & Problema & Fenômeno & Experimento & Conclusão \\
\hline Ciência & & & & & & \\
\hline Método & 1 & & & & & \\
\hline Problema & 1 & 1 & & & & \\
\hline Fenômeno & 0 & 1 & 1 & & & \\
\hline Experimento & 0 & 0 & 1 & 0 & & \\
\hline Conclusão & 0 & 0 & 0 & 0 & 1 & \\
\hline
\end{tabular}

Figura 3.6 - Matriz obtida pelo modo L do programa ALA-Reader ${ }^{\circledR}$ para o texto presente no quadro 3.3 
As relações entre conceitos identificadas pelos dois modos de funcionamento do programa diferem devido ao distinto modo de leitura e análise do texto que realizam, sendo que, para o exemplo em questão, um maior número de relações foi encontrado no modo S. O quadro 3.4 a seguir mostra as relações identificadas ao longo do texto utilizado como exemplo por cada modo de leitura do programa ALA-Reader ${ }^{\circledR}$ destacando-se, em negrito, os pares de conceitos cuja relação é identificada de forma característica pelo modo L. No referido quadro, é possível perceber que a relação entre os conceitos método e fenômeno foi contemplada apenas no modo L, enquanto as relações entre os pares de conceitos fenômeno e experimento; fenômeno e conclusão e problema e conclusão foram contempladas apenas no modo S.

\begin{tabular}{|c|c|c|}
\hline Texto & $\begin{array}{l}\text { Relações entre conceitos } \\
\text { identificadas pelo modo } S\end{array}$ & $\begin{array}{l}\text { Relações entre conceitos } \\
\text { identificadas pelo modo } \mathrm{L}\end{array}$ \\
\hline $\begin{array}{l}\text { A ciência pode ser feita de diversas maneiras, não há } \\
\text { uma fórmula ou método fechado para realizá-lo. }\end{array}$ & Ciência - Método & \multirow{5}{*}{$\begin{array}{l}\text { Ciência - Método } \\
\text { Método - Ciência } \\
\text { Ciência - Problema } \\
\text { Problema - Método }\end{array}$} \\
\hline & & \\
\hline \multirow{3}{*}{$\begin{array}{l}\text { Um cientista ao enxergar um problema, pode tentar } \\
\text { resolvê-lo usando ou não um } \underline{\text { método. }}\end{array}$} & Ciência - Problema & \\
\hline & Ciência - Método & \\
\hline & Problema - Método & \\
\hline & & Método - Fenômeno \\
\hline \multirow{6}{*}{$\begin{array}{l}\text { Ao se deparar com algum fenômeno natural ou ao tentar } \\
\text { resolver algum problema, uma pessoa, ou um grupo } \\
\text { delas, faz experimentos, controlando parâmetros e } \\
\text { variáveis para tentar chegar a alguma conclusão. }\end{array}$} & Fenômeno - Problema & \multirow{3}{*}{ Fenômeno - Problema } \\
\hline & Fenômeno - Experimento & \\
\hline & Fenômeno - Conclusão & \\
\hline & Problema - Experimento & \multirow[t]{2}{*}{ Problema - Experimento } \\
\hline & Problema - Conclusão & \\
\hline & Experimento - Conclusão & Experimento - Conclusão \\
\hline
\end{tabular}

Quadro 3.4 - Relações entre conceitos identificadas em um texto pelos modos $\mathrm{S}$ e $\mathrm{L}$ do programa ALA-Reader ${ }^{\circledR}$

Diante das explicações acima referentes aos modos de funcionamento do programa ALA-Reader ${ }^{\circledR}$, ao pensar em seu uso para a análise dos dados da presente pesquisa, em que se tem um número considerável de textos de uma turma de alunos, algumas limitações foram identificadas:

- O programa exige que a lista de conceitos seja formada por, no máximo, trinta conceitos. Além disso, para cada conceito da lista, primeiro se escreve o conceito em sua forma original, seguida de seu radical e, na sequência, apenas duas variações semânticas ou sinônimos podem ser escritos; 
- Cada texto a ser analisado deve conter até trinta linhas, impossibilitando, por exemplo, a leitura direta de todos os textos produzidos por uma turma de alunos de uma só vez;

- Devido à necessidade de se analisar um texto de até trinta linhas por vez, ao se pensar em uma turma de alunos, o número de análises a serem realizadas e o número de matrizes a serem obtidas correspondem ao número de alunos da turma. Portanto, para se chegar a uma matriz soma representativa de uma turma, é necessário efetuar a soma de todas as matrizes obtidas individualmente para cada texto, o que pode ser uma tarefa relativamente demorada, dependendo do número de textos que se tem;

- Independentemente do modo de leitura (S ou L), percebe-se que mesmo que um par de conceitos esteja relacionado mais de uma vez no decorrer de um texto, o programa contabiliza aquela relação uma única vez, o que pode interferir na posterior análise do professor / pesquisador. Dependendo do objetivo da atividade e do tema do texto escrito pelos alunos, pode ser importante saber que determinadas relações entre conceitos foram estabelecidas várias vezes.

\subsubsection{Utilização do programa $\mathrm{Hamlet}^{\circledR}$ para a obtenção de matrizes}

O programa Hamlet ${ }^{\circledR}$ foi desenvolvido por Alan P. Brier e Bruno Hopp e sua ideia principal consiste na busca por palavras em arquivos de texto, tendo como referência uma lista de vocabulário elaborada previamente, fornecendo também a frequência com que essas palavras aparecem ao longo de todo o texto, de frases ou de qualquer unidade de contexto especificada (BRIER; HOPP, 2010).

A frequência determinada pelo programa após a análise de um texto pode ser tanto individual, ou seja, para cada palavra isoladamente, como pode ser conjunta, fornecendo a frequência com que pares de palavras aparecem relacionadas ao longo do texto. Estas frequências são organizadas pelo programa em uma matriz de similaridade, que pode posteriormente passar por uma série de análises estatísticas, tais como análises de cluster ou multidimensional, as quais podem indicar relações significativas entre palavras.

No presente trabalho, algumas ferramentas principais do programa Hamlet ${ }^{\circledR}$ foram testadas e utilizadas para a análise de textos produzidos por alunos: 
- Wordlist: É a primeira ferramenta do programa a ser utilizada antes de iniciar a efetiva análise de um texto. Este procedimento gera uma lista ordenada contendo todas as palavras encontradas em um arquivo de texto escolhido, além de suas respectivas frequências e o número de vezes que apareceram ao longo do texto analisado.

Como se pode perceber, essa ferramenta é particularmente útil para a posterior elaboração de uma lista de vocabulário bastante completa, uma vez que indica quais foram as palavras mais utilizadas em determinado texto, sendo possível verificar as variações semânticas e sinônimos dessas palavras que mais apareceram.

Neste contexto, vale ressaltar que os textos analisados na presente pesquisa são provenientes de uma pergunta cujo enunciado fornece conceitos, os chamados termos indutores, deixando claro que tais conceitos podem ser utilizados de forma livre pelos alunos. Desta forma, é necessário considerar que existe uma grande possibilidade de os alunos utilizarem palavras diferentes dos conceitos fornecidos no enunciado, porém com o mesmo sentido. É aqui que a ferramenta Wordlist se mostra extremamente valiosa.

- Vocabulary list: A elaboração da lista de vocabulário deve preceder a análise de frequência conjunta, ou seja, aquela que mostra a frequência com que pares de conceitos se relacionam ao longo de um texto. No caso do presente trabalho, a lista de vocabulário consiste na lista de conceitos fornecida ao aluno para a elaboração de seu texto, além das variações semânticas e sinônimos que a ferramenta Wordlist descrita anteriormente permite identificar.

A título de exemplo, o quadro 3.5 apresenta a configuração de uma lista de vocabulário que o programa teve como referência para fazer a busca por relações entre palavras nos textos escritos pelos alunos da disciplina Química Ambiental II, que constituem parte dos dados da presente pesquisa. Esta lista foi elaborada com base nos termos indutores fornecidos no enunciado da atividade realizada pelos alunos, além das variações semânticas e sinônimos que a ferramenta Wordlist permitiu identificar. 


\begin{tabular}{|c|c|c|c|}
\hline TERMO INDUTOR & $\begin{array}{c}\text { SINÔNIMOS E VARIAÇÕES } \\
\text { SEMÂNTICAS }\end{array}$ & TERMO INDUTOR & $\begin{array}{l}\text { SINÔNIMOS E VARIAÇÕES } \\
\text { SEMÂNTICAS }\end{array}$ \\
\hline catálise ou catalisador & $\begin{array}{c}\text { catalisadores, catalisadas, catalitica, } \\
\text { cataliticas, catalitico, cataliticos, } \\
\text { processos cataliticos, reação } \\
\text { catalisada, reações cataliticas, } \\
\text { sistemas cataliticos }\end{array}$ & matérias-primas & matéria-prima \\
\hline condições reacionais & ( & $\begin{array}{c}\text { matérias-primas } \\
\text { renováveis }\end{array}$ & $\begin{array}{l}\text { matéria-prima renovável, } \\
\text { matérias-primas verdes }\end{array}$ \\
\hline dióxido de carbono & - & minimizar & $\begin{array}{l}\text { minimiza, minimizados, } \\
\text { minimizando, minimizem }\end{array}$ \\
\hline eficiência atômica & economia atômica & petroquímica & petroquimicas \\
\hline efluentes aquosos & - & pressão de vapor & - \\
\hline emissões & emissão & reagentes & reagente \\
\hline estequiométricas(os) & estequiométrica, estequiométricos & resíduos & residuo \\
\hline gás hidrogênio & - & sais inorgânicos & - \\
\hline gás oxigênio & - & seletividade & $\begin{array}{l}\text { seleção, selecionar, seletiva, } \\
\text { seletivas, seletivo, seletivos }\end{array}$ \\
\hline indústria farmacêutica & inđústrias farmacêuticas & síntese orgânica & sinteses orgânicas \\
\hline indústria química & indústrias quimicas & solventes & solvente \\
\hline
\end{tabular}

Quadro 3.5 - Lista de vocabulário contemplando termos indutores e suas variações semânticas para análise dos textos da disciplina Química Ambiental II

- Hamlet Joint frequencies: É o principal procedimento de análise do programa, sendo útil na busca por relações entre conceitos ao longo de um texto. Conforme citado anteriormente, trata-se de uma ferramenta que mostra a frequência e o número de vezes com que pares de conceitos presentes na lista de vocabulário se relacionam ao longo de um texto por meio de uma matriz de similaridade.

Para gerar esta matriz de similaridade, a forma como o programa realiza a leitura dos textos e quantifica as relações entre as palavras presentes na lista de vocabulário é relativamente simples: para uma determinada sentença, todas as palavras presentes neste fragmento e que constam na lista de vocabulário são reconhecidas pelo programa como palavras relacionadas, ou seja, palavras que apresentam alguma conexão entre elas. Desta forma, por exemplo, se uma sentença escrita por um aluno apresenta cinco diferentes conceitos que constam na lista de vocabulário, o programa reconhece dez diferentes relações nesta sentença, similarmente ao que é exposto no quadro 3.6. 


\begin{tabular}{|c|c|c|}
\hline SENTENÇA & & $\begin{array}{l}\text { LAÇÕES ENTRE PALAVRAS } \\
\text { ERCEBIDAS PELO HAMLET }\end{array}$ \\
\hline \multirow{10}{*}{$\begin{array}{l}\text { "Enfim, a utilização de sistemas catalíticos pode causar o aumento da } \\
\text { eficiência atômica, facilitando, por exemplo, reações de hidrogenação } \\
\text { (utilizando gás hidrogênio) ou reações de oxidação (utilizando gás } \\
\text { oxigênio), produzindo assim menos sais inorgânicos em efluentes". }\end{array}$} & 1 & sistemas catalíticos - eficiência atômica \\
\hline & 2 & sistemas catalíticos - gás hidrogênio \\
\hline & 3 & sistemas catalíticos - gás oxigênio \\
\hline & 4 & sistemas cataliticos - sais inorgânicos \\
\hline & 5 & eficiência atômica - gás hidrogênio \\
\hline & 6 & eficiência atômica - gás oxigênio \\
\hline & 7 & eficiência atômica - sais inorgânicos \\
\hline & 8 & gás hidrogênio - gás oxigênio \\
\hline & 9 & gás hidrogênio - sais inorgânicos \\
\hline & 10 & gás oxigênio - sais inorgânicos \\
\hline
\end{tabular}

Quadro 3.6 - Exemplo contendo relações percebidas pelo Hamlet ${ }^{\circledR}$ para uma sentença extraída de texto coletado na disciplina Química Ambiental II

O quadro acima mostra quais relações são percebidas pelo programa para uma dada sentença extraída de um texto, no entanto, o resultado final da análise realizada pelo Hamlet $^{\circledR}$ por meio da ferramenta Hamlet Joint frequencies consiste em uma matriz de similaridade que organiza e quantifica as conexões identificadas entre conceitos da lista de vocabulário presentes no texto em análise.

Assim, para a sentença exemplificada, tendo como referência a lista de vocabulário que consta no quadro 3.5, a matriz de similaridade representada a seguir é obtida, em que para cada relação entre conceitos presente na sentença é atribuído o valor numérico 1 e o valor 0 significa a não ocorrência de relação entre conceitos: 


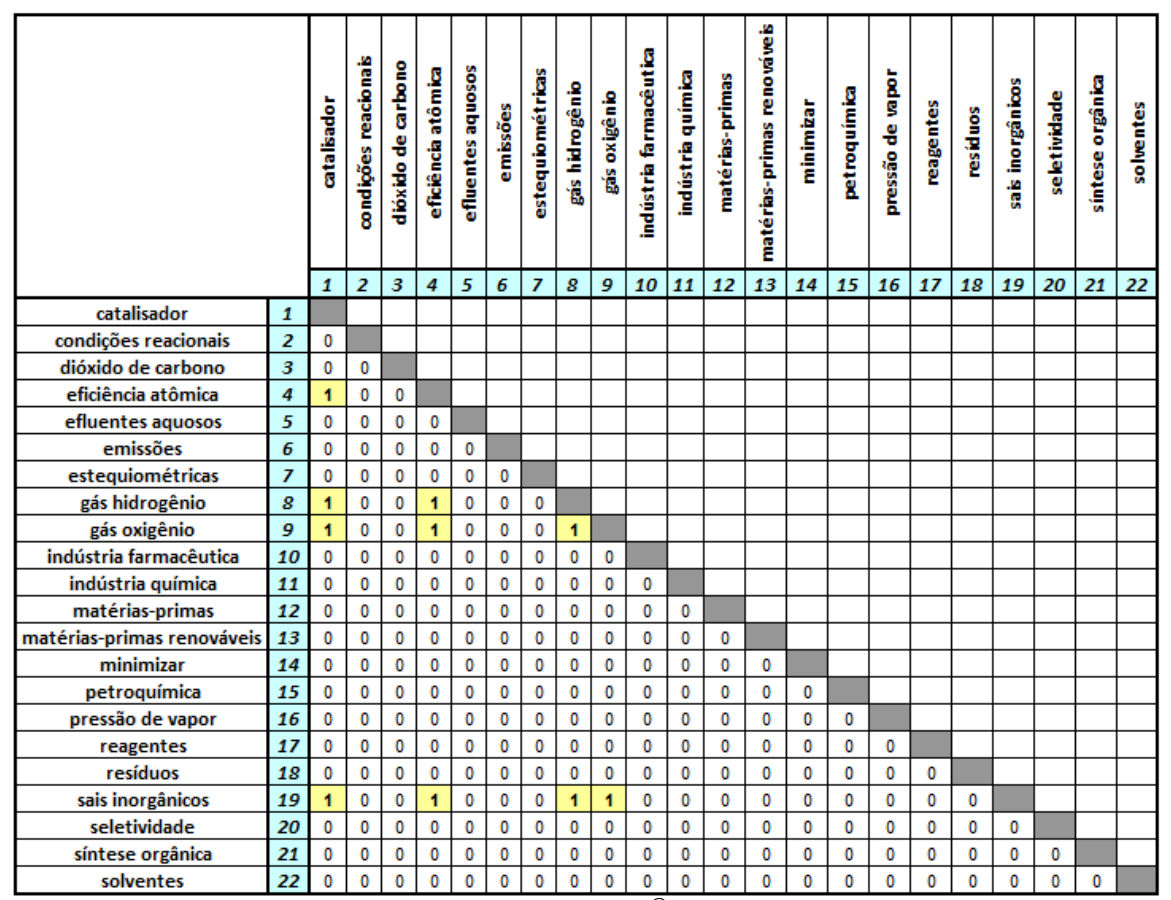

Figura 3.7 - Matriz de similaridade obtida pelo Hamlet $^{\circledR}$ para uma sentença extraída de texto coletado na disciplina Química Ambiental II

Como se pode perceber, a matriz apresentada na figura 3.7 é composta pelos valores numéricos 1 e 0 , que indicam a ocorrência ou não de uma relação entre conceitos na sentença analisada. No entanto, um dos diferenciais do programa Hamlet ${ }^{\circledR}$ é justamente a possibilidade de obter matrizes em que são contabilizadas todas as vezes que determinada relação ocorre em diferentes sentenças ao longo de um texto. Desta forma, para um texto constituído por várias sentenças, o programa reconhece e quantifica uma mesma relação entre conceitos que aparece em mais de uma sentença (e não na mesma sentença) ao longo do texto e, por este motivo, o produto final da análise do Hamlet $^{\circledR}$ pode ser uma matriz que não seja composta apenas pelos valores numéricos 1 e 0 .

A fim de exemplificar o tipo de matriz que é obtida pelo Hamlet ${ }^{\circledR}$ após a análise de um texto constituído por várias sentenças, a matriz da figura 3.8 quantifica as relações entre conceitos identificadas pelo Hamlet ${ }^{\circledR}$ após a leitura do texto que se encontra transcrito no quadro 3.7 a seguir, de onde foi extraída a sentença apresentada no quadro 3.6, referente à produção de um aluno da disciplina Química Ambiental II. No texto, as palavras escritas em negrito referem-se aos conceitos ou variações semânticas presentes na lista de vocabulário utilizada pelo programa para realizar a busca por relações entre conceitos. 
No contexto da atividade química, é necessário determinar condições reacionais menos nocivas ao ambiente e sempre visando minimizar a geração de resíduos, obedecendo alguns tópicos da química verde.

Desta forma, a utilização de matérias-primas renováveis apresenta-se de grande interesse, pois apresentam pouca persistência após o descarte, sendo biodegradadas a produtos pouco nocivos.

Sendo assim, a busca do desenvolvimento de sínteses orgânicas partindo de matérias-primas verdes tem sido realizada com veemência atualmente.

Contudo, alguns reagentes ainda provêm de derivados do petróleo (indústria petroquímica) sendo utilizados como matéria-prima na síntese de diversos produtos de consumo, sendo largamente estudadas novas rotas sintéticas para a elaboração desses produtos finais a partir de reagentes menos agressivos.

Ainda analisando rotas industriais, observa-se o interesse na diminuição dos efluentes aquosos gerados (os quais podem conter sais inorgânicos), assim como a utilização de solventes orgânicos, sendo esse um dos princípios da química verde.

A diminuição dos resíduos gerados e da utilização de solventes orgânicos é observada nos cálculos de eficiência atômica, que mensura o quanto dos átomos dos reagentes e solventes auxiliares efetivamente participa do produto final.

Outro princípio da química verde que auxilia na eficiência do processo alem de minimizar os impactos ao ambiente é a utilização de sistemas catalíticos.

A catálise leva à seletividade do produto gerado, minimizando também as perdas causadas por reações estequiométricas, sendo que tais reações catalisadas também podem ser realizadas em solventes alternativos (dióxido de carbono supercrítico) diminuindo também as perdas com solventes.

O dióxido de carbono utilizado como solvente a 78 bar e 31 graus Celsius provém da própria atmosfera, não sendo causador de novas emissões desse gás estufa.

Outro problema relacionado ao uso de solventes orgânicos está relacionado a sua volatilidade, ou seja, alta pressão de vapor, levando a emissões de compostos orgânicos voláteis causadores de danos a atmosfera.

Enfim, a utilização de sistemas catalíticos pode causar o aumento da eficiência atômica, facilitando, por exemplo, reações de hidrogenação (utilizando gás hidrogênio) ou reações de oxidação (utilizando gás oxigênio), produzindo assim menos sais inorgânicos em efluentes.

Tais desenvolvimentos têm afetado / influenciado industrias farmacêuticas e químicas, as quais possuíam uma grande geração de resíduos provenientes da larga utilização de solventes e de reações estequiométricas.

Desta forma o desenvolvimento de novos meios reacionais (às vezes sem solventes), a utilização de catalisadores e de condições reacionais mais amenas são observadas diretamente nos cálculos de eficiência atômica.

Quadro 3.7 - Texto elaborado por um aluno da disciplina Química Ambiental II 


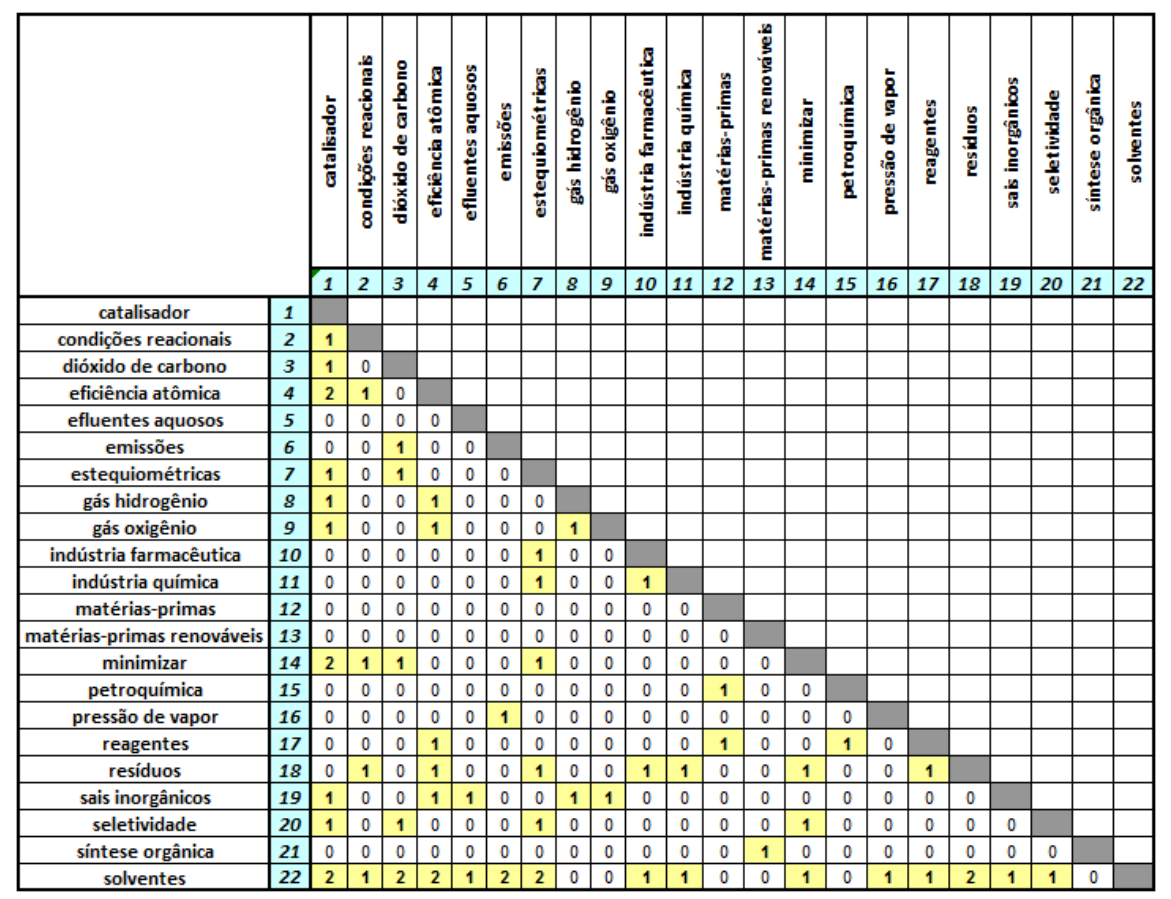

Figura 3.8 - Matriz de similaridade obtida pelo Hamlet $^{\circledR}$ para um texto coletado na disciplina Química Ambiental II

Para gerar uma matriz de similaridade, o programa Hamlet ${ }^{\circledR}$ analisa um texto e identifica todas as possibilidades de relação entre os conceitos da lista de vocabulário presentes em cada sentença do texto em questão, de forma semelhante ao modo $\mathrm{S}$ do programa $A L A$-Reader ${ }^{\circledR}$, descrito anteriormente. No entanto, o Hamlet ${ }^{\circledR}$ apresenta vantagens consideráveis em relação ao modo $\mathrm{S}$ do $A L A$-Reader ${ }^{\circledR}$, o que justifica a escolha pelo uso dessa ferramenta computacional na presente pesquisa:

- No programa Hamlet $^{\circledR}$, tanto a lista de vocabulário quanto o texto a ser analisado não possuem limite de linhas. Assim, a lista de vocabulário pode ser formada por quantos conceitos, variações semânticas ou sinônimos forem necessários. O fato de não haver limite de linhas para o texto a ser analisado auxilia demais o professor / pesquisador quando se trata de um trabalho com uma turma de alunos, pois basta que todos os textos produzidos pela turma sejam acrescentados a um único arquivo. Assim, em vez de ler um texto por vez e gerar uma matriz de similaridade para cada um, o programa é capaz de ler um único arquivo de texto com muitas linhas e gerar uma única matriz de similaridade que, por sua vez, consiste na matriz representativa da turma.

- Outra vantagem já indicada de se utilizar o Hamlet $^{\circledR}$ consiste no fato de este programa contabilizar na matriz de similaridade todas as vezes que um par de conceitos relacionados aparece ao longo do texto. Por este motivo, é possível perceber pelo exemplo da 
figura 3.8 que a matriz de similaridade obtida após a análise de um arquivo de texto não é composta apenas pelos números 0 e 1 .

- KWIC (Key Word In Context): Para finalizar a explicação das principais ferramentas do programa Hamlet $^{\circledR}$, ressalta-se a importância da ferramenta KWIC na busca pelo contexto em que certo conceito aparece ao longo de um texto. Trata-se de um importante recurso utilizado neste trabalho especialmente com o intuito de verificar as frases de ligação entre um par de conceitos, deixando clara a natureza de determinada relação.

\subsubsection{Definição das possíveis estruturas dos textos a serem analisados pelo programa} Hamlet $^{\circledR}$

Na seção anterior, procurou-se esclarecer ao leitor a maneira como os programas ALAReader $^{\circledR}$ e Hamlet $^{\circledR}$ fazem a leitura e análise de textos, a fim de quantificar relações entre conceitos na forma de uma matriz de similaridade. Além disso, foram explicitadas as vantagens do uso do programa Hamlet $^{\circledR}$ em relação ao programa ALA-Reader ${ }^{\circledR}$, de forma a justificar sua escolha para o desenvolvimento da presente pesquisa.

Ao observar as relações entre conceitos quantificadas pelo programa nos exemplos das figuras 3.7 e 3.8 paralelamente à leitura da sentença ou texto de origem, é possível afirmar que algumas das relações entre conceitos quantificadas nas matrizes podem não ser consideradas diretas ou proposicionais. Desta forma, em alguns casos, o que se tem é a quantificação de relações entre conceitos apenas pelo fato de os mesmos estarem presentes em uma mesma sentença, sem estabelecerem uma relação explícita ou de caráter proposicional entre eles.

Neste aspecto, visando estabelecer comparações entre diferentes maneiras de se analisar textos escritos por alunos, um importante trabalho consiste na busca pelas relações explícitas entre conceitos presentes em determinado texto. Este trabalho, na realidade, significa extrair as proposições presentes no texto em questão, lembrando que proposições são definidas como dois ou mais conceitos ligados por palavras em uma unidade semântica (NOVAK; GOWIN, 1984).

Uma vez que depende da compreensão e interpretação do leitor quanto ao texto que está sendo analisado, parece inevitável que o trabalho de extrair proposições tenha certo caráter subjetivo e, para que fique clara a maneira como é feita a extração das proposições a 
partir de um texto, os quadros abaixo organizam as proposições identificadas pela autora do presente trabalho para duas sentenças, indicadas como $\mathrm{N}^{\circ} 01$ e $\mathrm{N}^{\circ} 02$, extraídas do texto de um aluno da disciplina Química Ambiental II:

\begin{tabular}{|c|c|}
\hline SENTENÇA Nº1 & PROPOSIÇÕES EXTRAÍDAS \\
\hline \multirow{4}{*}{$\begin{array}{l}\text { "A diminuição dos residuos gerados e da utilização de solventes } \\
\text { orgânicos é observada nos cálculos de eficiência atômica, que mensura o } \\
\text { quanto dos átomos dos reagentes e solventes auxiliares efetivamente } \\
\text { participa do produto final". }\end{array}$} & $\begin{array}{l}\text { Eficiência atômica seus cálculos mostram diminuição na } \\
\text { geração de resíduos. }\end{array}$ \\
\hline & $\begin{array}{l}\text { Eficiência atômica seus cálculos mostram diminuição no uso } \\
\text { de solventes. }\end{array}$ \\
\hline & $\begin{array}{l}\text { Reagentes o quanto dos seus átomos participou do produto } \\
\text { final é mostrado pelo cálculo da eficiência atômica. }\end{array}$ \\
\hline & $\begin{array}{l}\text { Solventes o quanto dos seus átomos participou do produto final } \\
\text { é mostrado pelo cálculo da eficiência atômica. }\end{array}$ \\
\hline
\end{tabular}

Quadro 3.8 - Exemplo contendo proposições extraídas de uma sentença presente em texto coletado na disciplina Química Ambiental II

\begin{tabular}{|c|c|}
\hline SENTENÇA Nº2 & PROPOSIÇÕES EXTRAÍDAS \\
\hline \multirow{4}{*}{$\begin{array}{l}\text { "Enfim, a utilização de sistemas catalíticos pode causar o aumento da } \\
\text { eficiência atômica, facilitando, por exemplo, reações de hidrogenação } \\
\text { (utilizando gás hidrogênio) ou reações de oxidação (utilizando gás } \\
\underline{\text { oxigênio), produzindo assim menos sais inorgânicos em efluentes". }}\end{array}$} & $\begin{array}{c}\underline{\text { Sistemas catalíticos seu uso pode aumentar a eficiência }} \\
\text { atômica. }\end{array}$ \\
\hline & $\begin{array}{l}\text { Sistemas catalíticos podem facilitar reações de hidrogenação } \\
\text { utilizando gás hidrogênio. }\end{array}$ \\
\hline & $\begin{array}{l}\text { Sistemas catalíticos podem facilitar reações de oxidação } \\
\text { utilizando gás oxigênio. }\end{array}$ \\
\hline & $\underline{\text { Sistemas catalíticos podem produzir menos sais inorgânicos. }}$ \\
\hline
\end{tabular}

Quadro 3.9 - Exemplo contendo proposições extraídas de uma sentença presente em texto coletado na disciplina Química Ambiental II

A tarefa de extrair proposições de um texto sugeriu uma diferença considerável quanto à quantificação das relações entre conceitos, dependendo da estrutura desse texto. Assim, o número de relações entre conceitos presentes em um texto na forma como foi escrito (texto original) é diferente do número de relações entre conceitos identificadas após a tarefa de extrair proposições (texto modificado).

Ao observar as proposições extraídas das sentenças $\mathrm{N}^{\circ} 01$ e $\mathrm{N}^{\circ} 02$ (quadros 3.8 e 3.9), é possível comparar os pares de conceitos que aparecem relacionados nestas proposições com aqueles que são identificados pelo Hamlet $^{\circledR}$ como relacionados nas sentenças na forma como foram escritas originalmente. Para os exemplos em questão, tem-se uma diferença perceptível quanto ao número de pares de conceitos identificados, dependendo da estrutura do texto analisado - texto original ou texto modificado. Para as sentenças $\mathrm{N}^{\circ} 01$ e $\mathrm{N}^{\circ} 02$, um número 
maior de pares de conceitos relacionados é identificado na análise dos textos originais. Os quadros a seguir esclarecem quais relações entre conceitos são identificadas em cada caso.

\begin{tabular}{|c|c|c|}
\hline SENTENÇA N ${ }^{\circ} 01$ & $\begin{array}{l}\text { RELAÇÕES ENTRE PALAVRAS } \\
\text { PRESENTES NO TEXTO ORIGINAL }\end{array}$ & $\begin{array}{l}\text { RELAÇÕES ENTRE PALAVRAS } \\
\text { PRESENTES NAS PROPOSIÇÕES } \\
\text { EXTRAÍDAS }\end{array}$ \\
\hline \multirow{6}{*}{$\begin{array}{l}\text { "A diminuição dos resíduos gerados e da utilização de } \underline{\text { solventes orgânicos }} \\
\text { é observada nos cálculos de eficiência atômica, que mensura o quanto } \\
\text { dos átomos dos reagentes e solventes auxiliares efetivamente participa do } \\
\text { produto final". }\end{array}$} & residuos - solventes & \\
\hline & residuos - eficiência atômica & residuos - eficiência atômica \\
\hline & residuos - reagentes & \\
\hline & solventes - eficiência atômica & solventes - eficiência atômica \\
\hline & solventes - reagentes & \\
\hline & eficiência atômica - reagentes & eficiência atômica - reagentes \\
\hline
\end{tabular}

Quadro 3.10 - Comparação das relações entre conceitos percebidas no texto original e no texto modificado para a sentença $\mathrm{N}^{\circ} 01$

\begin{tabular}{|c|c|c|}
\hline SENTENÇA N02 & $\begin{array}{c}\text { RELAÇÕES ENTRE PALAVRAS } \\
\text { PRESENTES NO TEXTO ORIGINAL }\end{array}$ & $\begin{array}{c}\text { RELAÇÕES ENTRE PALAVRAS } \\
\text { PRESENTES NAS PROPOSIÇÕES } \\
\text { EXTRAÍDAS } \\
\end{array}$ \\
\hline \multirow{10}{*}{$\begin{array}{l}\text { "Enfim, a utilização de sistemas catalíticos pode causar o aumento da } \\
\text { eficiência atômica, facilitando, por exemplo, reações de hidrogenação } \\
\text { (utilizando gás hidrogênio) ou reações de oxidação (utilizando gás } \\
\text { oxigênio), produzindo assim menos sais inorgânicos em efluentes". }\end{array}$} & sistemas cataliticos - eficiência atômica & sistemas cataliticos - eficiência atômica \\
\hline & sistemas cataliticos - gás hidrogênio & sistemas cataliticos - gás hidrogênio \\
\hline & sistemas cataliticos - gás oxigênio & sistemas cataliticos - gás oxigênio \\
\hline & sistemas cataliticos - sais inorgânicos & sistemas cataliticos - sais inorgânicos \\
\hline & eficiência atômica - gás hidrogênio & \\
\hline & eficiência atômica - gás oxigênio & \\
\hline & eficiência atômica - sais inorgânicos & \\
\hline & gás hidrogênio - gás oxigênio & \\
\hline & gás hidrogênio - sais inorgânicos & \\
\hline & gás oxigênio - sais inorgânicos & \\
\hline
\end{tabular}

Quadro 3.11 - Comparação das relações entre conceitos percebidas no texto original e no texto modificado para a sentença $\mathrm{N}^{\circ} 02$

Os exemplos apresentados mostram que as relações entre conceitos a serem identificadas pelo Hamlet $^{\circledR}$ em sua análise dependem essencialmente da estrutura do texto em questão, portanto, a matriz gerada pelo programa para quantificar essas relações entre conceitos também será diferente, de acordo com a estrutura do texto analisado.

É possível dizer que a matriz obtida pelo Hamlet $^{\circledR}$ a partir da análise do texto original dos alunos quantifica relações entre conceitos consideradas diretas e indiretas, o que quer dizer que parte das relações identificadas coincidem com aquelas também identificadas no texto modificado, porém outras relações não. Para a sentença $\mathrm{N}^{\circ} 01$, por exemplo, as relações entre os três pares de conceitos resíduos - eficiência atômica, solventes - eficiência atômica e eficiência atômica - reagentes são identificadas pela análise dos dois tipos de estrutura de texto, de acordo com o que é mostrado no quadro 3.10. As relações entre os pares de conceitos resíduos - solventes, resíduos - reagentes e solventes - reagentes, por sua vez, não 
podem ser consideradas diretas ou proposicionais, tendo sido reconhecidas pelo Hamlet $^{\circledR}$ na análise do texto original pelo fato de os conceitos citados estarem presentes na mesma sentença.

A matriz obtida pelo Hamlet $^{\circledR}$ a partir da análise do texto modificado quantifica exatamente as relações proposicionais entre conceitos estabelecidas pelo aluno, o que tem grande importância dentro do contexto da investigação da estrutura de conhecimentos dos alunos sobre determinado tema. No entanto, deve-se considerar que a matriz obtida pelo Hamlet $^{\circledR}$ após a análise do texto original também tem sua relevância dentro deste mesmo contexto, uma vez que ao escrever sentenças que compõem um texto o aluno reflete e considera a existência de alguma relação entre os conceitos que utiliza em sua produção, sem necessariamente estabelecer relações proposicionais entre todos esses conceitos. Desta forma, é possível dizer que as matrizes obtidas tanto a partir do texto original quanto do texto modificado têm grande importância para a presente pesquisa, possibilitando focos distintos para as posteriores análises dessas matrizes.

Diante da percepção sobre a influência da estrutura do texto na matriz a ser obtida pelo programa Hamlet ${ }^{\circledR}$, decidiu-se por analisar todos os textos dos alunos das disciplinas Química Ambiental II e Química e Sociedade das duas maneiras descritas, ou seja, efetuou-se a análise dos textos originais dos alunos e de seus textos modificados, contendo apenas as proposições extraídas dos textos originais. Em ambos os casos, o programa Hamlet ${ }^{\circledR}$ quantificou as relações entre conceitos presentes no texto analisado e gerou uma matriz de similaridade, que poderá ser chamada de matriz representativa da turma, uma vez que o arquivo de texto analisado pelo $\mathrm{Hamlet}^{\circledR}$ continha os textos originais ou as proposições extraídas dos textos de todos os alunos de cada uma das disciplinas que compõem os dados da presente pesquisa.

No entanto, para todos os dados que compõem esta pesquisa será necessário diferenciar as matrizes obtidas de acordo com a estrutura do texto de origem, por isso, a matriz obtida a partir dos textos originais será denominada como matriz representativa (1) e a matriz obtida a partir dos textos modificados será denominada como matriz representativa (2). Desta forma, o processo de obtenção das matrizes a partir dos textos originais e das proposições extraídas referentes a todos os alunos das disciplinas Química Ambiental II e Química e Sociedade é representado na figura a seguir. 


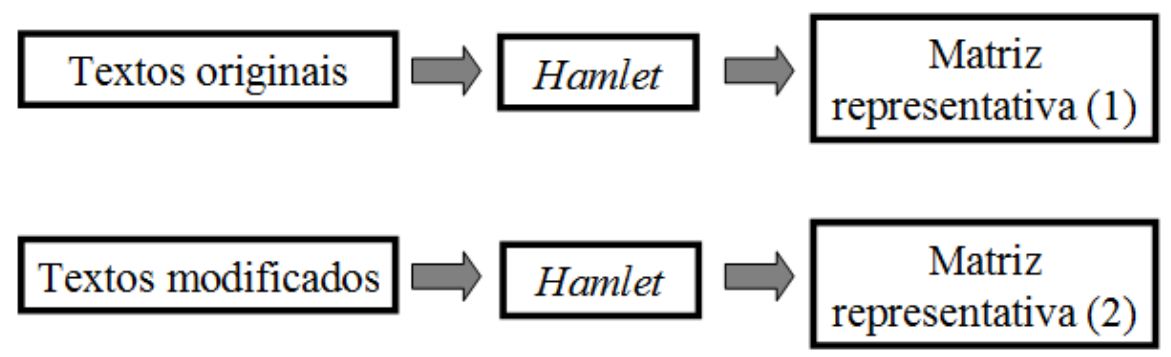

Figura 3.9 - Processo de obtenção de matrizes representativas

As matrizes representativas da turma possibilitam uma série de inferências e comparações relevantes no que diz respeito às relações entre conceitos estabelecidas nos textos dos alunos. No entanto, as informações presentes em uma matriz representativa podem ser compreendidas de maneira mais clara e objetiva quando convertidas para uma estrutura gráfica, como redes e mapas conceituais. A seguir, são apresentados os tipos de estruturas gráficas construídas a partir das matrizes obtidas com os dados que compõem a presente pesquisa.

\subsubsection{Obtenção de redes de conceitos}

As redes de conceitos consistem em estruturas gráficas mais simples que os mapas conceituais, uma vez que mostram relações existentes entre conceitos, mas não a natureza destas relações. Da mesma forma que os mapas conceituais, as redes podem ser obtidas a partir de matrizes utilizando diferentes critérios, sendo que neste trabalho o objetivo principal é sistematizar e representar da maneira mais próxima possível a estrutura de conhecimentos de uma turma de alunos. As redes de conceitos mostradas nesta pesquisa, referentes aos dados coletados nas disciplinas Química Ambiental II e Química e Sociedade, são de dois tipos: rede de conceitos considerando o(s) vizinho(s) mais próximo(s) e rede de conceitos a partir de corte percentual.

\section{- Redes de conceitos contemplando o(s) vizinho(s) mais próximo(s): Rede (V+P)}

A rede de conceitos contemplando o(s) vizinho(s) mais próximo(s), como o próprio nome diz, é aquela que apresenta o conceito que foi relacionado mais vezes a outro 
determinado conceito, podendo existir mais de um vizinho mais próximo para qualquer conceito. O primeiro passo para a obtenção desse tipo de rede consiste na marcação do(s) vizinho(s) mais próximo(s) na matriz representativa de origem, ou seja, na linha ou coluna correspondente a cada conceito na matriz marcam-se os maiores valores numéricos presentes.

$\mathrm{Na}$ figura a seguir, por exemplo, percebe-se que os maiores valores numéricos encontrados para os conceitos lei, modelo, previsão e verdade se referem à relação estabelecida com o conceito teoria, na seguinte sequência de valores: 8, 12, 5 e 5. Desta forma, o conceito teoria é considerado o vizinho mais próximo dos conceitos lei, modelo, previsão e verdade.

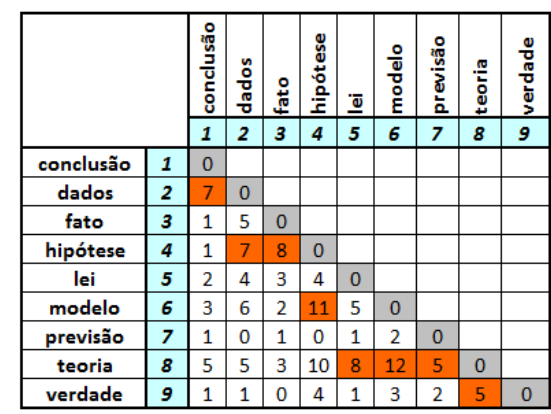

Figura 3.10 - Exemplo de uma matriz com o(s) vizinho(s) mais próximo(s) de cada conceito em destaque

A partir desta matriz contendo o(s) vizinho(s) mais próximo(s) em destaque, é construída a rede de conceitos correspondente, na qual se verifica a presença de setas cujos sentidos indicam o(s) vizinho(s) mais próximo(s) de um determinado conceito. A seguir é apresentada a rede de conceitos contemplando o(s) vizinho(s) mais próximo(s) referente à matriz da figura 3.10. Para a rede ilustrada na figura 3.11, as setas incluem o número de vezes que cada par de conceitos foi relacionado, além de indicarem o(s) vizinho(s) mais próximo(s) de cada conceito através de seu sentido.

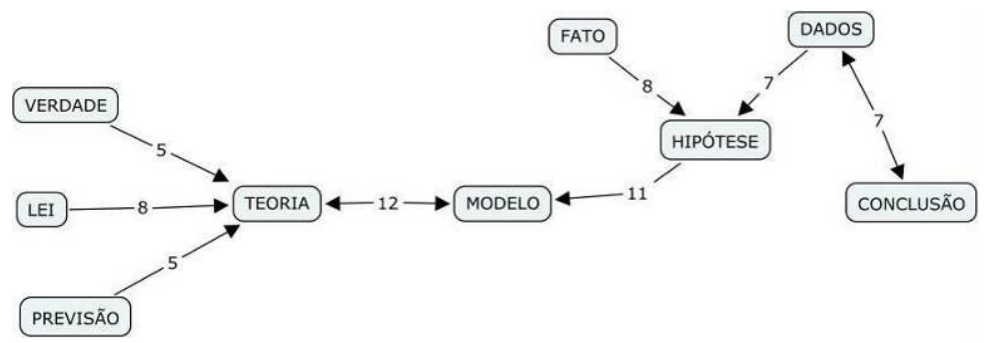

Figura 3.11 - Rede de conceitos do tipo $(\mathrm{V}+\mathrm{P})$ referente à matriz apresentada na figura 3.10 


\section{- Redes de conceitos a partir de corte percentual: Rede (\%)}

A estrutura gráfica denominada neste trabalho como rede de conceitos obtida a partir de um corte percentual baseia-se na ideia de representar as relações entre conceitos que mais foram estabelecidas nos textos originais e nos textos modificados dos alunos. No entanto, conforme será exposto a seguir, dependendo do corte percentual escolhido, redes com diferentes estruturas podem ser obtidas, possivelmente apresentando muitos grupos de conceitos isolados ou excesso de conceitos relacionados, o que dificulta a análise e compromete a utilidade da estrutura gráfica obtida.

O corte percentual é feito da seguinte forma: em primeiro lugar, para uma determinada matriz representativa, os valores numéricos que nela aparecem são ordenados e, então, contabiliza-se quantas vezes cada um desses valores numéricos aparece nessa matriz. A título de exemplo, a seguir é apresentada a matriz representativa (1) referente aos dados coletados na disciplina Química Ambiental II e, na sequência, a tabela 3.1 mostra como os valores numéricos presentes nessa matriz foram ordenados e contabilizados para o estabelecimento do corte percentual.

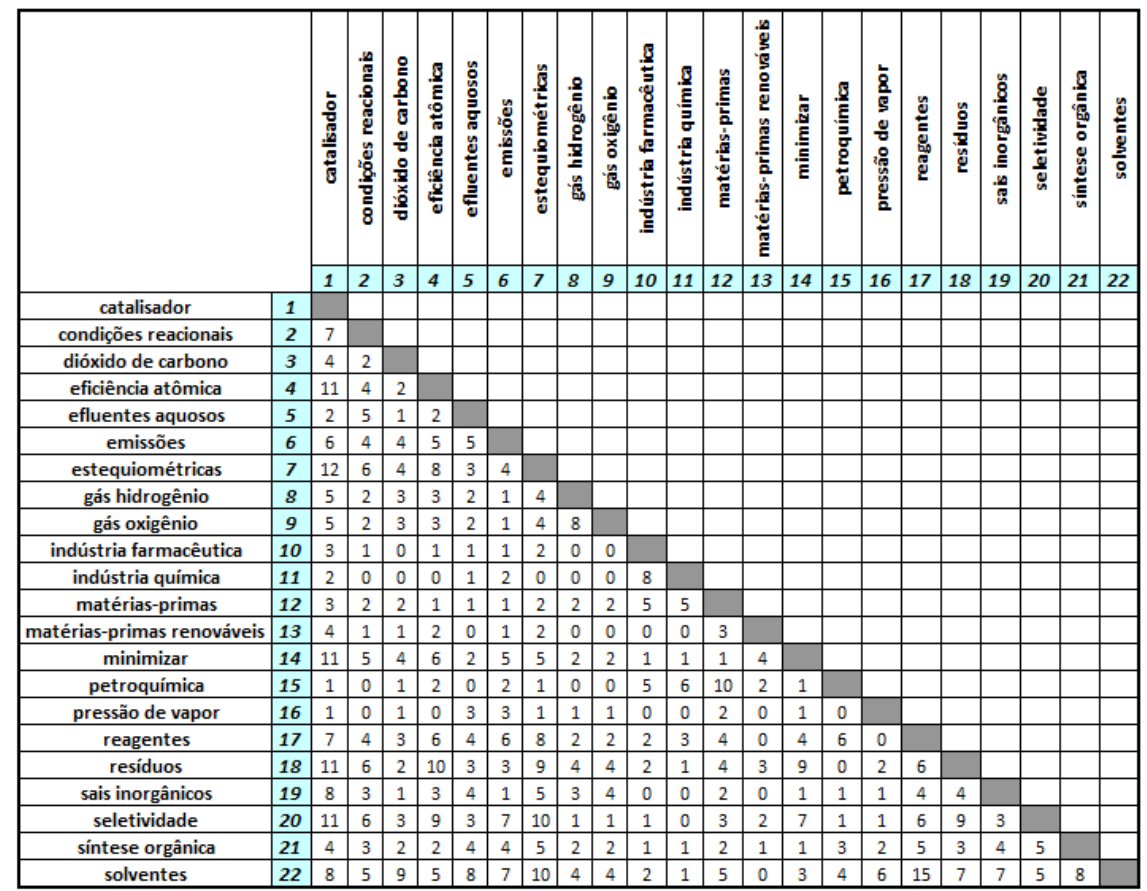

Figura 3.12 - Matriz representativa (1) referente aos dados da disciplina Química Ambiental II 
Tabela 3.1 - Ordenação e quantificação dos valores presentes na matriz da figura 3.12

\begin{tabular}{|c|c|c|c|c|c|c|c|c|c|c|c|c|c|c|c|}
\hline $\begin{array}{c}\text { Valor presente na matriz } \\
\text { representativa (1) }\end{array}$ & 1 & 2 & 3 & 4 & 5 & 6 & 7 & 8 & 9 & 10 & 11 & 12 & 13 & 14 & 15 \\
\hline $\begin{array}{c}\mathbf{N}^{\circ} \text { de vezes que o valor } \\
\text { aparece na matriz }\end{array}$ & 43 & 40 & 26 & 29 & 19 & 12 & 7 & 8 & 5 & 4 & 4 & 1 & 0 & 0 & 1 \\
\hline
\end{tabular}

O corte percentual pode então ser estabelecido em 5\%,10\%, 15\%, 25\%, 50\% ou qualquer outro percentual do número total de relações estabelecidas entre conceitos na matriz, levando-se em consideração que, dependendo do corte percentual escolhido, diferentes redes são obtidas. Assim, considerando que o número de diferentes relações estabelecidas entre conceitos na matriz da figura 3.12 foi de 199 (somatória dos valores da segunda linha da tabela 3.1), o corte percentual em $25 \%$ deste valor, por exemplo, corresponde a 49,75.

Uma vez que neste trabalho o objetivo é obter redes em que estejam presentes as principais relações entre conceitos, ou seja, as relações mais estabelecidas nos textos dos alunos, para o exemplo em questão partiu-se dos maiores valores encontrados na matriz da figura 3.12 e foi feita a somatória do número de vezes que cada um desses valores numéricos apareceu na matriz até chegar ao valor mais próximo de 49,75. No caso da matriz da figura 3.12 , isto corresponde a relações estabelecidas a partir de 6 vezes, o que se encontra em destaque e explicado na figura a seguir:

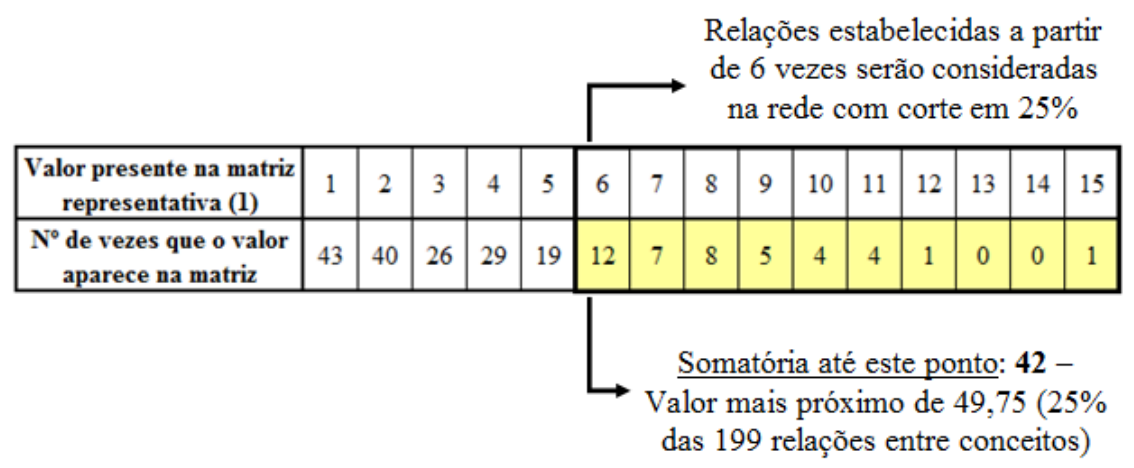

Figura 3.13 - Exemplo de corte percentual em 25\% aplicado aos dados da matriz da figura 3.12

Desta forma, a rede de conceitos com corte percentual em $25 \%$ pode ser construída, considerando-se apenas as relações entre conceitos que aparecem na matriz da figura 3.12 a partir de 6 vezes, ou seja, as relações que mais foram estabelecidas, de acordo com o corte percentual considerado. 
Conforme já mencionado, o corte percentual para a elaboração de uma rede de conceitos é variável, podendo gerar redes com diferentes estruturas. Durante a realização do presente trabalho, com o objetivo de estabelecer comparações e de obter a melhor estrutura gráfica que possibilitasse estudar e analisar o entendimento dos alunos, foram construídas redes de conceitos com cortes percentuais em 5\%,10\%, 15\%, 25\% e 50\% para todas as matrizes representativas obtidas pelo Hamlet $^{\circledR}$.

A figura a seguir, por exemplo, agrupa as redes obtidas com os cortes percentuais em $5 \%, 10 \%, 15 \%$ e $25 \%$ a partir da matriz apresentada na figura 3.12 , referente aos textos originais coletados na disciplina Química Ambiental II. Nesta representação, fica claro o quanto o estabelecimento de diferentes cortes percentuais para determinada matriz pode interferir na estrutura da rede conceitual obtida.

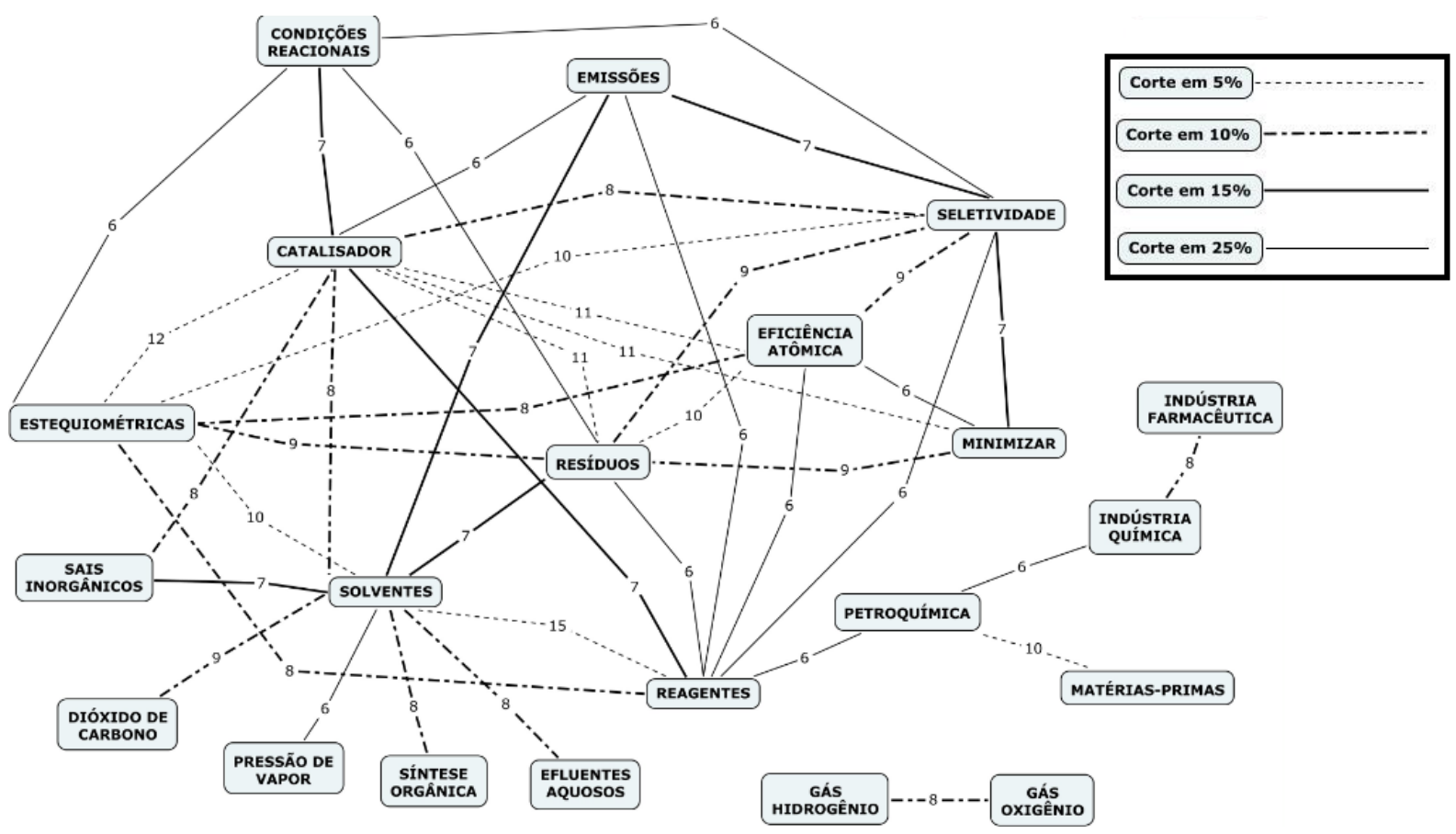

Figura 3.14 - Redes de conceitos com diferentes cortes percentuais obtidas a partir da matriz da figura 3.12

Além disso, nota-se que a estrutura da rede depende essencialmente dos valores numéricos presentes na matriz que a originou e, por este motivo, no caso de todas as redes obtidas para as matrizes representativas (1) e (2) desta pesquisa, têm-se redes baseadas no mesmo corte percentual, porém estruturalmente diferentes. A título de exemplo, é possível citar as redes das figuras 3.15 e 3.16 que se tratam de redes baseadas no mesmo corte 
percentual em $50 \%$, porém, sem realizar uma análise profunda dessas redes, percebe-se que as mesmas diferem substancialmente quanto ao número de ligações presentes.

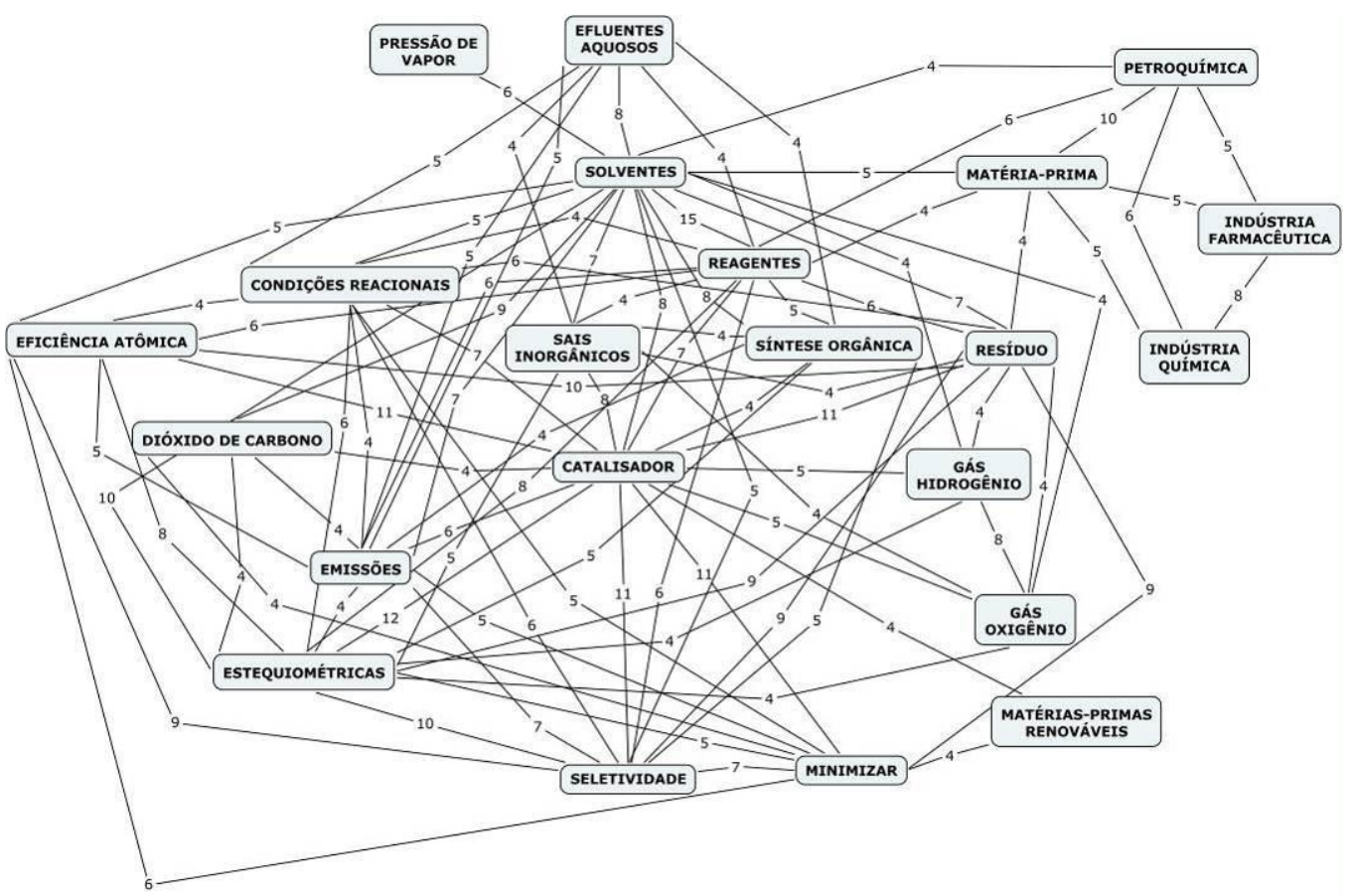

Figura 3.15 - Rede com corte percentual $50 \%$ obtida a partir de uma matriz representativa (1)

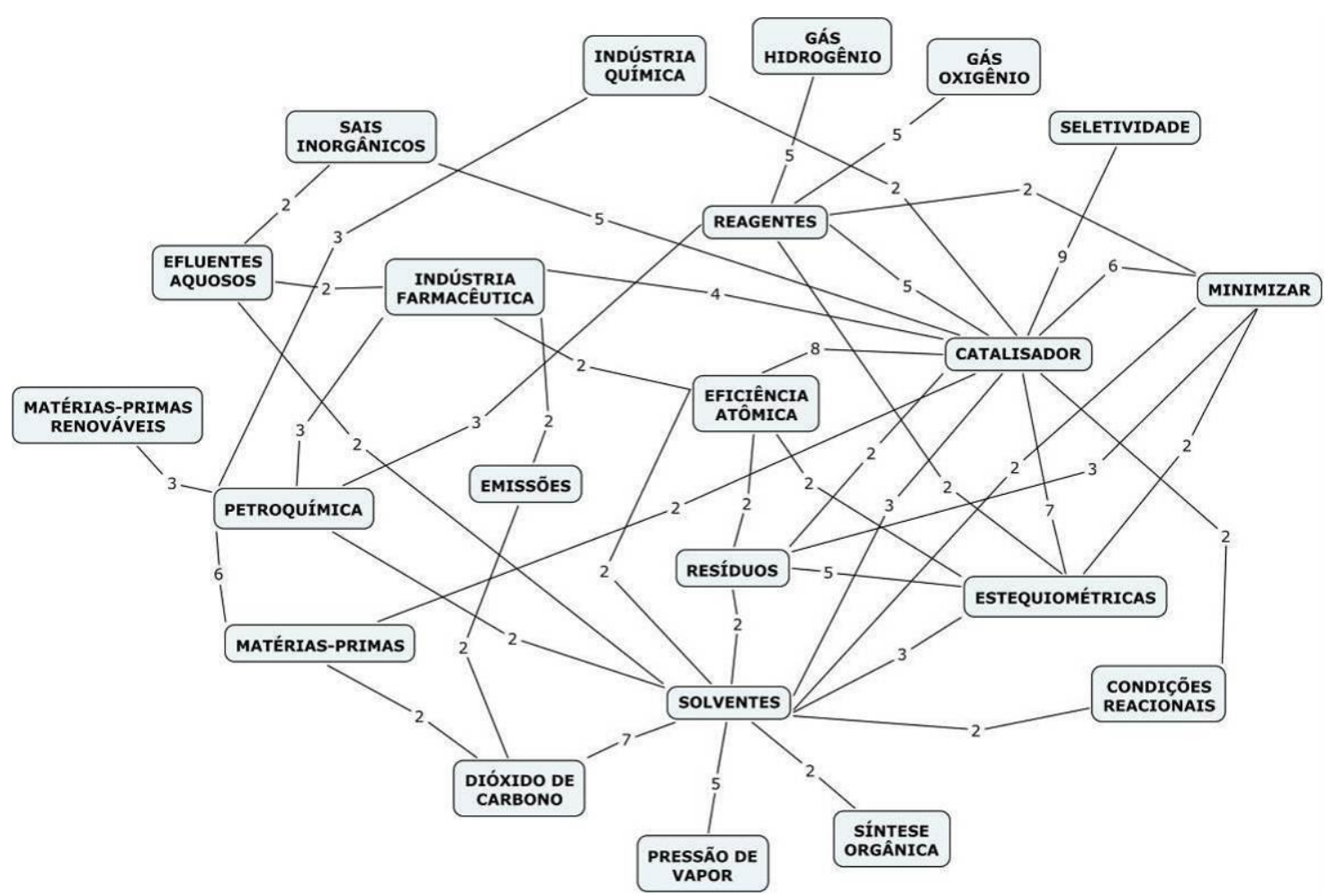

Figura 3.16 - Rede com corte percentual 50\% obtida a partir de uma matriz representativa (2) 
A obtenção de diferentes redes baseadas nos diversos valores de corte percentual foi o que possibilitou uma análise comparativa a fim de escolher as estruturas gráficas que melhor representassem as ideias e o entendimento dos alunos acerca do que foi trabalhado nas disciplinas Química Ambiental II e Química e Sociedade, o que será detalhado no capítulo 4 deste trabalho, que trata da discussão dos resultados obtidos na pesquisa.

\subsubsection{Obtenção de mapas conceituais}

O presente trabalho também inclui a obtenção de mapas conceituais a partir de matrizes representativas que quantificam relações entre conceitos. Os mapas conceituais são estruturas gráficas que organizam e representam relações significativas entre conceitos, contemplando relações proposicionais, onde se verifica a natureza da relação estabelecida entre os conceitos (NOVAK; CAÑAS, 2007).

Conforme mencionado anteriormente, uma observação relevante durante o uso do Hamlet $^{\circledR}$ para a obtenção de matrizes diz respeito à possibilidade de o programa contabilizar relações entre conceitos que estejam presentes em uma mesma sentença, mesmo não existindo relação proposicional entre um conceito e o outro. Desta forma, ao fazer a leitura de um texto, o programa não é capaz de identificar se dois conceitos presentes em uma mesma frase estão diretamente relacionados, ou seja, se existe uma relação proposicional entre eles. Por este motivo, apresentou-se o processo de modificação de textos em que são extraídas as proposições de um texto na forma como foi escrito originalmente, de modo a obter uma matriz que quantifica apenas as relações proposicionais entre conceitos estabelecidas (matriz (2)).

Os mapas conceituais elaborados na presente pesquisa referem-se às duas matrizes representativas possíveis de se obter, as quais possuem diferenças substanciais em relação ao número de relações presentes. O ponto de partida para a construção do mapa conceitual correspondente à determinada matriz representativa é uma rede de conceitos com algum corte percentual escolhido. A partir desta rede, com o auxílio da ferramenta KWIC (Key Word In Context) do Hamlet $^{\circledR}$, é possível realizar a busca pelas frases de ligação entre conceitos que se encontram relacionados na rede escolhida, de modo a construir as proposições que fazem parte do mapa conceitual. Tanto as redes quanto os mapas conceituais construídos neste trabalho foram elaborados por meio da ferramenta CmapTools (CAÑAS et al., 2004) e a 
figura a seguir apresenta o processo de construção de mapas conceituais utilizado nesta pesquisa a partir de textos com diferentes estruturas.

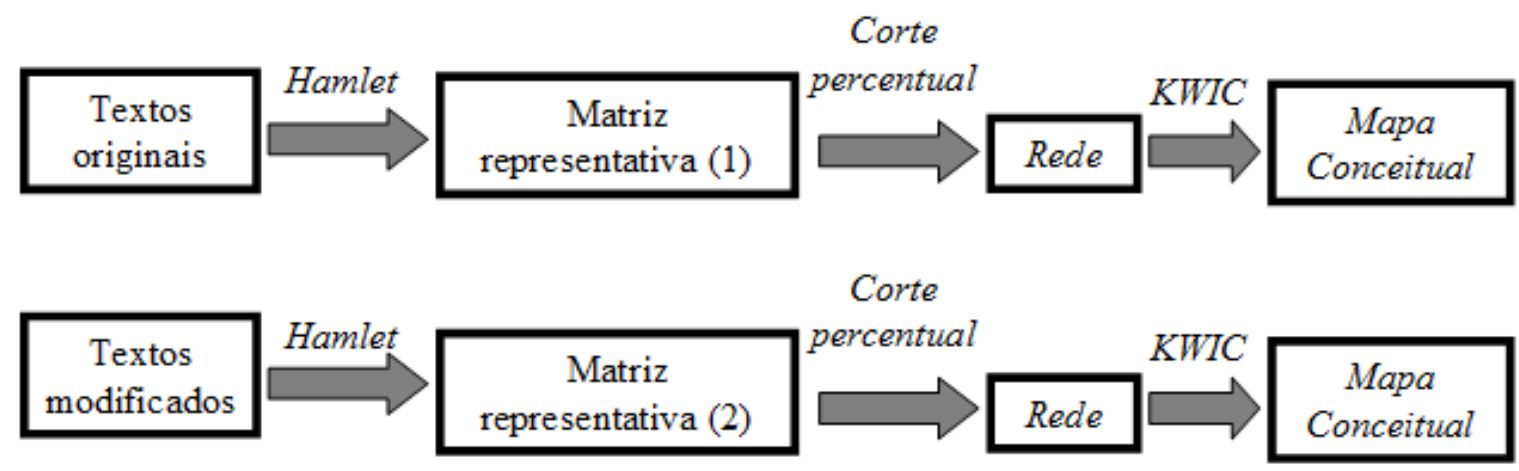

Figura 3.17 - Processo de obtenção de mapas conceituais a partir de textos com diferentes estruturas

Ao se pensar na elaboração de um mapa conceitual a partir de uma matriz representativa como as que são obtidas neste trabalho, é coerente pensar que o mapa conceitual mais fiel ao que foi escrito nos textos dos alunos e, portanto, que melhor representa as ideias e relações mais significativas presentes no conjunto dos textos produzidos por cada indivíduo do grupo seja justamente o mapa construído a partir de uma matriz representativa (2), uma vez que nesta matriz são computadas apenas as relações que realmente formam proposições entre os conceitos.

No entanto, conforme indicado na figura 3.17, nesta pesquisa optou-se por construir mapas conceituais partindo-se tanto dos textos originais quanto dos textos modificados, com o objetivo de convergir e comparar as estruturas gráficas obtidas dos dois modos. Esta escolha por obter mapas conceituais a partir das duas possíveis estruturas de texto também se justifica pelo objetivo que se tem em demonstrar o quanto as duas estruturas gráficas se aproximam uma da outra, uma vez que o trabalho inicial de modificação de textos consiste em uma atividade que demanda certo tempo por parte de um pesquisador ou professor.

$\mathrm{O}$ esquema a seguir refere-se à sentença $\mathrm{N}^{\circ} 01$ mostrada anteriormente no quadro 3.10 e nesse esquema procura-se demonstrar como o processo de construção de um mapa conceitual a partir de matrizes provenientes das duas possíveis estruturas de texto consiste em um processo dinâmico e interativo, no qual se recorre constantemente ao texto e à estrutura gráfica para a elaboração de uma representação coerente e fiel ao que foi registrado pelo autor do texto. 

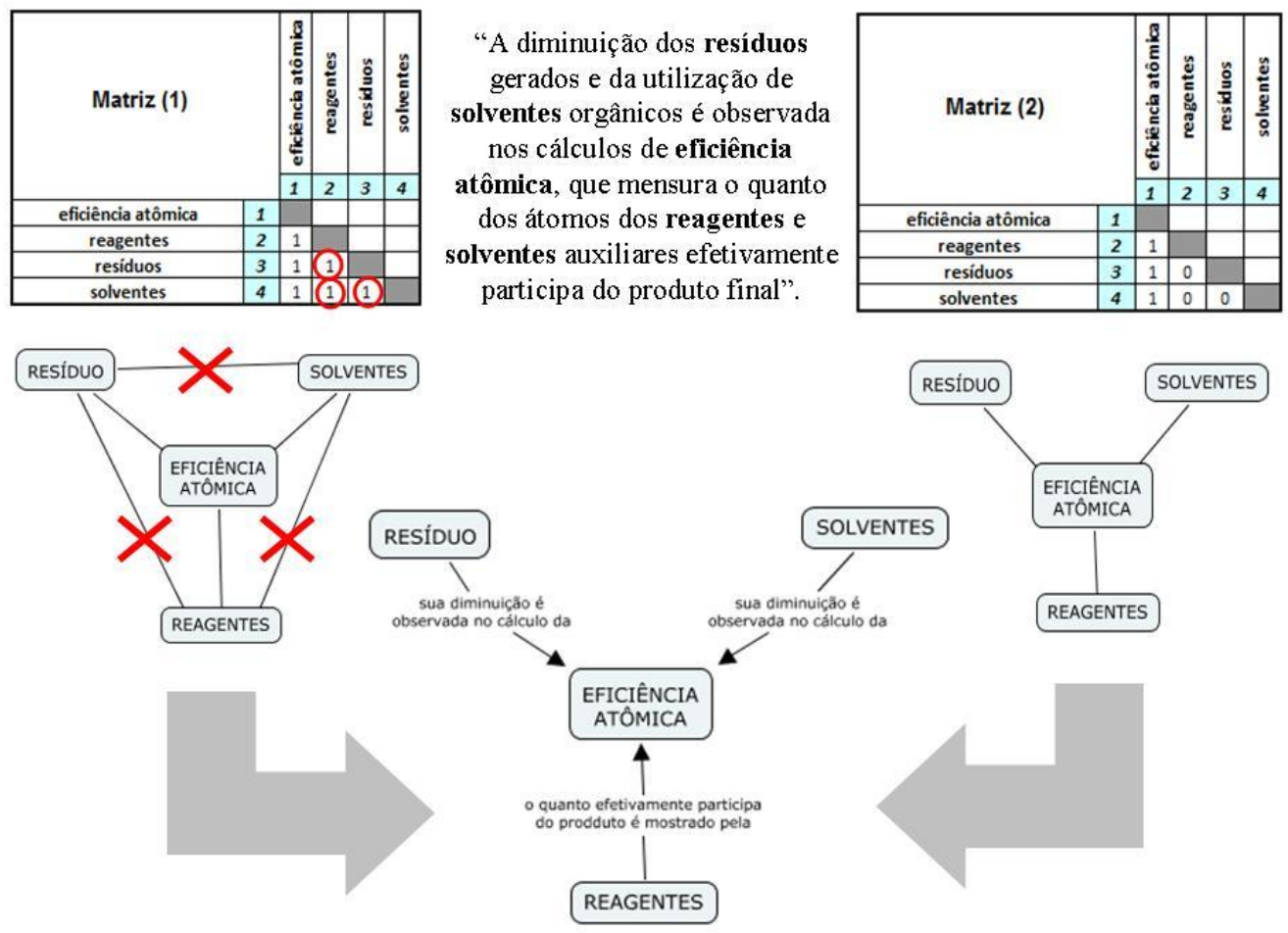

Esquema 3.1 - Processo de elaboração de um mapa conceitual a partir das duas possíveis estruturas de texto

Conforme exemplificado no esquema 3.1, em uma rede proveniente de uma matriz representativa (1) podem ser encontradas relações entre conceitos que não possuem caráter proposicional. A busca pelas frases de ligação entre os pares de conceitos para a construção de um mapa conceitual permite verificar que uma parte do número de relações entre conceitos contempladas na rede não é de caráter proposicional. Assim, para alguns pares de conceitos, o número de vezes em que a relação foi estabelecida pode diminuir quando se compara a rede com o mapa conceitual, sendo possível até mesmo que algumas relações entre conceitos presentes na rede deixem de existir no mapa conceitual construído.

Desta forma, ao elaborar um mapa conceitual a partir de uma rede deste tipo, espera-se que o número de relações entre conceitos presentes no mapa seja inferior ao que se tem na rede de conceitos de origem, o que de fato ocorre e será demonstrado de forma mais completa no capítulo 4 deste trabalho para os dados coletados nas disciplinas Química Ambiental II e Química e Sociedade. 


\section{Capítulo 4.}

\section{RESULTADOS E DISCUSSÃO}




\section{Capítulo 4. RESULTADOS E DISCUSSÃO}

\subsection{Análises referentes à disciplina Química Ambiental II}

A análise dos textos dos alunos da disciplina Química Ambiental II se deu das duas maneiras já descritas: a partir dos textos originais e dos textos modificados. Em ambos os casos, as relações entre conceitos presentes no texto analisado foram quantificadas com auxílio do programa Hamlet $^{\circledR}$, gerando uma matriz de similaridade que pode ser chamada de matriz representativa da turma, uma vez que o arquivo de texto analisado pelo Hamlet $^{\circledR}$ continha os textos originais ou modificados referentes aos 16 alunos da disciplina. Conforme mencionado anteriormente, para diferenciar estas matrizes de acordo com a origem dos dados, a matriz obtida a partir dos textos originais será denominada como matriz representativa (1) e a matriz obtida a partir dos textos modificados será denominada como matriz representativa (2).

As matrizes representativas da turma possibilitaram uma série de inferências e comparações relevantes no que diz respeito às relações entre conceitos estabelecidas nos textos dos alunos. Nas figuras 4.1 e 4.2 são mostradas as matrizes representativas obtidas pelo Hamlet $^{\circledR}$ após a análise dos textos originais e modificados coletados na disciplina Química Ambiental II.

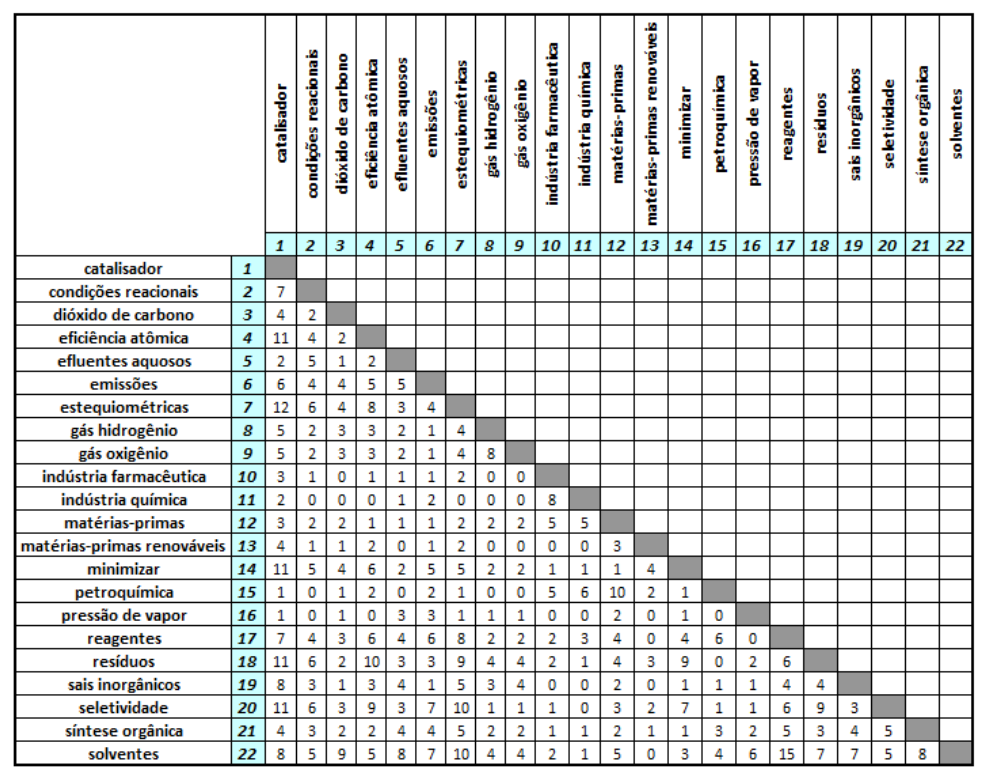

Figura 4.1 - Matriz representativa (1) obtida pelo Hamlet $^{\circledR}$ a partir dos textos originais 


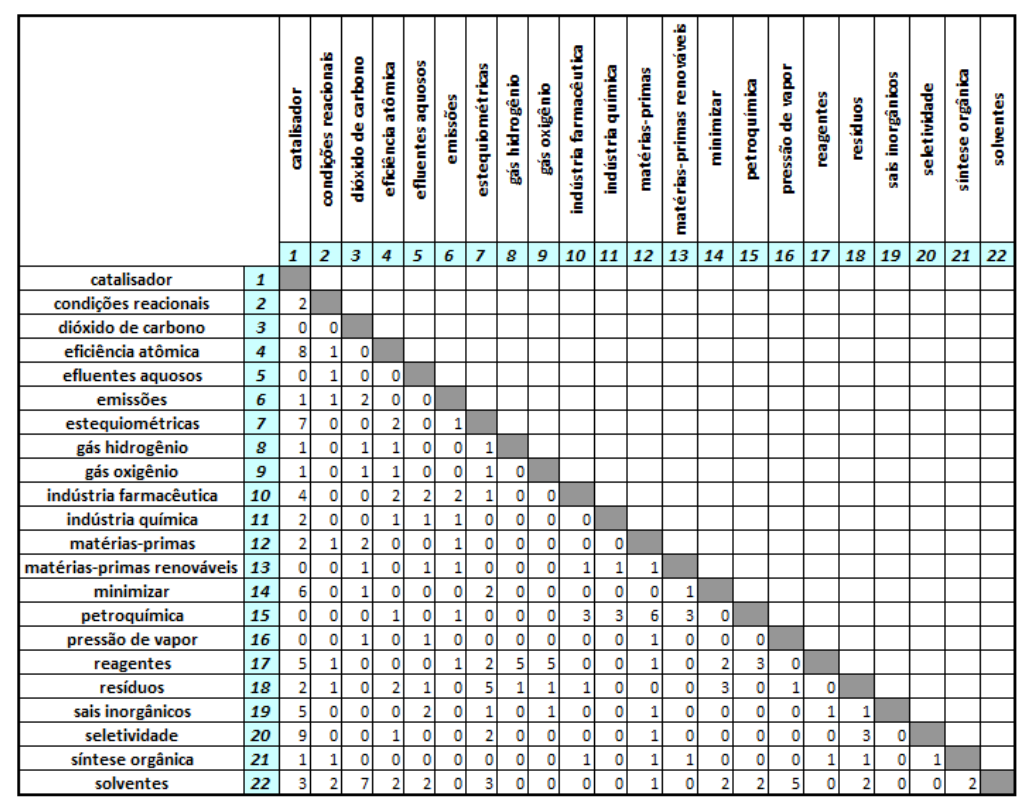

Figura 4.2 - Matriz representativa (2) obtida pelo Hamlet $^{\circledR}$ a partir dos textos modificados

\subsubsection{Análise das matrizes obtidas}

A primeira comparação possível de se fazer entre as matrizes representativas (1) e (2) diz respeito ao número total de relações estabelecidas entre os conceitos, número este referente à somatória de todos os valores numéricos presentes nas matrizes. O número total de relações presentes nas matrizes representativas (1) e (2) corresponde a 753 e 204, respectivamente. Verifica-se, portanto, que o número total de relações entre conceitos presentes na matriz proveniente da análise dos textos originais (matriz representativa (1)) é consideravelmente maior (quase quatro vezes) do que o que se tem na matriz proveniente dos textos modificados (matriz representativa (2)). Desta forma, confirma-se o que anteriormente já havia sido observado em relação à análise realizada pelo Hamlet ${ }^{\circledR}$ dos textos na forma como foram escritos originalmente: o programa, em sua leitura e análise, identifica todas as possibilidades de relações entre conceitos presentes numa mesma sentença, relações estas que não necessariamente possuem caráter proposicional.

Outra análise relevante refere-se ao número e à natureza dos pares de conceitos relacionados nos textos originais dos alunos ou nas proposições extraídas destes textos. Considerando que 22 conceitos faziam parte da lista de palavras que os alunos poderiam utilizar para escreverem seus textos, conforme enunciado apresentado na seção 3.1.1 deste 
trabalho, verifica-se a possibilidade de 231 diferentes relações entre conceitos. Em princípio, dentre estas diferentes possibilidades de relações entre conceitos, destacam-se aquelas identificadas nas matrizes representativas como inexistentes, ou seja, relações entre conceitos que não foram estabelecidas. Neste caso, 32 diferentes pares de conceitos não apresentam relação identificada na matriz representativa (1), enquanto 130 é o número de relações inexistentes presentes na matriz representativa (2). Além disso, a análise da matriz representativa (1) mostra que 199 diferentes relações entre conceitos foram estabelecidas, o que corresponde a cerca de $86 \%$ das possibilidades de diferentes relações. Já a mesma análise realizada para a matriz representativa (2) mostra que 101 diferentes relações entre conceitos foram estabelecidas, o que corresponde a cerca de $44 \%$ das relações possíveis de serem estabelecidas. Ou seja, no caso da matriz proveniente dos textos originais, é possível perceber que quase todos os conceitos foram relacionados entre eles alguma vez, restando poucas relações inexistentes entre conceitos (poucos zeros na matriz), o que é coerente com a observação já citada quanto à maneira como o Hamlet $^{\circledR}$ faz a leitura e análise de textos.

A título de exemplo, considerando-se apenas as relações entre conceitos estabelecidas a partir de 6 vezes na matriz representativa proveniente dos textos originais, tem-se um total de 13 diferentes relações entre conceitos que constam como relações inexistentes na matriz representativa proveniente dos textos modificados. Aqui, novamente, fica evidente a observação já percebida quanto ao funcionamento do programa Hamlet ${ }^{\circledR}$, em que relações entre conceitos consideradas inexistentes nos textos modificados podem eventualmente ser reconhecidas pelo programa ao realizar a análise dos textos originais. A figura a seguir mostra os pares de conceitos que constam como relacionados a partir de 6 vezes na matriz representativa (1) e nenhuma vez na matriz representativa (2). 
Tabela 4.1 - Comparação exemplificando relações entre conceitos identificadas e quantificadas na matriz representativa (1) e inexistentes na matriz representativa (2)

\begin{tabular}{ccc}
\hline PAR DE CONCEITOS & $\begin{array}{c}\text { No } \text { DE RELAÇÕES ESTABELECIDAS No } \\
\text { NA MATRIZ REPRESENTATIVA (1) }\end{array}$ & NA MATRIZ REPRESENTATIVA (2) \\
\hline REAGENTES - SOLVENTES & 15 & 0 \\
\hline INDÚSTRIA FARMACÊUTICA - INDÚSTRIA QUÍMICA & 8 & 0 \\
GÁS HIDROGÊNIO - GÁS OXIGÊNIO & & 0 \\
\hline EMISSÕES - SELETIVIDADE & 7 & \\
EMISSÕES - SOLVENTES & & \\
MINIMIZAR - SELETIVIDADE & & \\
SAIS INORGÂNICOS - SOLVENTES & & \\
CONDIÇÕES REACIONAIS - ESTEQUIOMÉTRICAS & 6 & \\
CONDIÇÕES REACIONAIS - SELETIVIDADE & & \\
EFICIÊNCIA ATÔMICA - MINIMIZAR & & \\
EFICIENNCIA ATÔMICA - REAGENTES & & \\
REAGENTES - RESÍDUOS & & \\
REAGENTES - SELETIVIDADE &
\end{tabular}

\subsubsection{Análise das redes de conceitos obtidas}

Os dados quantificados nas matrizes representativas (1) e (2) referentes à disciplina Química Ambiental II possibilitaram a construção de redes de conceitos que explicitam de forma clara e objetiva as relações entre conceitos identificadas nos textos dos alunos. Buscando mostrar informações distintas, as redes construídas a partir das matrizes referentes aos textos originais e modificados foram de dois tipos diferentes: rede de conceitos considerando o $(s)$ vizinho $(s)$ mais próximo $(s)$ e rede de conceitos a partir de corte percentual.

- Redes de conceitos contemplando o(s) vizinho(s) mais próximo(s): Rede (V+P)

A rede que contempla o(s) vizinho(s) mais próximo(s) é uma estrutura gráfica útil para a realização de análises com foco nos conceitos, uma vez que se trata de uma representação que mostra o conceito que foi relacionado mais vezes a outro, podendo existir mais de um vizinho mais próximo para determinado conceito. A seguir são apresentadas as matrizes representativas (1) e (2) com o destaque dos vizinhos mais próximos de cada conceito e, na sequiência de cada uma das matrizes, suas respectivas redes, denominadas como rede $(\mathrm{V}+\mathrm{P})$ (1) e rede $(\mathrm{V}+\mathrm{P})(2)$. 


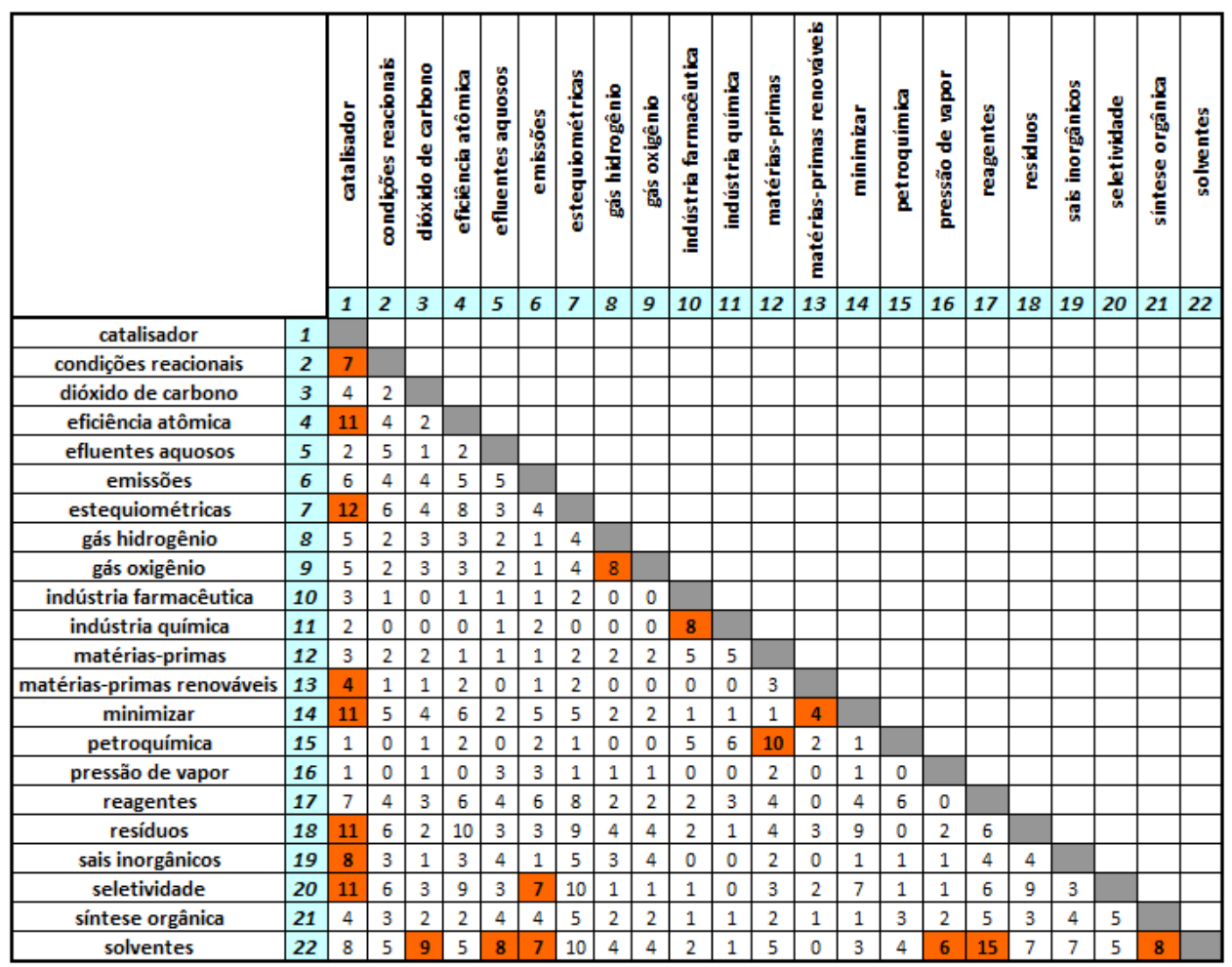

Figura 4.3 - Matriz representativa (1) com o(s) vizinho(s) mais próximo(s) de cada conceito em destaque

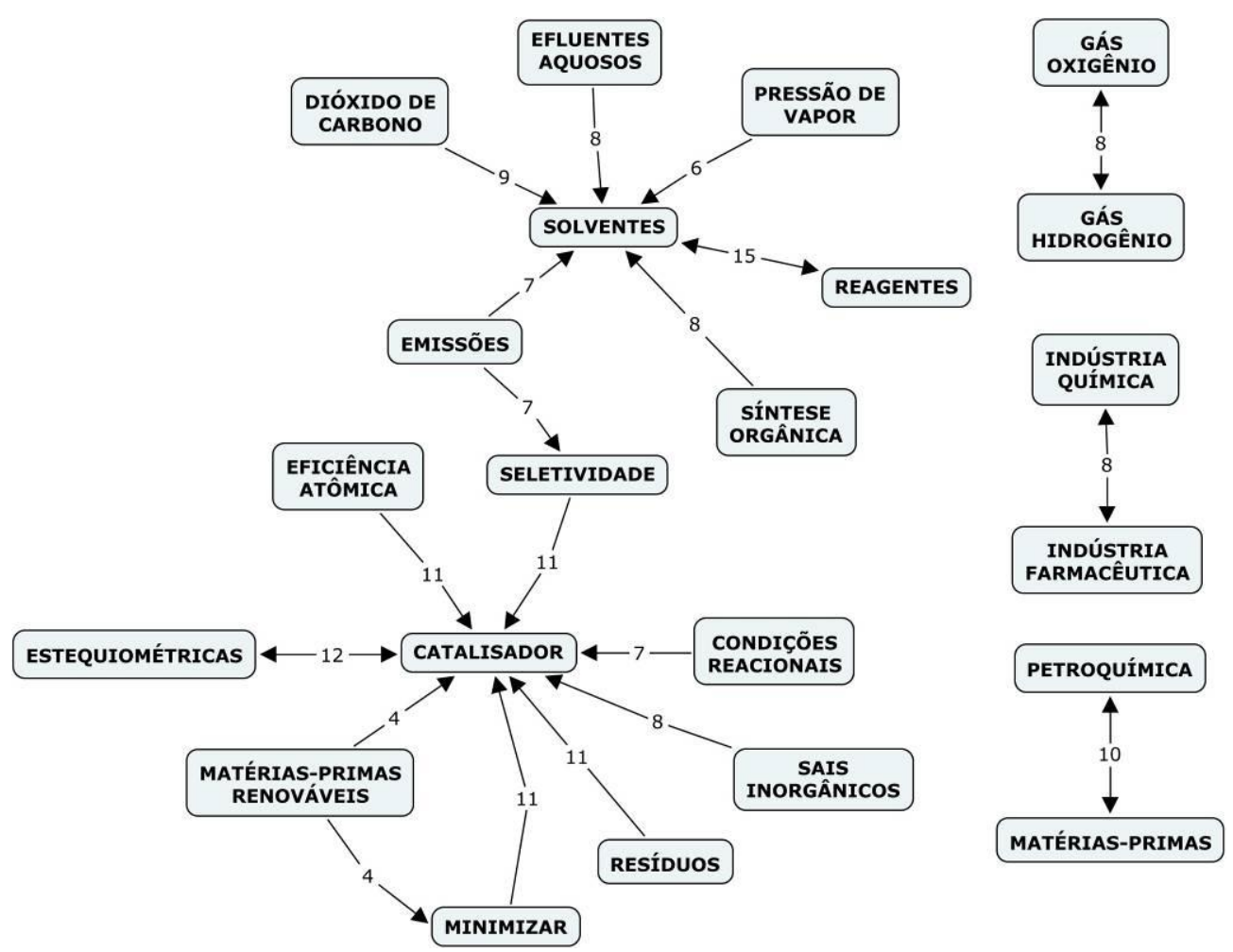

Figura 4.4 - Rede (V+P) (1) referente aos dados da disciplina Química Ambiental II 


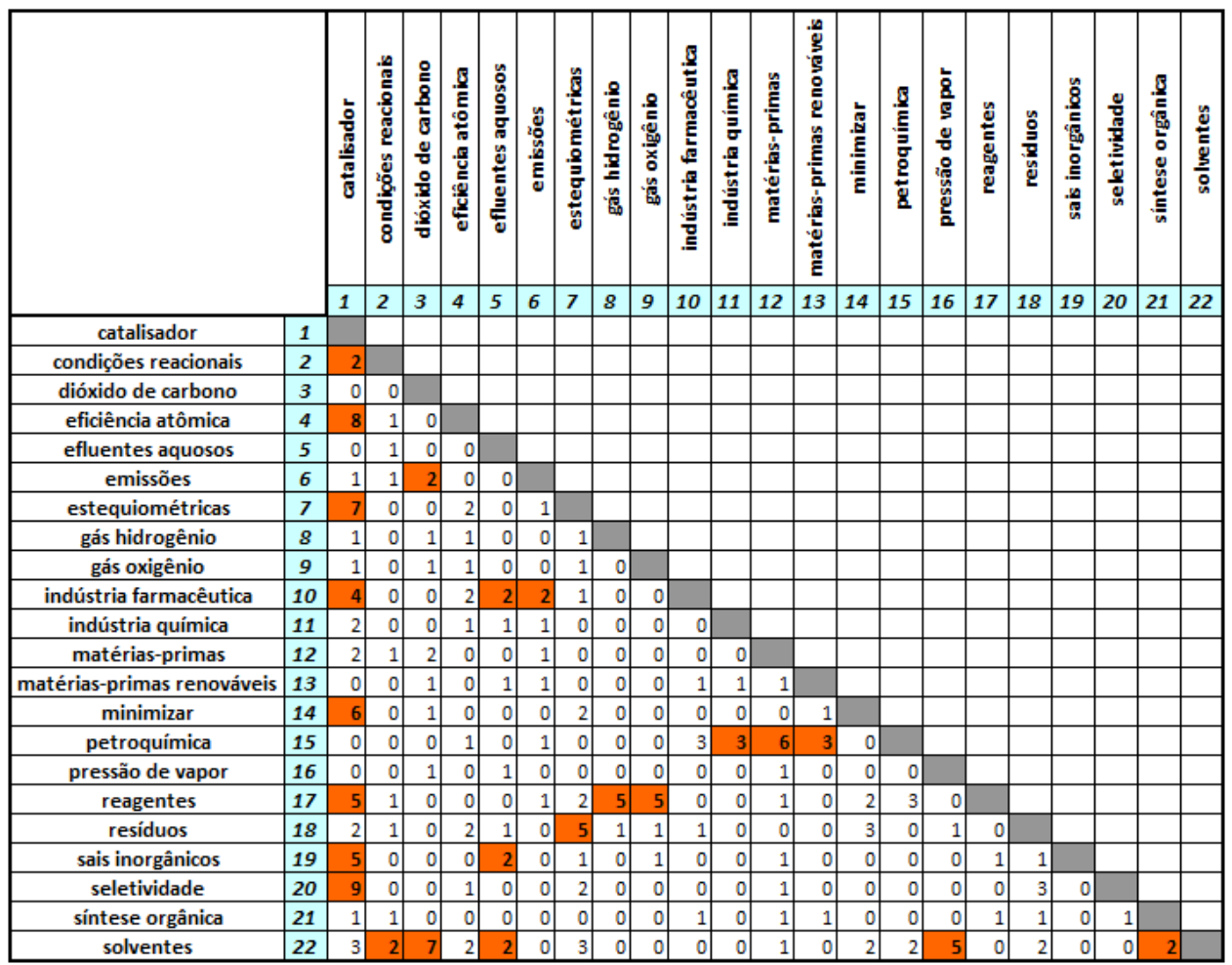

Figura 4.5 - Matriz representativa (2) com o(s) vizinho(s) mais próximo(s) de cada conceito em destaque

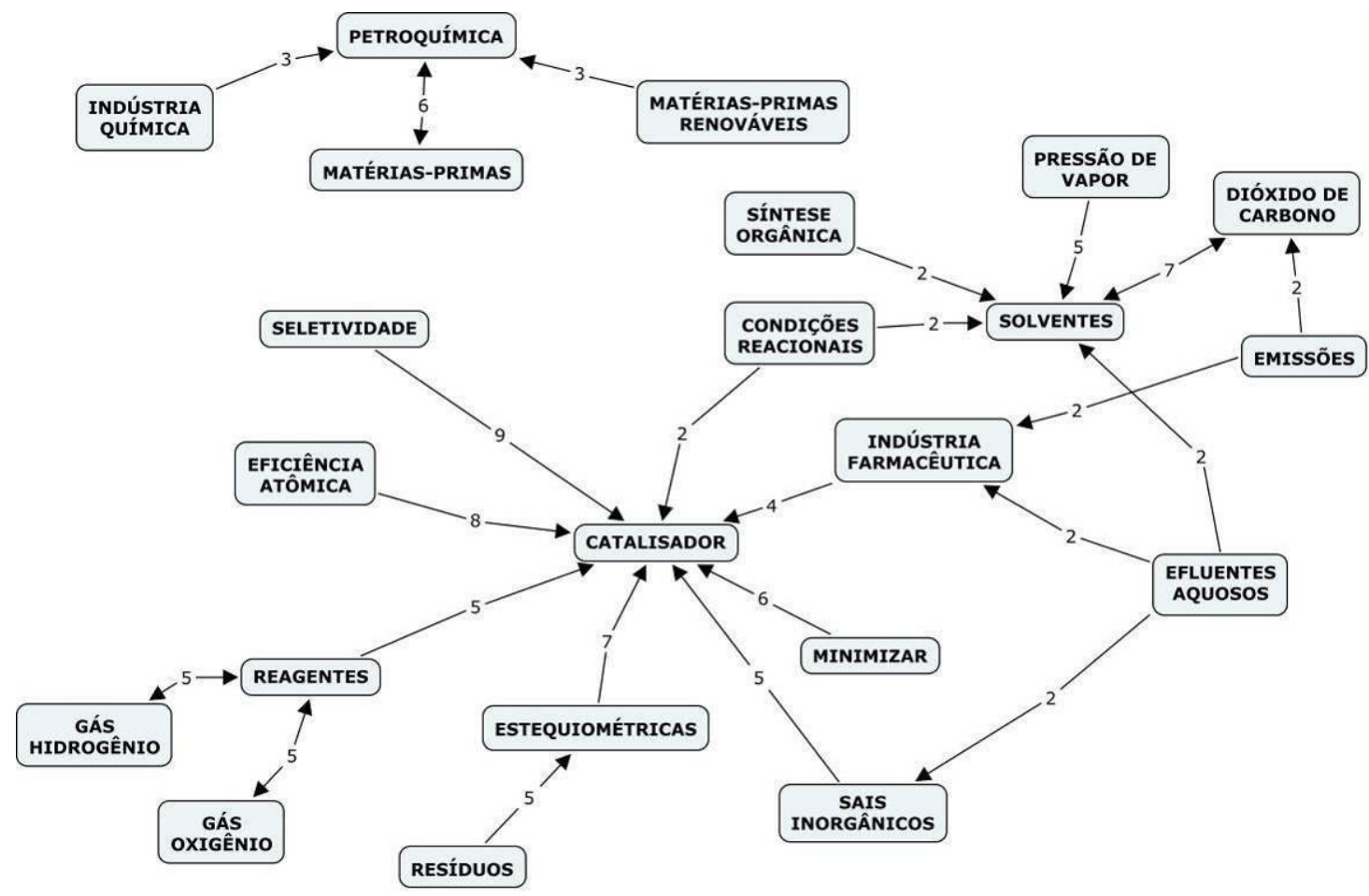

Figura 4.6 - Rede (V+P) (2) referente aos dados da disciplina Química Ambiental II 
Para as redes ilustradas nas figuras 4.4 e 4.6, as setas incluem o número de vezes que cada par de conceitos foi relacionado, além de indicarem o(s) vizinho(s) mais próximo(s) de cada conceito através de seu sentido. Ao observar as estruturas das redes de vizinhos mais próximos (1) e (2), verifica-se um total de 19 e 23 ligações presentes, respectivamente. Apesar de pequena, esta diferença mostra que na estrutura gráfica obtida a partir das proposições extraídas dos textos, os conceitos estão mais relacionados entre si. Isto se confirma com a observação do número de grupos isolados, além do número de conceitos terminais em cada uma das redes, ou seja, do número de conceitos que estabelecem relação com um único conceito. $\mathrm{Na}$ rede $(\mathrm{V}+\mathrm{P})(1), 4$ grupos isolados estão presentes e o número de conceitos terminais é de 16, enquanto na rede $(\mathrm{V}+\mathrm{P})(2)$ tem-se apenas 2 grupos isolados de conceitos e o número de conceitos terminais cai para 11 , sendo que ao comparar os conceitos terminais nessas redes, verifica-se que 8 deles são comuns às duas redes.

Além disso, é perceptível nas estruturas gráficas obtidas a ocorrência de conceitos centrais, ou seja, de conceitos que se encontram relacionados a vários outros, estabelecendo muitas ligações. Neste sentido, tratando-se de redes que contemplam o(s) vizinhos(s) mais próximo(s) de cada conceito, aqueles considerados centrais são os conceitos que se apresentam como vizinho mais próximo de vários outros conceitos sendo que, no presente trabalho, considerou-se como conceito central aquele que estabeleceu a partir de três ligações.

Novamente, percebe-se que na rede $(\mathrm{V}+\mathrm{P})(2)$ os conceitos estão mais relacionados entre si, apresentando um total de 6 conceitos centrais, enquanto na rede $(\mathrm{V}+\mathrm{P})(1)$ este número cai para apenas 2. Os dois conceitos centrais presentes na rede $(\mathrm{V}+\mathrm{P})$ (1) catalisador e solventes - também aparecem como centrais na rede $(\mathrm{V}+\mathrm{P})(2)$, inclusive com número bastante semelhante de ligações estabelecidas. Dentre os 8 conceitos que tem catalisador como vizinho mais próximo na rede $(\mathrm{V}+\mathrm{P})(1), 6$ são comuns à rede $(\mathrm{V}+\mathrm{P})(2) \mathrm{e}$, de forma semelhante, dos 6 conceitos que tem solventes como vizinho mais próximo na rede $(\mathrm{V}+\mathrm{P})(1), 4$ são comuns à rede $(\mathrm{V}+\mathrm{P})(2)$.

Apesar das semelhanças citadas, vale ressaltar o que já fora observado anteriormente quanto ao número de vezes em que cada uma dessas ligações comuns foi estabelecida, sendo que este número se mostra superior quando se trata da rede proveniente dos textos originais dos alunos, ou seja, da rede obtida a partir da matriz representativa (1). O quadro 4.1 organiza e permite comparar essas informações, além de fornecer a natureza dos conceitos considerados centrais e terminais para as redes $(\mathrm{V}+\mathrm{P})(1)$ e (2), em que os conceitos centrais ou terminais comuns às duas redes encontram-se destacados em negrito. 


\begin{tabular}{|c|c|c|}
\hline & Rede de vizinhos mais próximos (1) & Rede de vizinhos mais próximos (2) \\
\hline Natureza dos conceitos centrais & $\begin{array}{l}\text { catalisador } \\
\text { solventes }\end{array}$ & $\begin{array}{c}\text { catalisador } \\
\text { efluentes aquosos } \\
\text { indústria farmacêutica } \\
\text { petroquímica } \\
\text { reagentes } \\
\text { solventes } \\
\end{array}$ \\
\hline $\mathrm{N}^{\circ}$ de conceitos centrais & 2 & 6 \\
\hline Natureza dos conceitos terminais & $\begin{array}{l}\text { condições reacionais } \\
\text { dióxido de carbono } \\
\text { eficiência atômica } \\
\text { efluentes aquosos } \\
\text { estequiométricas } \\
\text { gás hidrogênio } \\
\text { gás oxigênio } \\
\text { indústria farmacêutica } \\
\text { indústria química } \\
\text { matérias-primas } \\
\text { petroquímica } \\
\text { pressão de vapor } \\
\text { reagentes } \\
\text { resíduos } \\
\text { sais inorgânicos } \\
\text { síntese orgânica }\end{array}$ & $\begin{array}{c}\text { eficiência atômica } \\
\text { gás hidrogênio } \\
\text { gás oxigênio } \\
\text { indústria química } \\
\text { matérias-primas } \\
\text { matérias-primas renováveis } \\
\text { minimizar } \\
\text { pressão de vapor } \\
\text { residuos } \\
\text { seletividade } \\
\text { sintese orgânica }\end{array}$ \\
\hline $\mathrm{N}^{\circ}$ de conceitos terminais & 16 & 11 \\
\hline $\mathrm{N}^{\circ}$ total de ligações & 19 & 23 \\
\hline
\end{tabular}

Quadro 4.1 - Comparação entre as redes (V+P) (1) e (2) quanto aos conceitos e ligações presentes

Outra análise relevante relacionada ao número de ligações comuns entre as redes obtidas consiste no cálculo do percentual médio de concordância (PMC) (CLARIANA; KOUL, 2008). Este índice possibilita uma comparação da similaridade entre duas estruturas gráficas distintas, considerando a existência ou não da ligação entre dois conceitos quaisquer (e não seu significado), sendo calculado pela equação:

$$
P M C=\left(\frac{N L_{R 1 R 2}}{N L_{R 1}}+\frac{N L_{R 1 R 2}}{N L_{R 2}}\right) \times \frac{1}{2}
$$

onde:

$N L_{R I R 2}=$ número de ligações comuns entre a rede 1 e a rede 2.

$N L_{R 1}$ ou $N L_{R 2}=$ número total de ligações da rede 1 ou rede 2.

O significado do valor de PMC obtido é simples: uma vez que o valor 1 (um) indica total semelhança entre duas redes, valores próximos ao número 1 (um) indicam alta semelhança entre as redes, ao passo que valores próximos do número 0 (zero) querem dizer que existem poucas ligações similares entre as redes comparadas. 
$\mathrm{O}$ valor do $\mathrm{PMC}$ obtido na comparação entre a rede $(\mathrm{V}+\mathrm{P})(1)$ e a rede $(\mathrm{V}+\mathrm{P})$ referente aos dados da disciplina Química Ambiental II foi de 0,55. Este valor indica que as estruturas gráficas apresentam 55\% de semelhança, desta forma, a rede construída a partir da matriz referente aos textos originais apresenta semelhança média quando comparada com a rede gerada a partir da matriz referente aos textos modificados.

- Redes de conceitos a partir de corte percentual: Rede (\%)

As redes de conceitos obtidas a partir de determinado corte percentual baseiam-se na ideia de representar as relações entre conceitos que mais foram estabelecidas nos textos originais ou nos textos modificados dos alunos. No entanto, conforme exposto na seção 3.2.4 da metodologia desta pesquisa, dependendo do corte percentual escolhido, redes com diferentes estruturas podem ser obtidas, apresentando muitos grupos de conceitos isolados ou excesso de conceitos relacionados, o que pode dificultar a análise e comprometer a utilidade da estrutura gráfica obtida.

Com o objetivo de estabelecer comparações e de obter a melhor estrutura gráfica que possibilitasse estudar e analisar o entendimento dos alunos, a partir das matrizes representativas (1) e (2) obtidas com os dados da disciplina Química Ambiental II, foram estabelecidos diferentes cortes percentuais para a construção de redes com estruturas distintas, nas quais estão presentes as relações entre conceitos que mais ocorreram nos textos dos alunos, de acordo com o corte percentual considerado.

Para cada corte estabelecido, a rede correspondente contemplou diferentes relações entre conceitos, assim, a tabela a seguir apresenta o número mínimo de vezes que determinado par de conceitos deve ter sido relacionado de acordo com o corte percentual estabelecido para cada matriz representativa. 
Tabela 4.2 - Número mínimo de relações entre conceitos de acordo com corte percentual

\begin{tabular}{|c|c|c|}
\hline \multirow{2}{*}{ Corte percentual } & \multicolumn{2}{|c|}{$\mathrm{N}^{\circ}$ mínimo de relações entre conceitos } \\
\hline & matriz representativa (1) & matriz representativa (2) \\
\hline $5 \%$ & 10 & 6 \\
\hline $10 \%$ & 8 & 5 \\
\hline $15 \%$ & 7 & 4 \\
\hline $25 \%$ & 6 & 3 \\
\hline $\mathbf{5 0} \%$ & 4 & 2 \\
\hline
\end{tabular}

Como se pode perceber, foram construídas 5 diferentes redes para cada matriz representativa obtida pelo Hamlet $^{\circledR}$, totalizando 10 diferentes redes conceituais referentes aos dados da disciplina Química Ambiental II. Para uma melhor visualização e comparação entre as diferentes redes obtidas a partir das matrizes representativas (1) e (2), nas figuras 4.7 e 4.8 são mostradas as redes com corte percentual em 5\%,10\%, 15\% e 25\% agrupadas em uma única representação para cada caso, onde consta uma legenda para os cortes percentuais estabelecidos. Nas figuras 4.9 e 4.10 , por sua vez, são representadas as redes com corte percentual em $50 \%$ separadamente pelo fato de apresentarem um número considerável de ligações entre conceitos, o que dificultaria seu agrupamento com as redes dos demais cortes percentuais.

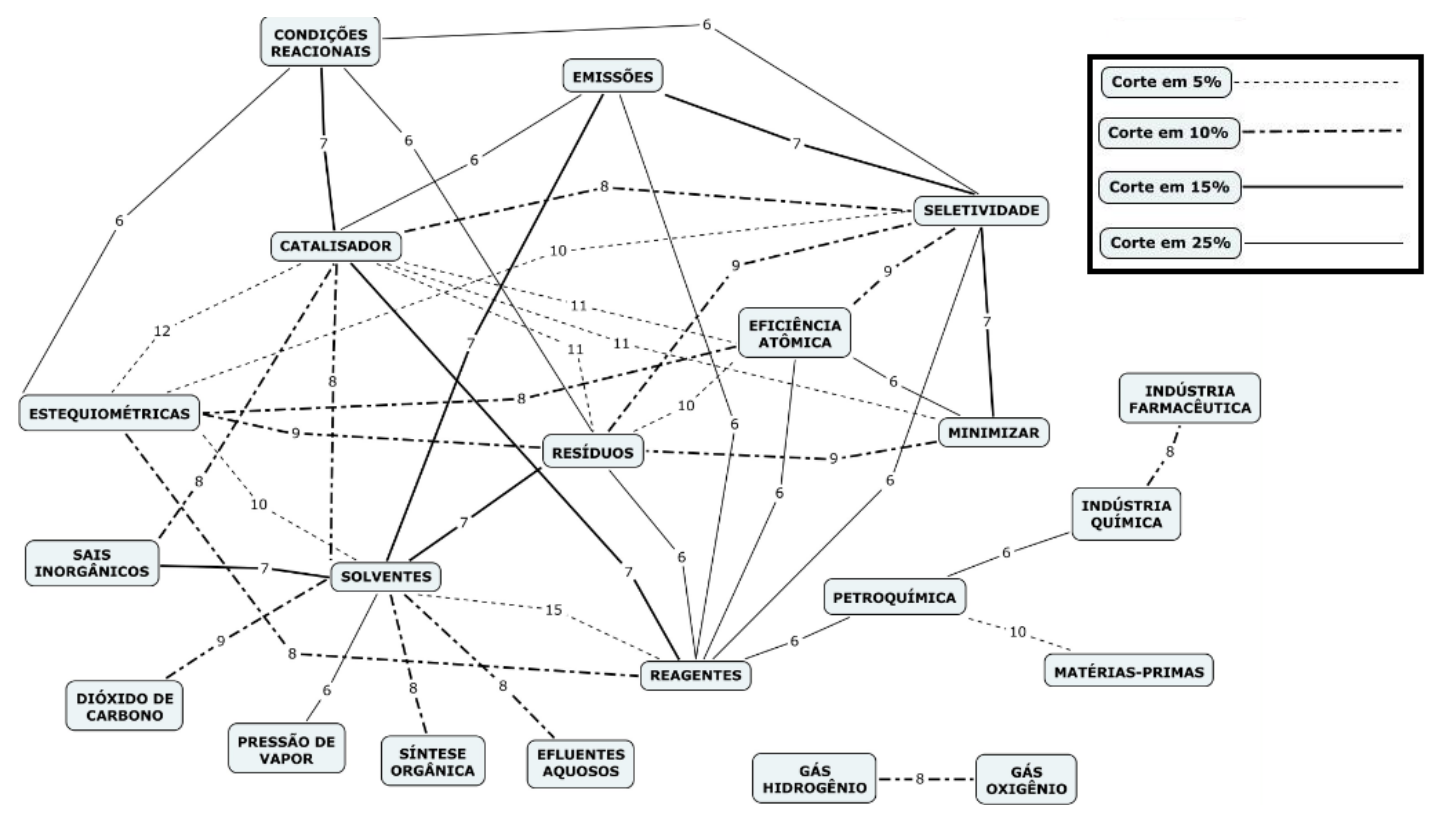

Figura 4.7 - Redes de conceitos com diferentes cortes percentuais obtidas a partir da matriz representativa (1) 


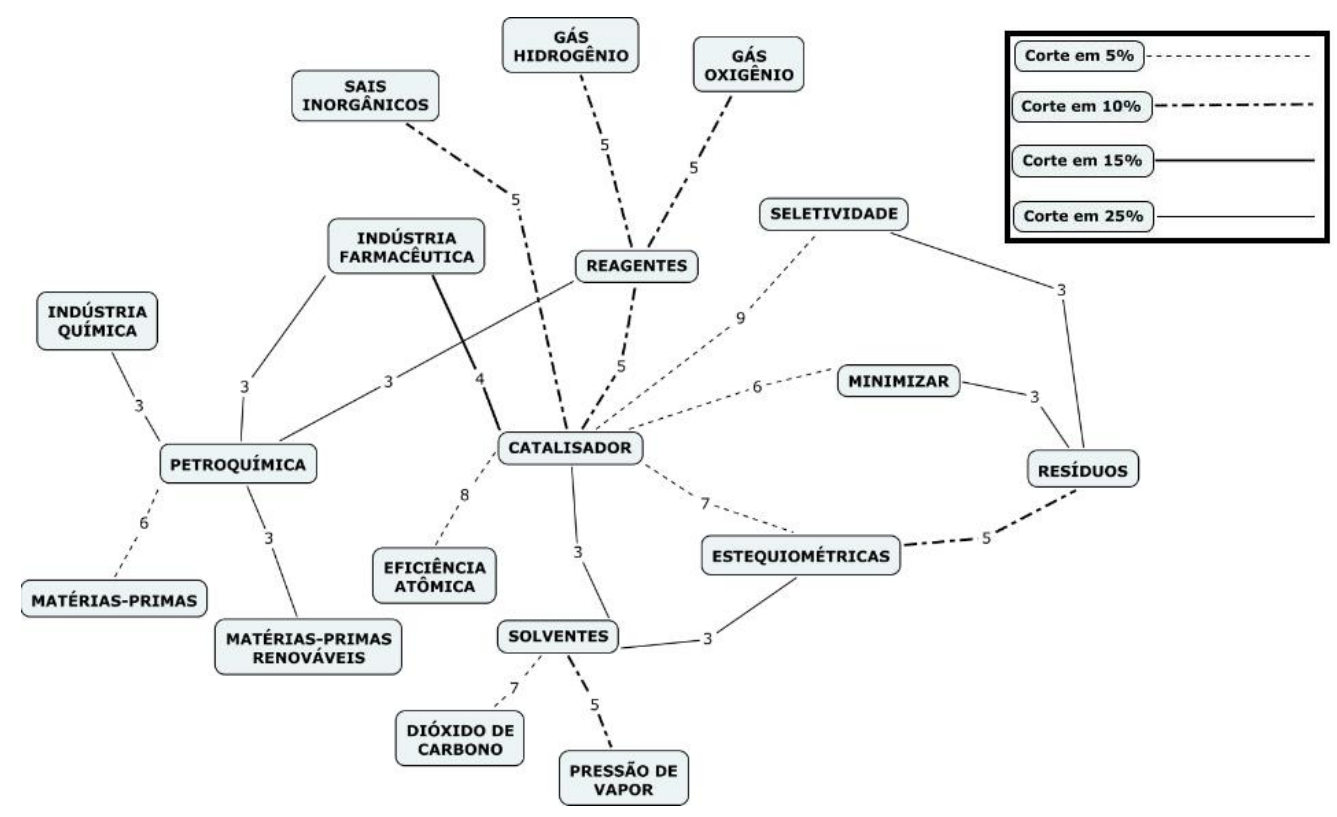

Figura 4.8 - Redes de conceitos com diferentes cortes percentuais obtidas a partir da matriz representativa (2)

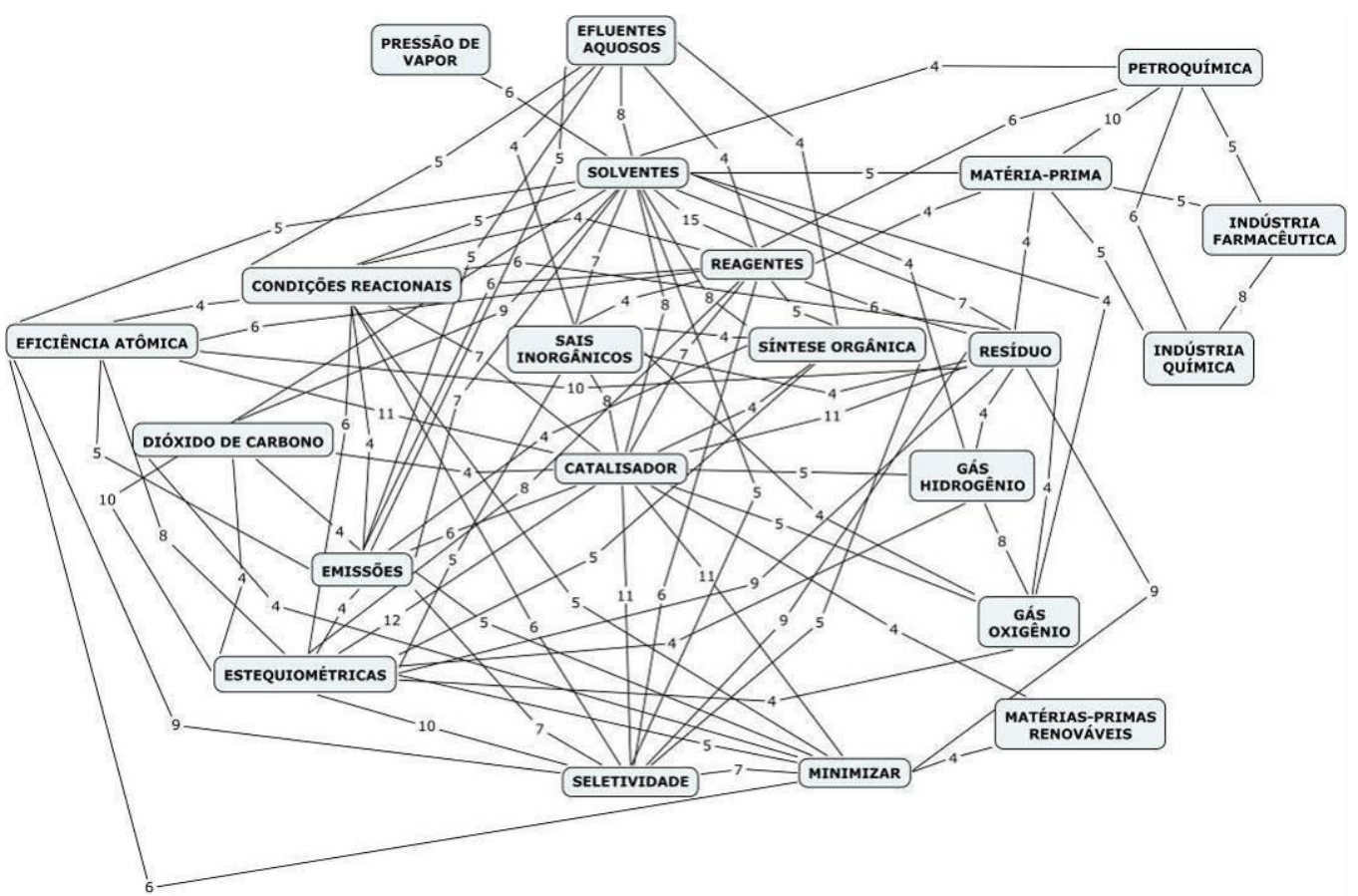

Figura 4.9 - Rede (50\%) (1) referente aos dados da disciplina Química Ambiental II 


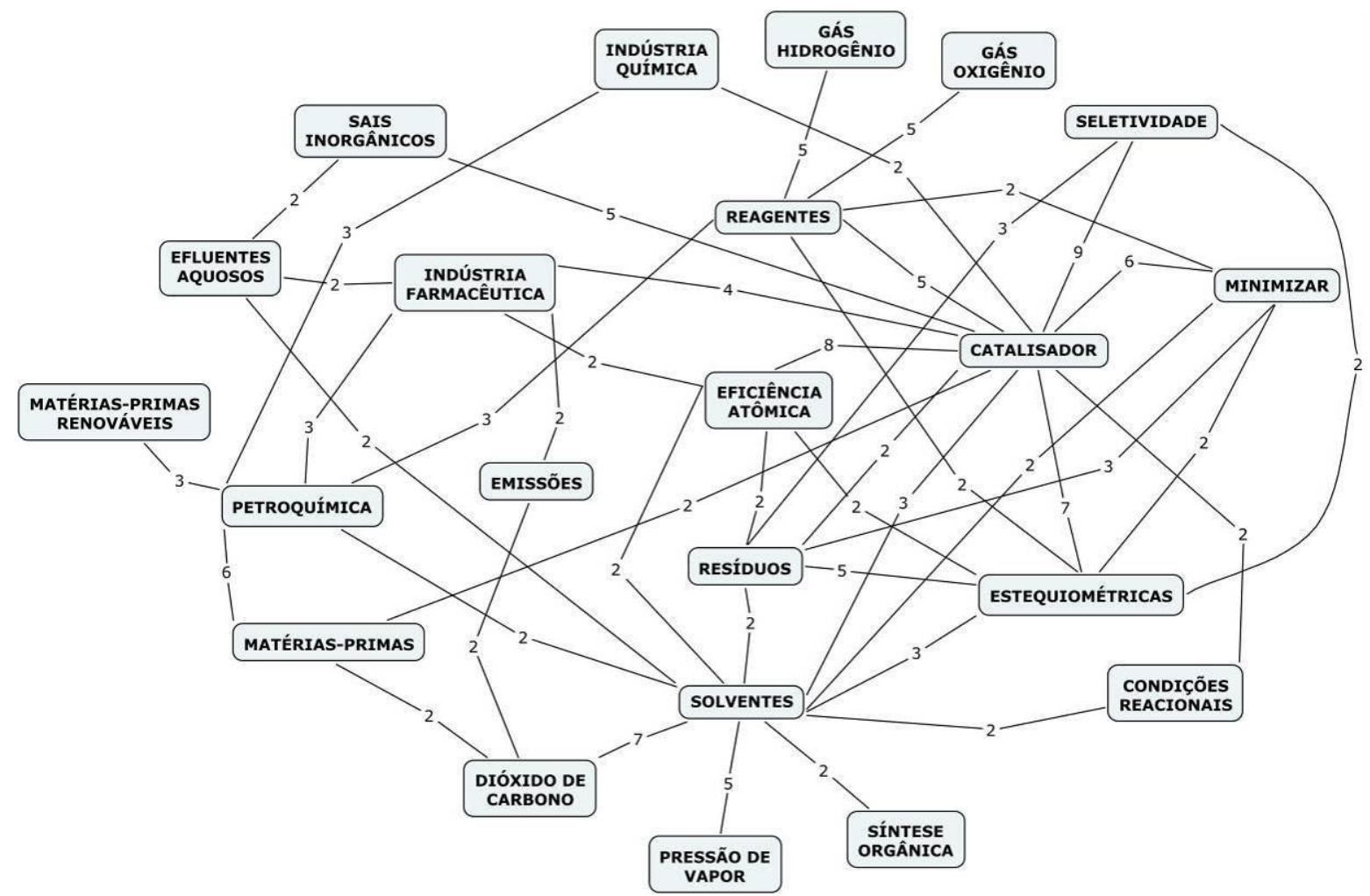

Figura 4.10 - Rede (50\%) (2) referente aos dados da disciplina Química Ambiental II

As estruturas gráficas apresentadas nas figuras 4.7, 4.8, 4.9 e 4.10 mostram o quanto o estabelecimento de diferentes cortes percentuais para determinada matriz pode interferir na estrutura da rede conceitual obtida. Além disso, nota-se que a estrutura da rede depende essencialmente dos valores numéricos presentes na matriz que a originou e, por este motivo, no caso de todas as redes obtidas para as matrizes representativas (1) e (2), têm-se redes baseadas no mesmo corte percentual, porém estruturalmente diferentes. A título de exemplo, é possível citar as redes das figuras 4.9 e 4.10 que se tratam de redes baseadas no mesmo corte percentual em 50\%, porém, as mesmas diferem substancialmente quanto ao número de ligações presentes.

A obtenção de diferentes redes baseadas nos diversos valores de corte percentual foi o que possibilitou uma análise comparativa a fim de escolher as estruturas gráficas que melhor representassem as ideias e o entendimento dos alunos acerca do que foi trabalhado na disciplina Química Ambiental II. Esta escolha se apoiou justamente na análise dos critérios organizados na tabela a seguir: 
Tabela 4.3 - Comparação entre as redes com diferentes cortes percentuais obtidas a partir das matrizes representativas (1) e (2) quanto aos conceitos e ligações presentes

\begin{tabular}{|c|c|c|c|c|c|c|c|c|c|c|}
\hline & \multicolumn{5}{|c|}{$\begin{array}{c}\text { Redes com corte percentual obtidas a partir da } \\
\text { matriz representativa (1) }\end{array}$} & \multicolumn{5}{|c|}{$\begin{array}{c}\text { Redes com corte percentual obtidas a partir da } \\
\text { matriz representativa ( } 2 \text { ) }\end{array}$} \\
\hline & $5 \%$ & $10 \%$ & $15 \%$ & $25 \%$ & $50 \%$ & $5 \%$ & $10 \%$ & $15 \%$ & $25 \%$ & $50 \%$ \\
\hline $\begin{array}{c}\mathrm{N}^{\circ} \text { de conceitos } \\
\text { presentes }\end{array}$ & 10 & 18 & 20 & 21 & 22 & 9 & 15 & 16 & 18 & 22 \\
\hline $\begin{array}{c}\mathrm{N}^{\circ} \text { de conceitos } \\
\text { centrais }\end{array}$ & 2 & 6 & 8 & 11 & 20 & 1 & 2 & 2 & 6 & 13 \\
\hline $\begin{array}{c}\mathrm{N}^{\circ} \text { de conceitos } \\
\text { terminais }\end{array}$ & 4 & 10 & 10 & 8 & 1 & 8 & 11 & 12 & 9 & 5 \\
\hline $\mathrm{N}^{\circ}$ total de ligações & 9 & 22 & 30 & 42 & 90 & 6 & 10 & 13 & 21 & 44 \\
\hline $\mathrm{N}^{\circ}$ de grupos isolados & 2 & 4 & 4 & 2 & 1 & 3 & 3 & 3 & 1 & 1 \\
\hline
\end{tabular}

De acordo com a tabela 4.3, as redes (5\%) inseridas nas figuras 4.7 e 4.8 apresentam um número de conceitos presentes consideravelmente inferior em relação ao número de conceitos fornecidos na atividade proposta aos alunos, ou seja, em relação ao número de termos indutores que foi de 22. Por se tratarem de redes que apresentam poucos conceitos presentes, verificam-se também valores pequenos para o número de conceitos centrais e terminais, além do baixo número de ligações presentes. $\mathrm{O}$ baixo número de conceitos centrais, por exemplo, apresenta-se como um problema para o uso destas redes como uma forma de analisar a compreensão dos alunos quanto ao tema em questão, uma vez que nelas a maior parte dos conceitos presentes está relacionada a um único conceito central. Além disso, o baixo número de ligações presentes torna ambas as redes limitadas e pouco esclarecedoras para a análise que se pretende fazer acerca das principais relações estabelecidas pelos alunos.

As redes com corte percentual em 10\% e 15\%, também representadas nas figuras 4.7 e 4.8 apresentam até 4 grupos isolados de conceitos, ou seja, grupos menores de conceitos relacionados que se encontram desconectados uns dos outros. Considerando que um dos objetivos em obter uma estrutura gráfica a partir de uma matriz representativa é justamente o de explicitar as principais relações entre conceitos estabelecidas por um grupo de alunos sobre determinado assunto, mostrando o quanto e como esses conceitos estão relacionados, a presença de grupos isolados nessas redes não se mostra algo interessante. Desta forma, cortes percentuais que geram estruturas gráficas com um número considerável de grupos isolados devem ser evitados quando possível, uma vez que relações relevantes entre conceitos podem acabar sendo desconsideradas. 
Nos casos específicos das redes com corte percentual em $10 \%$ e $15 \%$ referentes à matriz representativa (2), o número pequeno de conceitos centrais também é algo que as torna inadequadas para a análise que se pretende fazer em relação ao entendimento dos alunos, já que grande parte dos conceitos presentes se encontra relacionada a um número restrito de conceitos centrais.

Ao observar a rede (50\%) (1) apresentada na figura 4.9, por sua vez, percebe-se um número excessivo de ligações presentes, totalizando 90 diferentes relações, o que dificulta consideravelmente qualquer análise mais aprofundada da estrutura gráfica. Além disso, verifica-se que o número de conceitos centrais nesta rede é praticamente igual ao número total de conceitos presentes na mesma, formando assim uma rede em que praticamente tudo parece estar relacionado. Uma rede como esta, portanto, também não se mostra adequada para a compreensão acerca das relações estabelecidas pelos alunos, justamente por suscitar a ideia de que os alunos não estabelecem qualquer organização ou hierarquização mínima entre os conceitos considerados em sua estrutura cognitiva.

Após a análise comparativa das redes com cortes percentuais de $25 \%$ e $50 \%$ provenientes da matriz representativa (2), é possível afirmar que a rede (50\%) (2) se mostra mais rica no que diz respeito às relações estabelecidas entre conceitos pelos alunos. No caso, essas redes (25\%) (2) e (50\%) (2) se originam da matriz proveniente da análise dos textos modificados, ou seja, elas mostram relações entre conceitos identificadas em proposições extraídas dos textos dos alunos, portanto, são estruturas que se aproximam bastante do que foi escrito pelos alunos em seus textos originais. No entanto, é possível dizer que a escolha pelo corte percentual em $50 \%$ parece ser mais adequada do que pelo corte em $25 \%$, uma vez que na rede (50\%) (2) um número consideravelmente maior de ligações entre os conceitos está presente, totalizando 44 diferentes ligações entre os 22 conceitos que compõem a rede.

Desta forma, considerando os critérios observados acima e, dentre as redes obtidas a partir dos diversos cortes percentuais para as matrizes representativas (1) e (2), apresentam-se como estruturas gráficas adequadas a cada uma dessas matrizes as redes de conceitos com corte percentual em $25 \%$ e $50 \%$, respectivamente. Conforme descrito na tabela 4.3 , estas redes são bastante semelhantes quanto ao número de ligações presentes, além do número total de conceitos que apresentam e do número de conceitos centrais e terminais muito próximos.

O valor do PMC obtido na comparação entre a rede (25\%) (1) e a rede (50\%) (2) referente aos dados da disciplina Química Ambiental II foi de 0,59, o que mostra que as estruturas gráficas apresentam 59\% de semelhança. Assim, considerando os cortes percentuais 
estabelecidos e escolhidos, a rede construída com base na análise dos textos originais apresenta uma semelhança média em comparação com a rede gerada a partir da análise dos textos modificados.

\subsubsection{Análise dos mapas conceituais obtidos}

O ponto de partida para a construção de mapas conceituais a partir das duas matrizes representativas obtidas com os dados da disciplina Química Ambiental II foram redes de conceitos com determinados cortes percentuais escolhidos. Assim, com o auxílio da ferramenta KWIC (Key Word In Context) do Hamlet $^{\circledR}$, foi possível realizar a busca pelas frases de ligação entre conceitos que se encontravam relacionados nas redes escolhidas, de modo a construir as proposições que compõem os mapas conceituais.

Conforme mencionado anteriormente, nesta pesquisa optou-se pela construção de mapas conceituais partindo-se tanto dos textos originais quanto dos textos modificados, com o objetivo de convergir e comparar as estruturas gráficas obtidas dos dois modos, de forma a demonstrar o quanto as mesmas se aproximam uma da outra. A construção do mapa conceitual referente aos textos modificados dos alunos da disciplina Química Ambiental II se deu a partir da rede (25\%) (2), representada na figura 4.8, a qual contempla relações entre conceitos estabelecidas a partir de 3 vezes, possuindo número de conceitos e de ligações presentes adequados para a construção de uma estrutura gráfica organizada e de fácil compreensão (figura 4.12).

De forma semelhante, a construção do mapa conceitual referente aos textos originais ocorreu a partir da rede (25\%) (1), representada na figura 4.7, em que são contempladas relações estabelecidas a partir de 6 vezes. No entanto, uma vez que a origem desta rede encontra-se nos dados da matriz representativa (1), ao realizar a busca pelas frases de ligação entre os pares de conceitos para a construção do mapa, percebeu-se que alguns pares de conceitos não estavam relacionados nos textos dos alunos de forma proposicional.

Assim, das 42 diferentes ligações entre conceitos presentes na rede (25\%) (1), 13 foram eliminadas durante a construção do mapa conceitual correspondente, pois se tratavam de relações entre conceitos sem qualquer caráter proposicional. Além disso, a busca pelas frases de ligação permitiu verificar que outros 13 diferentes pares de conceitos relacionados na rede $(25 \%)$ (1), na verdade, encontravam-se relacionados de forma proposicional por menos de 3 vezes. Neste contexto, considerando que a ideia aqui é justamente a de convergir 
os mapas (25\%) (1) e (25\%) (2), de forma a verificar a semelhança entre essas duas estruturas, não faria sentido construir o mapa conceitual (25\%) (1) contemplando relações entre conceitos estabelecidas por menos de 3 vezes, as quais também não são contempladas no mapa (25\%) (2). Assim, o mapa conceitual (25\%) (1) mostrado na figura 4.11 é constituído por um total de 16 diferentes ligações, em que se verifica que o número total de relações estabelecidas para cada par de conceitos é inferior em relação ao que se tem na rede de conceitos de origem.

O valor do PMC obtido na comparação entre o mapa conceitual (25\%) (1) e o mapa conceitual (25\%) (2) referente aos dados da disciplina Química Ambiental II foi de 0,88. Este valor indica que as estruturas gráficas apresentam $88 \%$ de semelhança, o que também pode ser observado pelas comparações estabelecidas e organizadas no quadro 4.2. Para facilitar a visualização das semelhanças entre os dois mapas conceituais, as únicas 5 diferentes ligações que estão presentes apenas no mapa conceitual (25\%) (2) encontram-se destacadas na figura 4.12 .

Desta forma, é possível dizer que a busca pelas frases de ligação para a construção de um mapa conceitual referente aos textos originais permitiu obter uma estrutura gráfica com semelhança considerável em relação ao mapa conceitual referente aos textos modificados. Além disso, a semelhança observada entre os mapas sugere que a utilização do programa Hamlet $^{\circledR}$ para a obtenção de matrizes que quantificam relações entre conceitos presentes em um texto na forma como foi escrito é eficiente quando comparada ao processo manual e mais demorado de se extraírem proposições de um texto para obter uma matriz. 


\begin{tabular}{|c|c|c|}
\hline & Mapa conceitual (25\%) (1) & Mapa conceitual (25\%) (2) \\
\hline $\mathrm{N}^{\circ}$ de conceitos presentes & 14 & 18 \\
\hline $\mathrm{N}^{\circ}$ de conceitos centrais & 5 & 6 \\
\hline Natureza dos conceitos centrais & $\begin{array}{l}\text { catalisador } \\
\text { estequiométricas } \\
\text { petroquímica } \\
\text { resíduos } \\
\text { solventes }\end{array}$ & $\begin{array}{c}\text { catalisador } \\
\text { estequiométricas } \\
\text { petroquímica } \\
\text { reagentes } \\
\text { resíduos } \\
\text { solventes }\end{array}$ \\
\hline $\mathrm{N}^{\circ}$ de conceitos terminais & 6 & 9 \\
\hline Natureza dos conceitos terminais & $\begin{array}{l}\text { dióxido de carbono } \\
\text { eficieência aômica } \\
\text { indústria química } \\
\text { matérias-primas } \\
\text { pressão de vapor } \\
\text { sais inorgânicos }\end{array}$ & $\begin{array}{c}\text { dióxido de carbono } \\
\text { eficiência atômica } \\
\text { gás hidrogênio } \\
\text { gás oxigênio } \\
\text { indústria química } \\
\text { matérias-primas } \\
\text { matérias-primas renováveis } \\
\text { pressão de vapor } \\
\text { sais inorgânicos }\end{array}$ \\
\hline $\mathrm{N}^{\circ}$ total de ligações & 16 & 21 \\
\hline
\end{tabular}

Quadro 4.2 - Comparação entre os mapas conceituais (25\%) (1) e (2) quanto aos conceitos e ligações presentes 


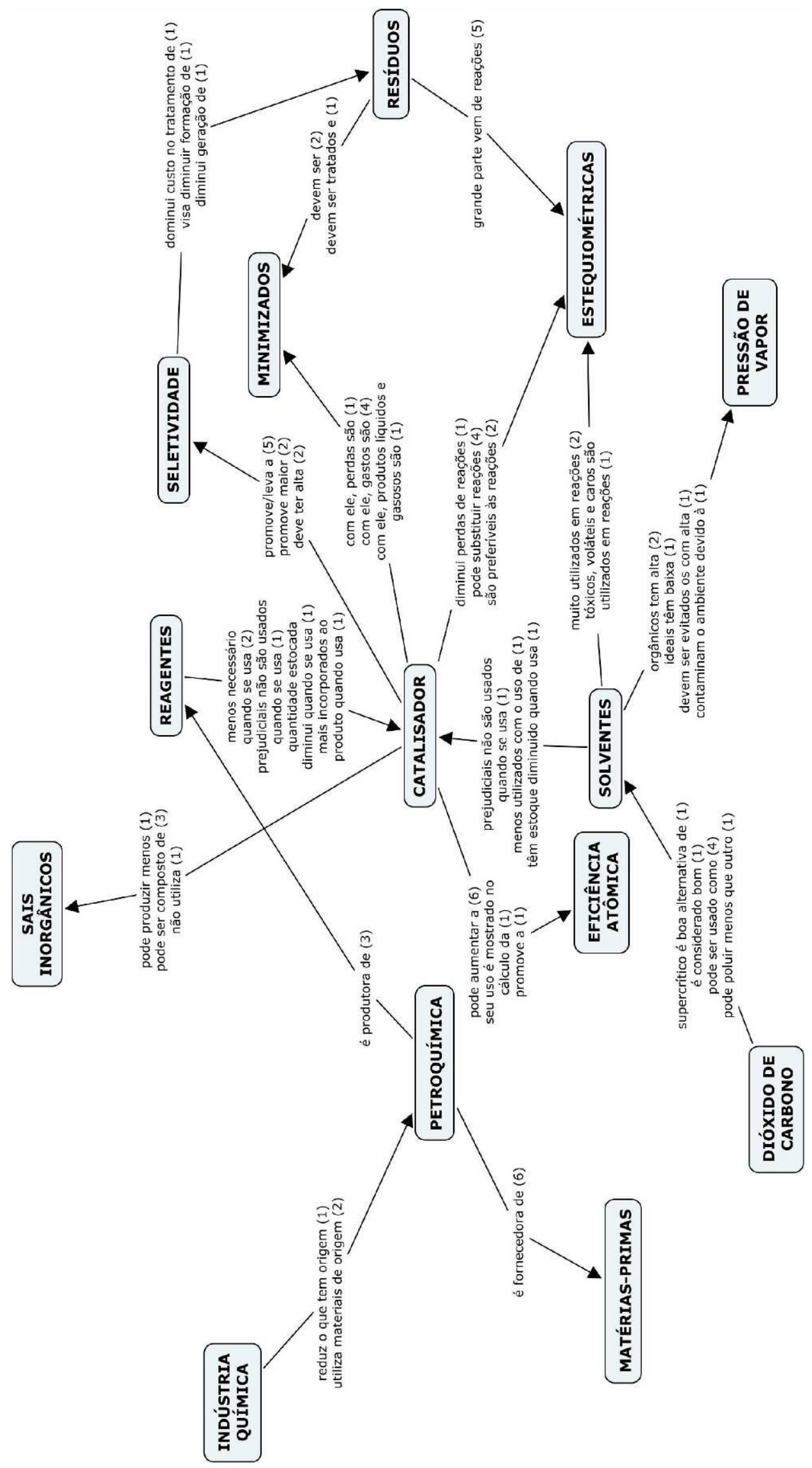

Figura 4.11 - Mapa conceitual (25\%) (1) referente aos dados da disciplina Química Ambiental II 


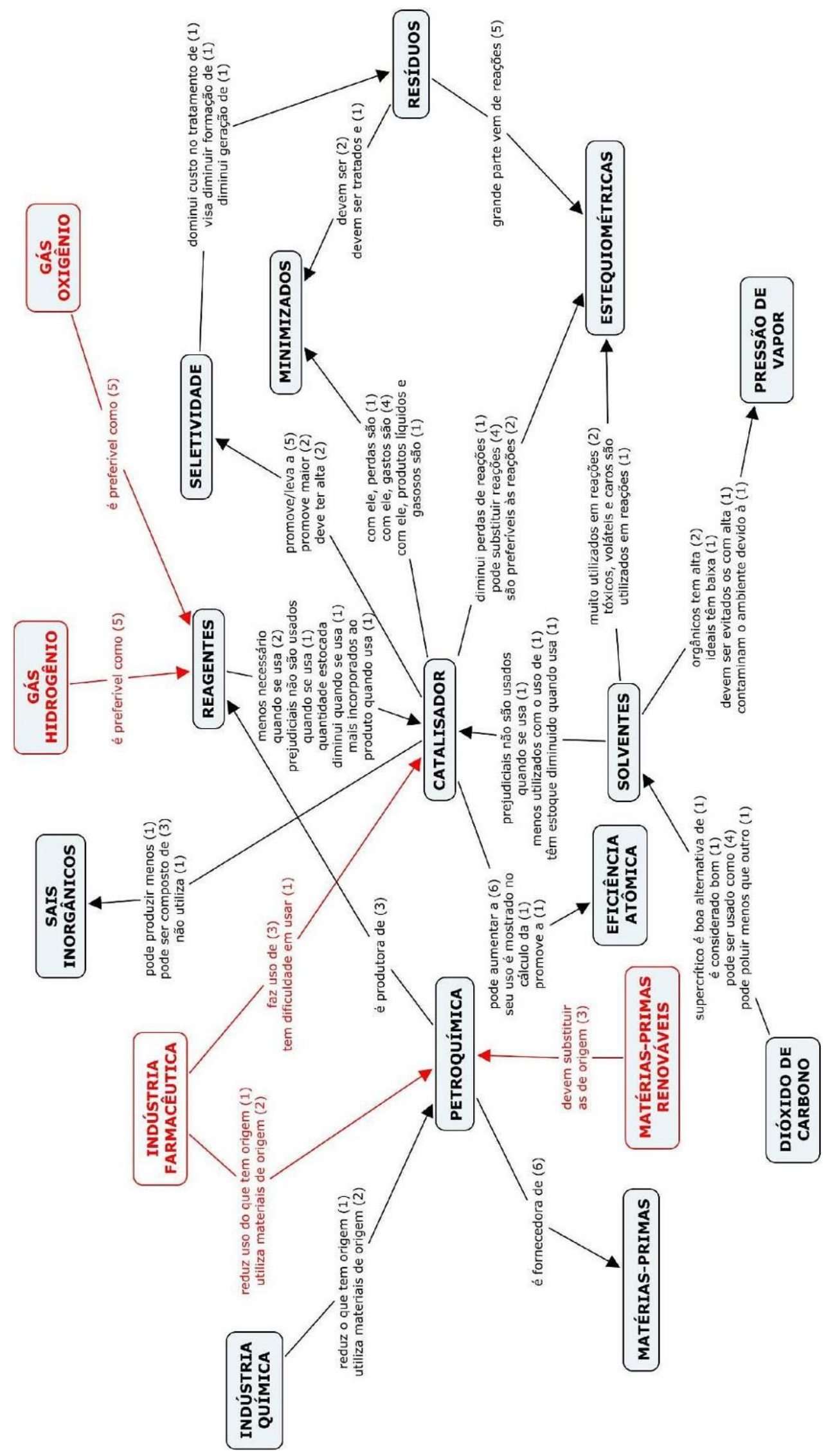

Figura 4.12 - Mapa conceitual (25\%) (2) referente aos dados da disciplina Química Ambiental II 


\subsubsection{Análise geral das estruturas gráficas obtidas no contexto da Química Verde}

Conforme observado nas seções anteriores, as estruturas gráficas obtidas por meio dos dados coletados na disciplina Química Ambiental II forneceram diferentes tipos de informações, as quais determinam a escolha por determinado tipo de estrutura gráfica. No caso das redes de conceitos contemplando o(s) vizinho(s) mais próximo(s), sua importância é notável quando o foco da análise da representação gráfica se encontra em cada um dos conceitos presentes. Já as redes de conceitos a partir de corte percentual são estruturas gráficas úteis quando o foco da análise está no número de vezes em que diferentes relações entre conceitos são estabelecidas. Finalmente, os mapas conceituais centram-se na natureza das diferentes relações entre os conceitos.

Como se pode perceber pelas estruturas gráficas presentes nas figuras 4.4 e 4.6 , as redes $(\mathrm{V}+\mathrm{P})(1)$ e (2) apresentam algumas semelhanças em relação às informações que fornecem sobre determinados conceitos ou grupos de conceitos. Em princípio, é possível identificar a presença de 5 grupos de conceitos na rede (V+P) (1), em que 3 deles encontramse isolados na estrutura gráfica, sendo formados pelos seguintes pares de conceitos: gás oxigênio - gás hidrogênio; indústria química - indústria farmacêutica e petroquímica matérias-primas. Apesar de não se tratarem de grupos isolados na rede de conceitos, é possível dizer que catalisador e solventes constituem outros dois grupos específicos na rede em questão, estando estes dois grupos conectados pelos conceitos seletividade e emissões. Já a rede $(\mathrm{V}+\mathrm{P})(2)$, apesar de apresentar um número menor de grupos isolados por ser uma rede com maior número de ligações, nela também é possível identificar grupos específicos e de destaque em torno dos conceitos catalisador, petroquímica e solventes.

De acordo com essas colocações, pode-se afirmar que, apesar das diferenças que existem entre as redes (V+P) (1) e (2), muitas semelhanças são verificadas principalmente em torno dos conceitos considerados centrais e dos grupos de conceitos isolados que são identificados nessas redes. No caso das redes $(\mathrm{V}+\mathrm{P})(1)$ e (2), os conceitos catalisador e solventes permanecem como centrais e constituindo grupos específicos de conceitos, o que demonstra a relevância desses dois conceitos para os alunos dentro do contexto da química verde.

Muitas das ligações encontradas nas redes $(\mathrm{V}+\mathrm{P})(1)$ e (2) também são contempladas nos mapas conceituais (25\%) (1) e (2), mostrados nas figuras 4.11 e 4.12. Essas estruturas 
gráficas apresentam diferentes focos, porém, podem ser consideradas complementares, uma vez que os mapas conceituais esclarecem a natureza das relações estabelecidas entre os conceitos. Assim, do ponto de vista da química verde, todas as estruturas gráficas obtidas no âmbito da disciplina Química Ambiental II refletem, com focos distintos, algumas informações presentes nos textos escritos pelos alunos relativas ao desenvolvimento de processos químicos para reduzir ou eliminar o uso ou geração de substâncias nocivas à saúde humana e ao ambiente, de forma a não provocar problemas ambientais, poluindo menos ou até mesmo não poluindo.

Os mapas conceituais representados nas figuras 4.11 e 4.12 , por exemplo, apresentam informações bastante ricas em relação aos 5 conceitos considerados centrais em ambas as estruturas gráficas - catalisador, estequiométricas, petroquímica, resíduos e solventes. $\mathrm{O}$ reconhecimento destes conceitos pelos alunos como centrais e importantes dentro do contexto da química verde já se mostra algo interessante do ponto de vista do entendimento dos alunos sobre o tema, principalmente a respeito dos chamados doze princípios da química verde (PRADO, 2003).

Nos referidos mapas conceituais, é possível identificar que parte dos textos dos alunos deixa claro o reconhecimento da indústria petroquímica como a atual produtora e fornecedora de materiais para as indústrias química e farmacêutica. Além disso, a natureza da relação entre os conceitos petroquímica e matérias-primas renováveis no mapa conceitual da figura 4.12 está de acordo com um dos princípios da química verde, referente ao uso de fontes renováveis de matéria-prima. De acordo com este princípio, sempre que possível, as indústrias devem procurar utilizar matérias-primas renováveis no lugar de fontes não renováveis (LENARDÃO et al., 2003).

Em ambos os mapas apresentados nas figuras 4.11 e 4.12, o conceito catalisador é considerado central, além de estar ligado a um maior número de conceitos quando comparado aos demais conceitos centrais. O destaque deste conceito para os alunos dentro do contexto da química verde é evidenciado nos referidos mapas conceituais e sua relação direta com o conceito estequiométricas nestes mapas vai de encontro a outro princípio elementar da química verde, que apresenta os reagentes catalíticos como opções melhores do que os tão utilizados reagentes estequiométricos.

A natureza das relações entre o conceito catalisador e os conceitos eficiência atômica, minimizados, reagentes e seletividade também são coerentes com outros três princípios da química verde, relativos à economia de átomos, à síntese de produtos menos perigosos e ao 
desenho de produtos seguros. Neste sentido, verifica-se que parte das proposições presentes nos mapas conceituais evidencia duas ideias principais: a primeira se refere a como o uso de catalisadores durante a síntese de produtos maximiza a incorporação dos reagentes no produto final, aumentando a chamada eficiência atômica e a segunda diz respeito a como o uso de catalisadores possibilita que a síntese de um produto ocorra sem a utilização nem geração de substâncias tóxicas (PRADO, 2003).

O conceito solventes também se destaca como central nos mapas representados nas figuras 4.11 e 4.12 e sua ligação com os conceitos estequiométricas e pressão de vapor expõe a problemática percebida por parte dos alunos relativa ao amplo uso de solventes nas reações estequiométricas, em que os solventes orgânicos são reconhecidos como prejudiciais ao ambiente devido a alta pressão de vapor que possuem.

A natureza da relação entre os conceitos solventes e dióxido de carbono, por sua vez, evidencia o entendimento por parte dos alunos sobre outro princípio elementar da química verde, referente aos solventes e auxiliares mais seguros, especificamente sobre a possibilidade de se substituírem solventes orgânicos convencionais por solventes verdes, como fluidos supercríticos, tais como o dióxido de carbono em certa pressão e temperatura (LENARDÃO et al., 2003).

Apesar de ser reconhecido como conceito central apenas no mapa conceitual representado na figura 4.12, referente aos textos modificados dos alunos, o conceito reagentes estabelece duas importantes relações nessa estrutura gráfica, já identificadas anteriormente na rede de conceitos $(\mathrm{V}+\mathrm{P})(2)$, mostrada na figura 4.6. As duas referidas relações são com os conceitos gás hidrogênio e gás oxigênio, que ocorrem por 5 vezes nas estruturas gráficas mencionadas, sendo que a natureza dessas relações é evidenciada nos mapas conceituais, indicando essas substâncias como alternativas de reagentes para provocar reações de redução e de oxidação de forma menos agressiva ao meio ambiente em comparação com outros agentes redutores e oxidantes de uso mais comum.

\subsection{Análises referentes à disciplina Química e Sociedade}

A análise dos textos dos 26 alunos da disciplina Química e Sociedade ocorreu das duas maneiras já descritas: a partir dos textos originais e dos textos modificados. No entanto, para este conjunto de dados, as análises referem-se às produções textuais dos alunos referentes a 
dois momentos do curso, antes e após a instrução, ou seja, produções do início e do final da disciplina. Em ambos os casos, as relações entre conceitos presentes nos textos originais e modificados dos alunos foram quantificadas com auxílio do programa Hamlet ${ }^{\circledR}$, gerando um total de quatro matrizes de similaridade que podem ser chamadas de matrizes representativas da turma, uma vez que se referem a todos os alunos da disciplina. Para diferenciar essas matrizes de acordo com a origem dos dados, as matrizes obtidas a partir de textos originais serão denominadas como matriz representativa (pré-1) ou matriz representativa (pós-1), já as matrizes obtidas a partir de textos modificados serão denominadas como matriz representativa (pré-2) ou matriz representativa (pós-2).

Porém, antes mesmo da descrição de todos os resultados obtidos com a análise dos textos pré e pós-instrução para a disciplina Química e Sociedade, é preciso alertar o leitor que, durante o processo de modificação dos textos e de elaboração da lista de vocabulário para as posteriores análises realizadas pelo Hamlet $^{\circledR}$, percebeu-se que um importante conceito fornecido no enunciado da atividade apresentada na seção 3.1.2 sobre como se faz ciência foi utilizado pelos alunos sempre compondo uma frase de ligação entre outros dois conceitos e, por este motivo, não foi considerado como uma palavra que deveria compor a lista de vocabulário.

Isto ocorreu com a palavra observação, a qual se mostra extremamente importante para o tema da avaliação, mas que parece ter sido utilizada desta forma justamente pela possibilidade de estar presente nos textos tanto como substantivo quanto como verbo. Abaixo, são mostrados alguns exemplos de frases contendo a palavra observação e outras palavras fornecidas no enunciado da atividade, seguidas das respectivas proposições extraídas das mesmas:

\section{Exemplo 1:}

Frase original: Primeiramente para se fazer ciência é preciso observar os fatos e fenômenos que nos cercam.

Proposições: Ciência para se fazer é preciso observar fatos.

Ciência para se fazer é preciso observar fenômenos.

\section{Exemplo 2:}

Frase original: Para entender o que observa e analisa, o cientista constrói hipóteses e estabelece uma teoria. 
Proposição: Ciência para entender o que observa e analisa, constrói hipóteses.

\section{Exemplo 3:}

Frase original: O fazer ciência está na observação dos fatos, na sua interpretação, no raciocínio em cima das coisas com as quais lidamos.

Proposição: Ciência fazê-la inclui a observação dos fatos.

Os exemplos acima mostram que a palavra observação foi reconhecida pelos alunos como um importante conceito dentro do contexto da atividade, porém seu uso nos textos produzidos ocorreu de forma variada, ou seja, compondo a frase de ligação entre dois determinados conceitos. Desta forma, justifica-se o motivo pelo qual a palavra observação fornecida no enunciado da atividade proposta não aparecerá nos resultados obtidos a serem descritos a seguir.

As matrizes representadas nas figuras $4.13,4.14,4.15$ e 4.16 quantificam as relações entre os conceitos pertencentes à lista de vocabulário que foram identificadas nos textos originais e modificados dos alunos, referentes aos momentos pré e pós-instrução.

\begin{tabular}{|c|c|c|c|c|c|c|c|c|c|c|c|c|c|c|c|c|c|c|}
\hline & 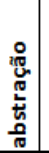 & $\begin{array}{l}\frac{\pi}{0} \\
\frac{\mathbb{d}}{U}\end{array}$ & 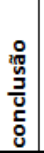 & $\begin{array}{l}n \\
0 \\
0 \\
\frac{\pi}{0}\end{array}$ & 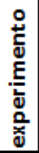 & $\underset{+}{+}$ & 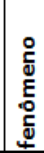 & 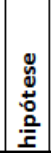 & $\underline{\underline{d}}$ & 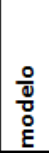 & 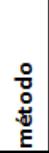 & 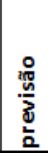 & $\begin{array}{l}\frac{\pi}{\varepsilon} \\
\frac{\delta}{0} \\
\frac{0}{0} \\
\frac{2}{2}\end{array}$ & 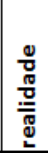 & 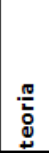 & $\stackrel{ \pm}{\sharp}$ & $\begin{array}{l}\frac{0}{0} \\
\frac{\pi}{0} \\
\frac{0}{j}\end{array}$ \\
\hline & & 1 & 2 & 3 & 4 & 5 & 6 & 7 & 8 & 9 & 10 & 11 & 12 & 13 & 14 & 15 & 16 & 17 \\
\hline abstração & 1 & 0 & & & & & & & & & & & & & & & & \\
\hline ciência & 2 & 0 & 0 & & & & & & & & & & & & & & & \\
\hline conclusão & 3 & 1 & 3 & 0 & & & & & & & & & & & & & & \\
\hline dados & 4 & 2 & 5 & 7 & 0 & & & & & & & & & & & & & \\
\hline experimento & 5 & 0 & 5 & 6 & 7 & 0 & & & & & & & & & & & & \\
\hline fato & 6 & 0 & 7 & 1 & 5 & 2 & 0 & & & & & & & & & & & \\
\hline fenômeno & 7 & 1 & 10 & 2 & 7 & 6 & 3 & 0 & & & & & & & & & & \\
\hline hipótese & 8 & 1 & 8 & 1 & 7 & 4 & 8 & 5 & 0 & & & & & & & & & \\
\hline lei & 9 & 0 & 3 & 2 & 4 & 5 & 3 & 3 & 4 & 0 & & & & & & & & \\
\hline modelo & 10 & 1 & 4 & 3 & 6 & 6 & 2 & 3 & 11 & 5 & 0 & & & & & & & \\
\hline método & 11 & 1 & 4 & 2 & 4 & 4 & 1 & 3 & 3 & 0 & 0 & 0 & & & & & & \\
\hline previsão & 12 & 0 & 1 & 1 & 0 & 3 & 1 & 3 & 0 & 1 & 2 & 1 & 0 & & & & & \\
\hline problema & 13 & 1 & 10 & 5 & 7 & 6 & 6 & 7 & 6 & 1 & 2 & 5 & 1 & 0 & & & & \\
\hline realidade & 14 & 0 & 4 & 3 & 4 & 4 & 1 & 1 & 2 & 2 & 1 & 1 & 1 & 2 & 0 & & & \\
\hline teoria & 15 & 0 & 7 & 5 & 5 & 8 & 3 & 8 & 10 & 8 & 12 & 2 & 5 & 4 & 3 & 0 & & \\
\hline teste & 16 & 0 & 4 & 3 & 6 & 9 & 2 & 4 & 7 & 3 & 7 & 0 & 0 & 2 & 2 & 6 & 0 & \\
\hline verdade & 17 & 0 & 4 & 1 & 1 & 3 & 0 & 2 & 4 & 1 & 3 & 2 & 2 & 1 & 0 & 5 & 2 & 0 \\
\hline
\end{tabular}

Figura 4.13 - Matriz representativa (pré-1) obtida pelo Hamlet ${ }^{\circledR}$ a partir dos textos originais 


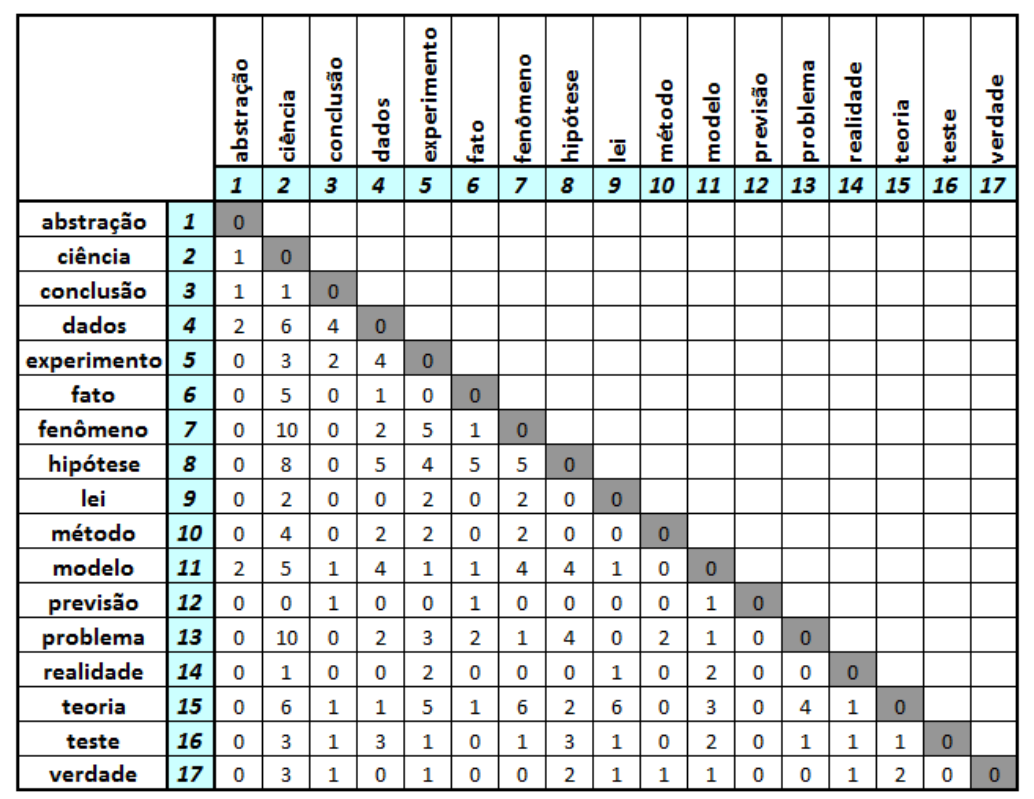

Figura 4.14 - Matriz representativa (pré-2) obtida pelo Hamlet $^{\circledR}$ a partir dos textos modificados

\begin{tabular}{|c|c|c|c|c|c|c|c|c|c|c|c|c|c|c|c|c|c|c|}
\hline & & 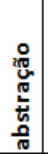 & $\begin{array}{l}\frac{\pi}{0} \\
\frac{\pi}{\pi} \\
\frac{d \pi}{u}\end{array}$ & 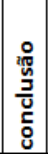 & $\begin{array}{l} \\
\text { on } \\
\frac{\pi}{0} \\
\frac{\pi}{0}\end{array}$ & 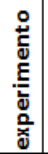 & $\stackrel{+}{+0}$ & 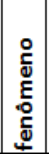 & 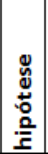 & $\bar{\Phi}$ & $\begin{array}{l}\frac{\circ}{\mathrm{v}} \\
\stackrel{\mathrm{g}}{\mathrm{g}} \\
\mathrm{\varepsilon}\end{array}$ & $\begin{array}{l}\circ \\
\stackrel{0}{0} \\
\dot{\sharp} \\
\varepsilon\end{array}$ & $\begin{array}{l}\frac{0}{20} \\
\frac{n}{3} \\
\frac{0}{2}\end{array}$ & 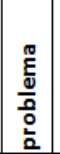 & 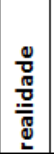 & 紊 & ఫ & $\begin{array}{l}\frac{0}{0} \\
\frac{\pi}{0} \\
\text { d }\end{array}$ \\
\hline & & 1 & 2 & 3 & 4 & 5 & 6 & 7 & 8 & 9 & 10 & 11 & 12 & 13 & 14 & 15 & 16 & 17 \\
\hline abstração & 1 & 0 & & & & & & & & & & & & & & & & \\
\hline ciência & 2 & 2 & 0 & & & & & & & & & & & & & & & \\
\hline conclusão & 3 & 0 & 4 & 0 & & & & & & & & & & & & & & \\
\hline dados & 4 & 0 & 5 & 2 & 0 & & & & & & & & & & & & & \\
\hline experimento & 5 & 2 & 9 & 3 & 3 & 0 & & & & & & & & & & & & \\
\hline fato & 6 & 3 & 6 & 1 & 2 & 5 & 0 & & & & & & & & & & & \\
\hline fenômeno & 7 & 1 & 10 & 1 & 2 & 4 & 2 & 0 & & & & & & & & & & \\
\hline hipótese & 8 & 3 & 14 & 4 & 5 & 16 & 5 & 9 & 0 & & & & & & & & & \\
\hline lei & 9 & 0 & 5 & 1 & 1 & 3 & 2 & 6 & 8 & 0 & & & & & & & & \\
\hline modelo & 10 & 2 & 8 & 0 & 1 & 5 & 1 & 4 & 8 & 4 & 0 & & & & & & & \\
\hline método & 11 & 2 & 20 & 0 & 1 & 7 & 3 & 2 & 6 & 1 & 4 & 0 & & & & & & \\
\hline previsão & 12 & 0 & 4 & 0 & 0 & 3 & 0 & 5 & 4 & 2 & 2 & 0 & 0 & & & & & \\
\hline problema & 13 & 2 & 14 & 1 & 1 & 3 & 2 & 4 & 3 & 0 & 3 & 6 & 0 & 0 & & & & \\
\hline realidade & 14 & 1 & 5 & 1 & 2 & 2 & 0 & 1 & 3 & 2 & 4 & 1 & 1 & 0 & 0 & & & \\
\hline teoria & 15 & 1 & 13 & 1 & 4 & 8 & 5 & 12 & 14 & 10 & 10 & 3 & 6 & 4 & 3 & 0 & & \\
\hline teste & 16 & 1 & 8 & 2 & 3 & 5 & 2 & \begin{tabular}{|l|}
1 \\
\end{tabular} & 12 & 3 & 5 & 5 & 1 & 1 & 2 & 4 & 0 & \\
\hline verdade & 17 & 0 & 8 & 1 & 0 & \begin{tabular}{|l|l}
3 \\
\end{tabular} & 0 & 0 & 1 & 0 & 3 & 2 & 1 & 1 & 0 & 3 & 0 & 0 \\
\hline
\end{tabular}

Figura 4.15 - Matriz representativa (pós-1) obtida pelo Hamlet $^{\circledR}$ a partir dos textos originais 


\begin{tabular}{|c|c|c|c|c|c|c|c|c|c|c|c|c|c|c|c|c|c|c|}
\hline & 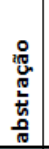 & $\begin{array}{l}\frac{\pi}{0} \\
\frac{\pi}{0} \\
\frac{\pi}{0}\end{array}$ & 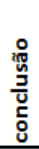 & $\begin{array}{l}n \\
\frac{0}{0} \\
\frac{\pi}{0}\end{array}$ & 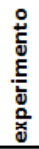 & $\stackrel{+}{\stackrel{9}{+}}$ & 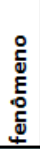 & 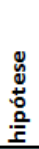 & $\underline{\underline{\Phi}}$ & 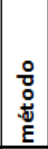 & $\begin{array}{l}\circ \\
\stackrel{0}{\mathrm{~d}} \\
\mathrm{o} \\
\mathrm{E}\end{array}$ & 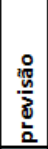 & 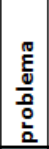 & 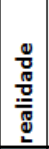 & 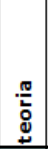 & $\stackrel{\Xi}{\sharp}$ & $\begin{array}{l}\stackrel{0}{0} \\
\frac{\pi}{0} \\
\frac{\pi}{2}\end{array}$ \\
\hline & & 1 & 2 & 3 & 4 & 5 & 6 & 7 & 8 & 9 & 10 & 11 & 12 & 13 & 14 & 15 & 16 & 17 \\
\hline abstração & 1 & 0 & & & & & & & & & & & & & & & & \\
\hline ciência & 2 & 2 & 0 & & & & & & & & & & & & & & & \\
\hline conclusão & 3 & 0 & 3 & 0 & & & & & & & & & & & & & & \\
\hline dados & 4 & 0 & 8 & 3 & 0 & & & & & & & & & & & & & \\
\hline experimento & 5 & 0 & 10 & 2 & 0 & 0 & & & & & & & & & & & & \\
\hline fato & 6 & 0 & 4 & 1 & 0 & 0 & 0 & & & & & & & & & & & \\
\hline fenômeno & 7 & 0 & 10 & 0 & 0 & 1 & 0 & 0 & & & & & & & & & & \\
\hline hipótese & 8 & 0 & 13 & 3 & 1 & 8 & 2 & 5 & 0 & & & & & & & & & \\
\hline lei & 9 & 0 & 4 & 1 & 0 & 0 & 0 & 3 & 4 & 0 & & & & & & & & \\
\hline método & 10 & 0 & 19 & 0 & 0 & 2 & 1 & 1 & 3 & 0 & 0 & & & & & & & \\
\hline modelo & 11 & 0 & 10 & 0 & 0 & 1 & 0 & 2 & 1 & 1 & 2 & 0 & & & & & & \\
\hline previsão & 12 & 0 & 3 & 0 & 0 & 0 & 0 & 2 & 1 & 1 & 0 & 1 & 0 & & & & & \\
\hline problema & 13 & 0 & 12 & 0 & 0 & 2 & 0 & 2 & 0 & 0 & 4 & 0 & 0 & 0 & & & & \\
\hline realidade & 14 & 0 & 2 & 1 & 1 & 0 & 0 & 0 & 1 & 0 & 0 & 5 & 0 & 0 & 0 & & & \\
\hline teoria & 15 & 0 & 12 & 0 & 2 & 1 & 3 & 6 & 7 & 3 & 1 & 5 & 2 & 2 & 0 & 0 & & \\
\hline teste & 16 & 1 & 1 & 1 & 0 & 0 & 0 & 0 & 3 & 0 & 0 & 1 & 0 & 0 & 0 & 1 & 0 & \\
\hline verdade & 17 & 0 & 6 & 0 & 0 & 0 & 0 & 0 & 1 & 0 & 1 & 0 & 1 & 0 & 0 & 0 & 0 & 0 \\
\hline
\end{tabular}

Figura 4.16 - Matriz representativa (pós-2) obtida pelo Hamlet $^{\circledR}$ a partir dos textos modificados

\subsubsection{Análise das matrizes obtidas}

Em princípio, algumas informações gerais no que diz respeito às relações entre conceitos estabelecidas nos textos dos alunos podem ser obtidas por meio da interpretação das matrizes representativas mostradas. Uma das informações relevantes em relação aos dados quantificados nessas matrizes refere-se ao número total de relações identificadas entre os conceitos nos textos analisados, desta forma, para as matrizes representativas (pré-1); (pré-2); (pós-1) e (pós-2) esses valores são respectivamente: 463; 215; 482 e 230.

Como se pode perceber, o número total de relações entre conceitos nas duas matrizes obtidas a partir da análise dos textos originais (pré-1 e pós-1) é bastante semelhante, o que também se verifica nos valores encontrados para as matrizes referentes aos textos modificados (pré-2 e pós-2). Além disso, nota-se que o número total de relações entre conceitos para as matrizes provenientes dos textos originais é relativamente maior (cerca de duas vezes) do que o valor referente às matrizes provenientes dos textos modificados. Esses valores confirmam o modo de funcionamento do programa Hamlet $^{\circledR}$ já apresentado e explicado anteriormente, em que a análise de textos na forma como foram escritos originalmente identifica e quantifica todas as possibilidades de relações entre conceitos presentes em uma mesma sentença, não distinguindo qualquer caráter proposicional que possa existir nessas relações. 
Outra observação de destaque se relaciona ao número e à natureza dos pares de conceitos que se encontram relacionados na matriz, o que leva também à observação das relações inexistentes na mesma. Considerando que as relações identificadas pelo programa e quantificadas nas matrizes eram referentes a 17 conceitos fornecidos na atividade proposta, é possível afirmar que existia a possibilidade de os alunos estabelecerem até 136 diferentes relações entre esses conceitos.

A análise das matrizes (pré-1) e (pós-1) mostradas nas figuras 4.13 e 4.15, bem como das matrizes (pré-2) e (pós-2) mostradas nas figuras 4.14 e 4.16, indica que os dados referentes aos momentos pré e pós-instrução são relativamente semelhantes em relação ao número de diferentes pares de conceitos relacionados. Nos textos originais pré-instrução foram identificadas 119 diferentes relações, enquanto nos textos originais pós-instrução 115 diferentes relações foram estabelecidas, dentre as 136 possíveis. Já para os textos modificados, conforme esperado, esses valores são inferiores, verificando-se a ocorrência de 82 diferentes relações entre conceitos para o momento pré-instrução e 66 para o momento pós-instrução.

A quantificação das relações entre conceitos que não foram estabelecidas, ou seja, consideradas inexistentes, nada mais é do que a diferença entre o número total de diferentes relações possíveis (no caso, 136) e o número de diferentes relações identificadas na matriz em questão. Para as matrizes (pré-1) e (pós-1) (figuras 4.13 e 4.15) são observadas 17 e 21 relações inexistentes, respectivamente, enquanto para as matrizes (pré-2) e (pós-2) (figuras 4.14 e 4.16) esses valores aumentam para 54 e 70 , respectivamente.

Dentre os pares de conceitos não relacionados nas matrizes provenientes dos textos originais e modificados, destacam-se aqueles que foram comuns em ambas as situações pré e pós-instrução, tratando-se, desta forma, de conceitos que não apresentaram qualquer relação significativa para os alunos tanto antes quanto após a instrução sobre o tema da atividade como se faz ciência. Para as matrizes provenientes dos textos originais, 6 pares de conceitos não foram relacionados nos textos dos alunos antes e após a instrução, foram eles: leiabstração; previsão-abstração; verdade-abstração; previsão-dados; verdade-fato; verdaderealidade. Já para as matrizes referentes aos textos modificados, 36 diferentes relações entre conceitos não foram estabelecidas nos textos dos alunos tanto antes quanto após a instrução. 


\subsubsection{Análise das redes de conceitos obtidas}

As matrizes obtidas pelo Hamlet $^{\circledR}$ após a análise dos textos originais e modificados, referentes aos momentos pré e pós-instrução, permitiram a construção de redes de conceitos que representam graficamente algumas relações entre conceitos presentes nos referidos textos. No contexto dos dados obtidos na disciplina Química e Sociedade, as quatro matrizes obtidas permitiram a construção dos seguintes tipos de redes: rede de conceitos considerando o $(s)$ vizinho(s) mais próximo(s) e rede de conceitos a partir de corte percentual.

- Redes de conceitos contemplando o(s) vizinho(s) mais próximo(s): Rede (V+P)

Conforme citado anteriormente, para determinado conceito, seu vizinho mais próximo é aquele que se encontra relacionado um maior número de vezes ao conceito em questão, podendo haver mais de um vizinho mais próximo para o conceito considerado. A rede de conceitos contemplando o(s) vizinho(s) mais próximo(s), por sua vez, é a estrutura gráfica que mostra as relações existentes entre esse grupo específico de conceitos.

Para os dados referentes à disciplina Química e Sociedade, primeiramente foi feita a marcação do(s) vizinho(s) mais próximo(s) de cada um dos 17 conceitos presentes nas matrizes representativas pré e pós-instrução. Desta forma, na linha ou coluna correspondente a cada conceito, os maiores valores numéricos presentes foram destacados e, a partir das matrizes contendo o(s) vizinho(s) mais próximo(s) em destaque, foram construídas as respectivas redes de conceitos, em que o sentido das setas indica o(s) vizinho(s) mais próximo(s) de um determinado conceito. As figuras a seguir apresentam as quatro matrizes referentes aos dados da disciplina Química e Sociedade, com as devidas marcações do(s) vizinho(s) mais próximo(s) e suas respectivas redes de conceitos. 


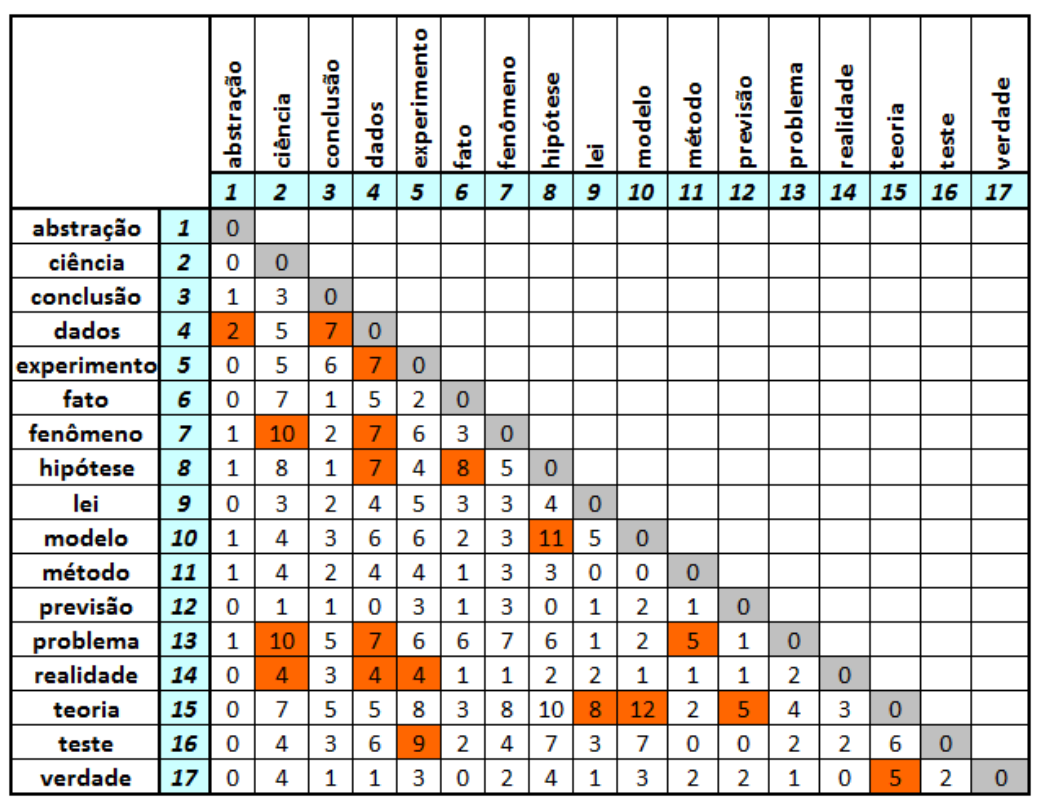

Figura 4.17 - Matriz representativa (pré-1) com o(s) vizinho(s) mais próximo(s) de cada conceito em destaque

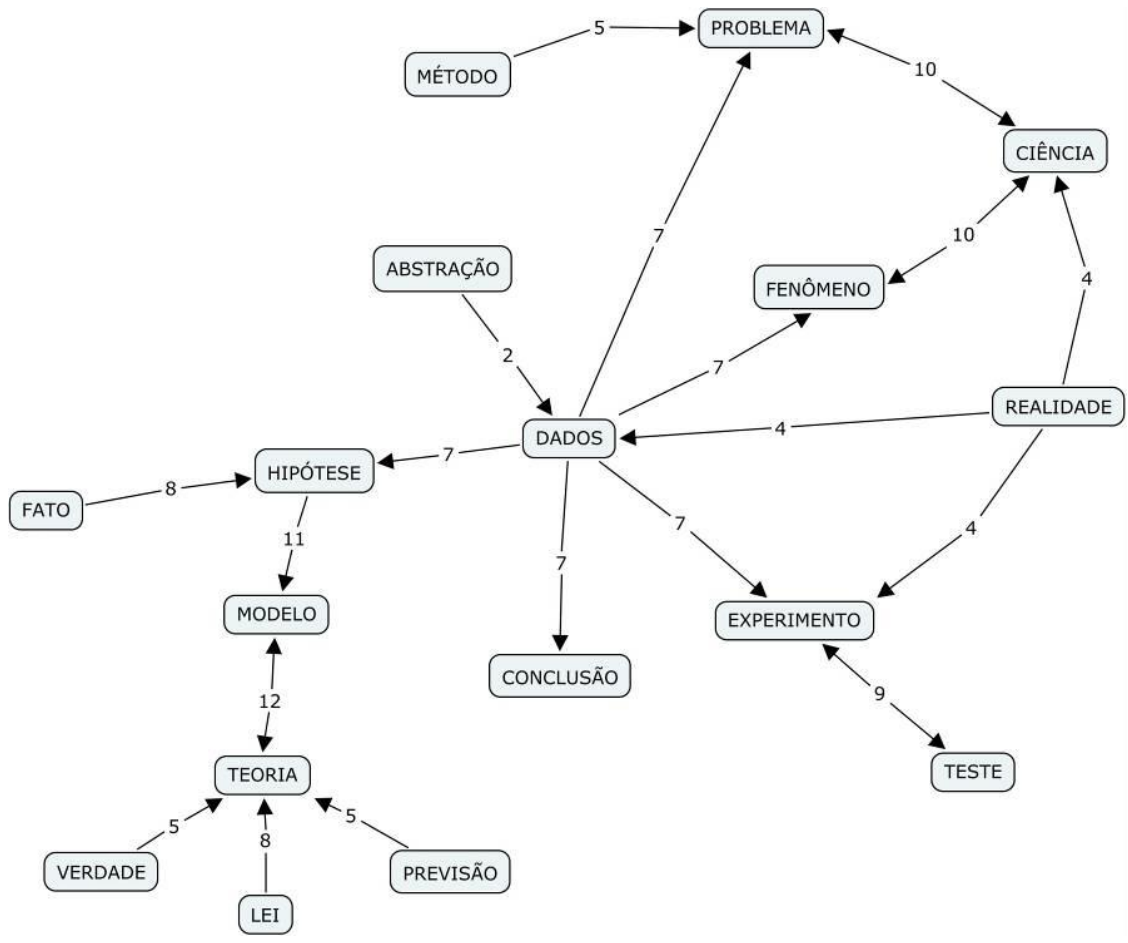

Figura 4.18 - Rede (V+P) (pré-1) referente aos dados da disciplina Química e Sociedade 


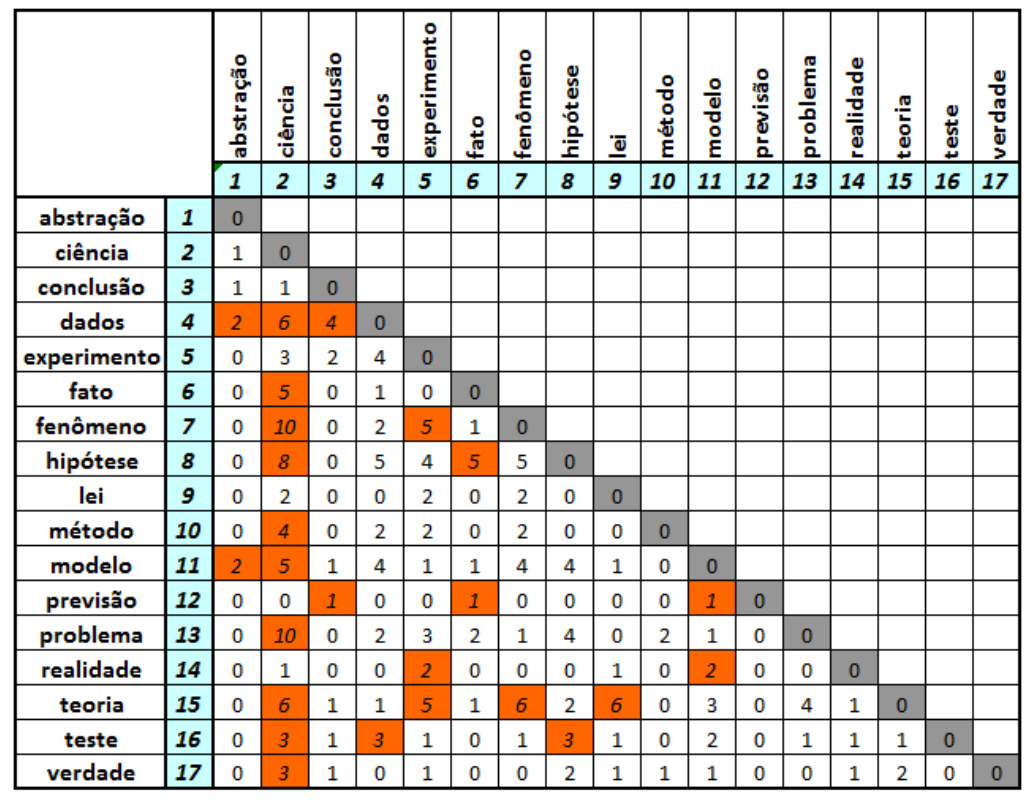

Figura 4.19 - Matriz representativa (pré-2) com o(s) vizinho(s) mais próximo(s) de cada conceito em destaque

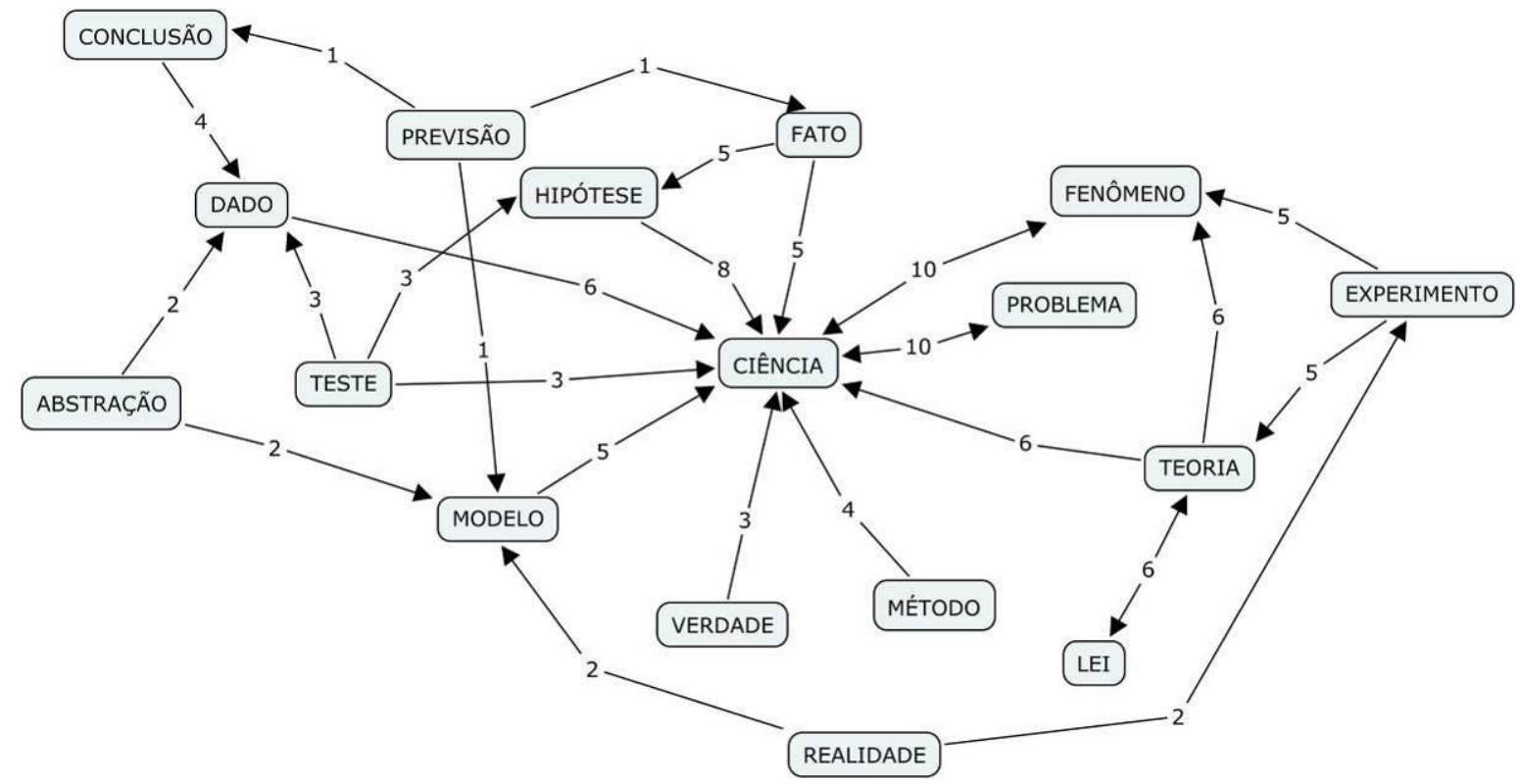

Figura 4.20 - Rede (V+P) (pré-2) referente aos dados da disciplina Química e Sociedade 


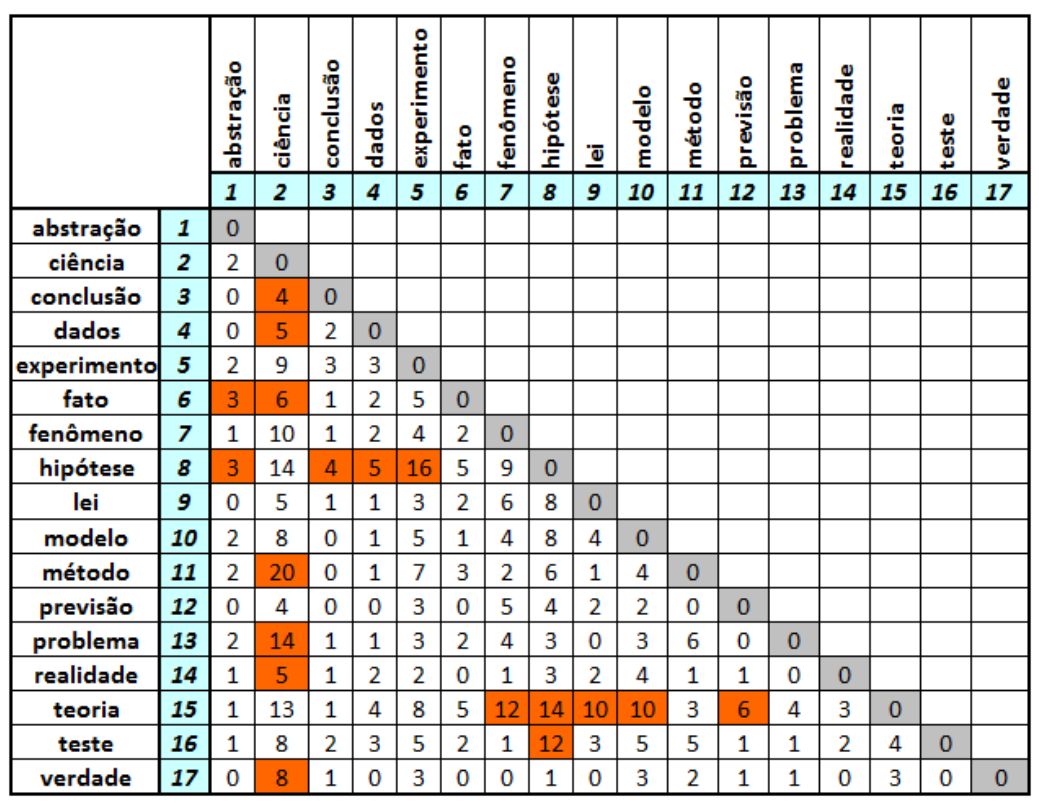

Figura 4.21 - Matriz representativa (pós-1) com o(s) vizinho(s) mais próximo(s) de cada conceito em destaque

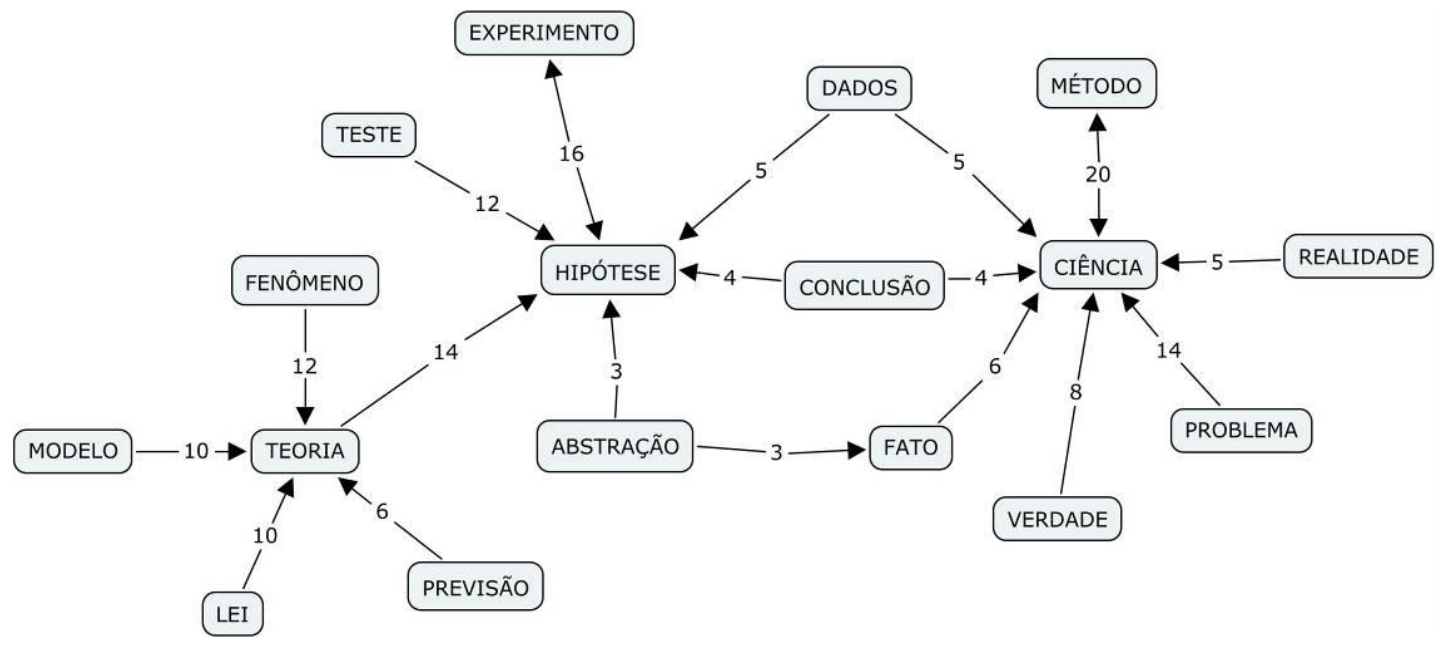

Figura 4.22 - Rede (V+P) (pós-1) referente aos dados da disciplina Química e Sociedade 


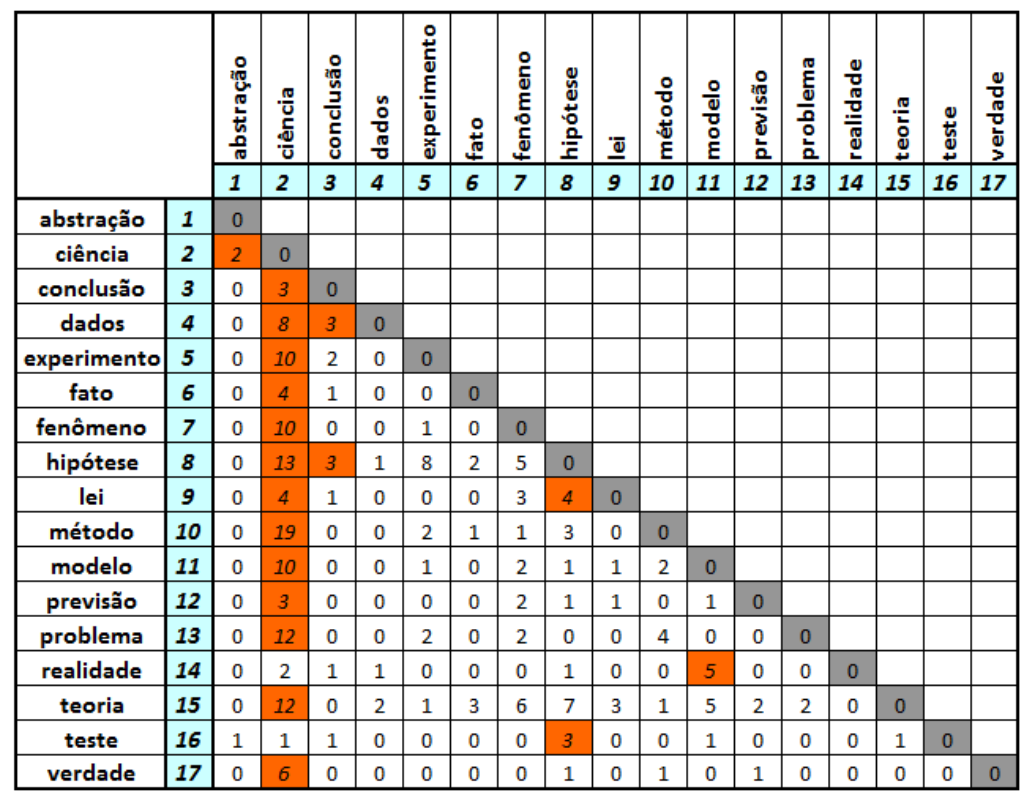

Figura 4.23 - Matriz representativa (pós-2) com o(s) vizinho(s) mais próximo(s) de cada conceito em destaque

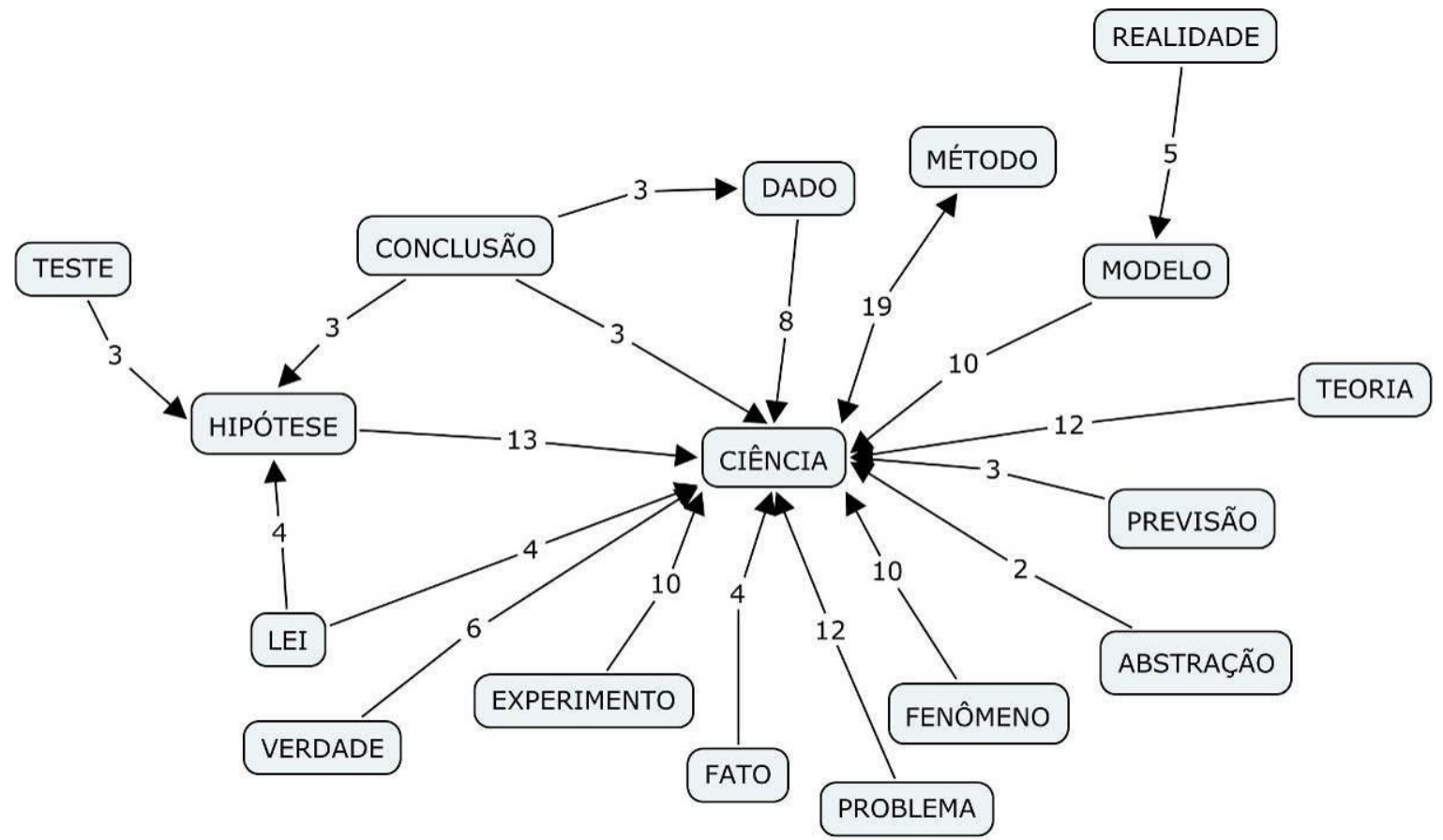

Figura 4.24 - Rede (V+P) (pós-2) referente aos dados da disciplina Química e Sociedade

A primeira observação que se pode fazer sobre as quatro redes $(\mathrm{V}+\mathrm{P})$ construídas diz respeito ao número de diferentes ligações entre conceitos, verificando-se a presença de 19, 25, 18 e 19 ligações entre conceitos para as redes (V+P) (pré-1), (pré-2), (pós-1) e (pós-2), respectivamente. Como se pode perceber, os valores encontrados são relativamente próximos 
e, por esse motivo, outras análises devem ser realizadas acerca das características das redes obtidas.

Neste sentido, nota-se a presença de alguns conceitos considerados centrais e terminais em todas as redes apresentadas, lembrando que os conceitos centrais podem ser entendidos como conceitos relacionados a pelo menos três outros conceitos, enquanto os conceitos terminais são aqueles que estabelecem relação com um único conceito. O quadro a seguir organiza e possibilita comparar essas informações em relação às redes de vizinhos mais próximos pré e pós-instrução, referentes aos textos originais e modificados, mostrando o número e a natureza dos conceitos considerados centrais e terminais em todos os casos.

\begin{tabular}{|c|c|c|c|c|}
\hline & Rede (V+P) (pré-1) & Rede $(\mathrm{V}+\mathrm{P})$ (pré-2) & Rede (V+P) (pós-1) & Rede (V+P) (pós-2) \\
\hline $\begin{array}{c}\text { Natureza dos conceitos } \\
\text { centrais }\end{array}$ & $\begin{array}{c}\begin{array}{c}\text { ciência } \\
\text { dados }\end{array} \\
\text { experimento } \\
\text { hipótese } \\
\text { problema } \\
\text { realidade } \\
\text { teoria }\end{array}$ & $\begin{array}{c}\text { ciência } \\
\text { dados } \\
\text { experimento } \\
\text { fato } \\
\text { fenômeno } \\
\text { hipótese } \\
\text { modelo } \\
\text { previsão } \\
\text { teoria } \\
\text { teste }\end{array}$ & $\begin{array}{l}\text { ciência } \\
\text { hipótese } \\
\text { teoria }\end{array}$ & $\begin{array}{l}\text { ciência } \\
\text { conclusão } \\
\text { hipótese }\end{array}$ \\
\hline $\mathrm{N}^{\circ}$ de conceitos centrais & 7 & 10 & 3 & 3 \\
\hline $\begin{array}{c}\text { Natureza dos conceitos } \\
\text { terminais }\end{array}$ & $\begin{array}{c}\text { abstração } \\
\text { conclusão } \\
\text { fato } \\
\text { lei } \\
\text { método } \\
\text { previsão } \\
\text { teste } \\
\text { verdade }\end{array}$ & $\begin{array}{c}\text { lei } \\
\text { método } \\
\text { problema } \\
\text { verdade }\end{array}$ & $\begin{array}{c}\text { experimento } \\
\text { fenômeno } \\
\text { lei } \\
\text { método } \\
\text { modelo } \\
\text { previsão } \\
\text { problema } \\
\text { realidade } \\
\text { teste } \\
\text { verdade }\end{array}$ & $\begin{array}{c}\text { abstração } \\
\text { experimento } \\
\text { fato } \\
\text { fenômeno } \\
\text { método } \\
\text { previsão } \\
\text { problema } \\
\text { realidade } \\
\text { teoria } \\
\text { teste } \\
\text { verdade }\end{array}$ \\
\hline $\mathrm{N}^{0}$ de conceitos terminais & 8 & 4 & 10 & 11 \\
\hline $\mathrm{N}^{\circ}$ total de ligações & 19 & 25 & 18 & 19 \\
\hline
\end{tabular}

Quadro 4.3 - Comparação entre as redes (V+P) (pré-1), (pré-2), (pós-1) e (pós-2) quanto aos conceitos e ligações presentes.

Ao observar as redes ( $\mathrm{V}+\mathrm{P})$ (pré-1) e (pré-2), representadas nas figuras 4.18 e 4.20, verifica-se que a rede referente aos textos modificados consiste em uma rede mais complexa devido ao maior número de ligações e do menor número de conceitos terminais presentes, tratando-se de uma rede em que os conceitos estão mais relacionados. Além disso, a comparação estabelecida no quadro 4.3 entre as redes $(\mathrm{V}+\mathrm{P})$ (pré-1) e (pré-2) destaca, em 
negrito, que as duas estruturas apresentam 5 conceitos considerados centrais e comuns às duas redes, são eles: ciência, dados, experimento, hipótese e teoria.

A análise das duas estruturas gráficas em questão permite perceber que o número de diferentes ligações que os conceitos considerados centrais estabelecem em cada uma das redes pode variar, no entanto, para os conceitos experimento, hipótese e teoria este valor é o mesmo em ambas as redes: 3, 3 e 4, respectivamente. Já para os conceitos ciência e dados algo diferente é observado, uma vez que o conceito central ciência estabeleceu 10 diferentes ligações na rede $(\mathrm{V}+\mathrm{P})$ (pré-2) contra apenas 3 na rede $(\mathrm{V}+\mathrm{P})$ (pré-1); já o conceito central dados estabeleceu 7 diferentes ligações na rede $(\mathrm{V}+\mathrm{P})$ (pré-1) contra apenas 3 na rede $(\mathrm{V}+\mathrm{P})$ (pré-2).

Desta forma, em relação ao número de diferentes relações estabelecidas pelos conceitos considerados centrais, não é possível verificar um padrão entre as redes $(\mathrm{V}+\mathrm{P})$ com origem nos textos originais ou modificados. No entanto, é relevante destacar que ambas as estruturas gráficas mostraram uma informação bastante importante quanto às ideias dos alunos em relação aos conceitos ciência, dados, experimento, hipótese e teoria, uma vez que, por terem sido considerados centrais, evidenciaram que, para os alunos, a maioria dos processos envolvidos na construção do conhecimento científico se relaciona a esses conceitos de alguma maneira, ou seja, os conceitos citados foram considerados relevantes e centrais dentro da visão de ciência dos alunos antes da instrução.

As redes $(\mathrm{V}+\mathrm{P})$ (pós-1) e (pós-2) inicialmente se mostram bastante semelhantes, uma vez que o número de ligações e os números de conceitos centrais e terminais em ambas as redes é muito parecido, como é possível perceber pelas comparações estabelecidas no quadro 4.3. Ao observar as duas estruturas gráficas, certamente o maior destaque se refere ao conceito ciência, considerado central e vizinho mais próximo de um número considerável de outros conceitos; 7 na rede $(\mathrm{V}+\mathrm{P})$ (pós-1) e 14 na rede $(\mathrm{V}+\mathrm{P})$ (pós-2), o que é bastante coerente com o tema proposto na atividade avaliativa - como se faz ciência.

Já o conceito hipótese, que também aparece como central em ambas as redes, estabeleceu um número maior de diferentes ligações na rede $(\mathrm{V}+\mathrm{P})$ (pós-1). Desta forma, novamente não se verifica um padrão entre as redes $(\mathrm{V}+\mathrm{P})$ com origem nos textos originais ou modificados em relação ao número de diferentes relações estabelecidas pelos conceitos considerados centrais em ambas as redes. 
$\mathrm{O}$ valor do PMC obtido na comparação entre a rede $(\mathrm{V}+\mathrm{P})($ pré-1) e a rede $(\mathrm{V}+\mathrm{P})$ (pré2) referente aos dados da disciplina Química e Sociedade foi de 0,33 , já para a comparação entre a rede $(\mathrm{V}+\mathrm{P})$ (pós-1) e a rede $(\mathrm{V}+\mathrm{P})$ (pós-2), o valor do PMC calculado foi de 0,43. Estes valores indicam que as estruturas gráficas apresentam 33\% e $43 \%$ de semelhança, respectivamente, o que quer dizer que as redes construídas a partir das matrizes referentes aos textos originais apresentam semelhança baixa quando comparadas com as redes geradas a partir das matrizes referentes aos textos modificados.

Uma breve análise referente aos momentos pré e pós-instrução também se mostra relevante, sendo possível realizá-la tanto para as redes com origem nos textos originais quanto para as redes com origem nos textos modificados. Inicialmente, é possível dizer que a estrutura da rede $(\mathrm{V}+\mathrm{P})$ (pós-1) se diferencia da rede $(\mathrm{V}+\mathrm{P})$ (pré-1) pelo número de conceitos centrais e terminais presentes. Na rede apresentada na figura 4.22, referente ao momento pósinstrução, verificam-se 3 conceitos centrais e 10 terminais, ao passo que na rede da figura 4.18, referente ao momento pré-instrução, são observados 7 conceitos centrais e 8 terminais.

Os conceitos ciência, hipótese e teoria são considerados centrais tanto na rede (V+P) (pré-1) quanto na rede $(\mathrm{V}+\mathrm{P})$ (pós-1), sendo que nesta última esses conceitos estão relacionados a 7, 6 e 5 outros conceitos, respectivamente. Essas observações referentes às redes com origem nos textos originais sugerem a importância dos conceitos ciência, hipótese e teoria para os alunos antes e após a instrução. Além disso, no caso da rede (V+P) (pós-1), é observado um aumento no número de vezes que algumas das relações envolvendo os conceitos centrais é estabelecida em comparação à rede $(\mathrm{V}+\mathrm{P})$ (pré-1), o que mostra uma consolidação ou reafirmação de algumas relações entre conceitos diante deste aumento no número de vezes em que foram estabelecidas. Ainda em relação aos conceitos considerados centrais em ambas as redes, verifica-se um maior número de conceitos relacionados a eles na rede após a instrução, o que pode indicar alguma mudança no que diz respeito às concepções dos alunos em relação ao tema como se faz ciência.

Neste sentido, tratando-se de redes que mostram justamente o(s) vizinho(s) mais próximo(s) de cada conceito, essa observação se mostra bastante relevante para o estabelecimento de conclusões sobre eventuais mudanças nas concepções dos alunos após a instrução. O conceito ciência, por exemplo, apresenta-se como vizinho mais próximo de 3 outros conceitos na rede $(\mathrm{V}+\mathrm{P})$ (pré-1) e de 7 na rede $(\mathrm{V}+\mathrm{P})$ (pós-1), sendo que apenas duas dessas relações são comuns às duas estruturas gráficas. Algo semelhante é verificado para o conceito hipótese, que é mostrado como vizinho mais próximo de 2 conceitos antes da 
instrução e de 6 conceitos após a instrução, apresentando uma única relação comum nas duas redes consideradas. Finalmente, para o conceito teoria verificam-se menos diferenças, uma vez que o conceito apresenta-se como vizinho mais próximo de 4 outros conceitos em ambas as redes, sendo três dessas relações comuns às duas redes de conceitos.

Em relação às redes $(\mathrm{V}+\mathrm{P})$ (pré-2) e (pós-2), cuja origem se encontra nos textos modificados, essas estruturas gráficas diferem quanto ao número de ligações presentes, sendo que a rede referente ao momento pré-instrução se mostra mais complexa e com maior número de ligações entre conceitos. Além disso, na rede apresentada na figura 4.20, referente ao momento pré-instrução, verificam-se 10 conceitos centrais e 4 terminais, enquanto na rede mostrada na figura 4.24, referente ao momento pós-instrução, são observados 3 conceitos centrais e 11 terminais.

Os conceitos ciência e hipótese são considerados centrais tanto na rede ( $\mathrm{V}+\mathrm{P})$ (pré-2) quanto na rede $(\mathrm{V}+\mathrm{P})$ (pós-2), conforme observado também para as redes referentes aos textos originais. $\mathrm{Na}$ rede $(\mathrm{V}+\mathrm{P})$ (pré-2), os conceitos ciência e hipótese encontram-se relacionados a 10 e 3 outros conceitos, respectivamente, já na rede $(\mathrm{V}+\mathrm{P})$ (pós-2) estes conceitos estão relacionados a 14 e 4 outros conceitos, respectivamente.

A permanência dos conceitos ciência e hipótese como centrais nas redes referentes aos textos modificados sugerem a importância destes conceitos para os alunos antes e após a instrução. Neste sentido, o conceito ciência, por exemplo, apresenta-se como vizinho mais próximo de 10 outros conceitos na rede $(\mathrm{V}+\mathrm{P})$ (pré-2) e de 14 na rede $(\mathrm{V}+\mathrm{P})$ (pós-2), sendo que 9 dessas relações são comuns às duas estruturas gráficas. Algo semelhante é verificado para o conceito hipótese, que é mostrado como vizinho mais próximo de 3 conceitos antes da instrução e de 4 conceitos após a instrução, apresentando 2 relações comuns às duas redes consideradas.

Desta forma, como se pode perceber, a observação atenta das redes que contemplam o(s) vizinho(s) mais próximo(s) de cada conceito, referente aos textos originais e modificados, tanto para o momento pré quanto pós-instrução, mostra tanto semelhanças quanto diferenças em relação às ligações presentes, à maneira como os conceitos estão relacionados e ao número de vezes que cada relação é estabelecida. A semelhança verificada entre as redes quanto à natureza de alguns conceitos centrais, por exemplo, levou a observações de diferenças consideráveis quanto ao número e aos conceitos relacionados a eles. Ressalta-se ainda que não só as diferenças entre as estruturas gráficas obtidas possibilitam inferências sobre o conhecimento dos alunos, mas as semelhanças percebidas entre as redes referentes aos dois 
momentos da disciplina Química e Sociedade também sugerem conclusões acerca do conhecimento dos alunos sobre o tema trabalhado. Comparando-se as redes $(\mathrm{V}+\mathrm{P})($ pré-1) e (pós-1), verificou-se que 7 pares de conceitos permaneceram como vizinhos mais próximos uns dos outros antes e após a instrução, ao passo que para as redes ( $\mathrm{V}+\mathrm{P})$ (pré-2) e (pós-2) 12 foram os pares de conceitos que permaneceram como vizinhos mais próximos uns dos outros antes e após a instrução.

- Redes de conceitos a partir de corte percentual: Rede (\%)

As chamadas redes de conceitos a partir de cortes percentuais consistem em estruturas gráficas que representam as relações entre conceitos que mais foram estabelecidas nos textos originais ou nos textos modificados dos alunos. Conforme mostrado na seção 3.2.4 deste trabalho, dependendo do corte percentual escolhido, redes com diferentes estruturas são obtidas, assim, algumas delas podem ser de difícil análise e pouco úteis devido à presença de muitos grupos de conceitos isolados ou ao excesso de ligações entre conceitos.

Para os dados referentes à disciplina Química e Sociedade foram estabelecidos diferentes cortes percentuais para a construção de redes com estruturas distintas, as quais se basearam nas matrizes obtidas pelo Hamlet $^{\circledR}$ após a análise dos textos originais e modificados dos alunos, tanto do momento pré quanto pós-instrução. Ao todo, foram construídas 20 redes, sendo 10 para cada momento do curso, contemplando os dados com origem nos textos originais e modificados. Nessas redes estão presentes as relações entre conceitos que mais ocorreram nos textos dos alunos, de acordo com o corte percentual considerado, sendo que a construção das diversas redes ocorreu justamente com o objetivo de estabelecer comparações e de obter as melhores estruturas gráficas que possibilitassem analisar o entendimento dos alunos em relação à disciplina.

Para cada corte estabelecido, a rede correspondente contemplou diferentes relações entre conceitos, desta forma, a tabela a seguir apresenta o número mínimo de vezes que determinado par de conceitos deve ter sido relacionado na matriz representativa, de acordo com o corte percentual considerado. 
Tabela 4.4 - Número mínimo de relações entre conceitos de acordo com corte percentual

\begin{tabular}{ccccc}
\hline & \multicolumn{5}{c}{$\mathbf{N}^{\circ}$ mínimo de relações entre conceitos } \\
Corte percentual & $\begin{array}{r}\text { matriz representativa } \\
\text { (pré-1) }\end{array}$ & $\begin{array}{r}\text { matriz representativa } \\
\text { (pré-2) }\end{array}$ & $\begin{array}{r}\text { matriz representativa } \\
\text { (pós-1) }\end{array}$ & $\begin{array}{c}\text { matriz representativa } \\
\text { (pós-2) }\end{array}$ \\
\hline $\mathbf{5 \%}$ & 9 & 7 & 13 & 12 \\
$\mathbf{1 0} \%$ & 8 & 6 & 10 & 7 \\
$\mathbf{1 5 \%}$ & 7 & 5 & 8 & 5 \\
$\mathbf{2 5} \%$ & 6 & 4 & 6 & 3 \\
\hline $\mathbf{5 0} \%$ & 4 & 2 & 4 & 3 \\
\hline
\end{tabular}

Para uma melhor visualização e comparação entre as diferentes redes obtidas a partir das matrizes representativas (pré-1), (pré-2), (pós-1) e (pós-2), referentes aos dados da disciplina Química e Sociedade, as figuras 4.25, 4.26, 4.29 e 4.30 mostram as redes com corte percentual em $5 \%, 10 \%, 15 \%$ e $25 \%$ agrupadas em uma única representação para cada caso, onde consta uma legenda referente aos cortes percentuais estabelecidos. As figuras 4.27, 4.28, 4.31 e 4.32 , por sua vez, mostram as redes com corte percentual em 50\% separadamente pelo fato de apresentarem um número consideravelmente maior de ligações entre conceitos, o que dificultaria seu agrupamento com as redes dos demais cortes percentuais.

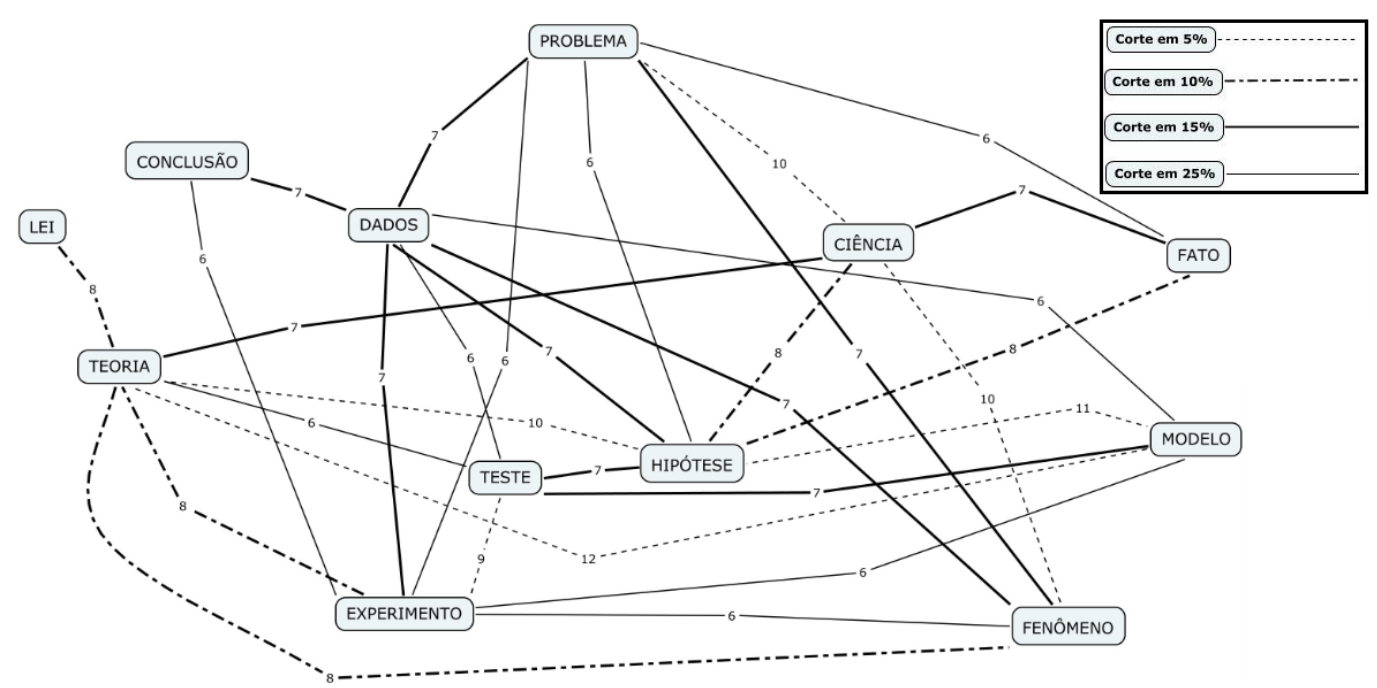

Figura 4.25 - Redes de conceitos com diferentes cortes percentuais obtidas a partir da matriz representativa (pré-1) 


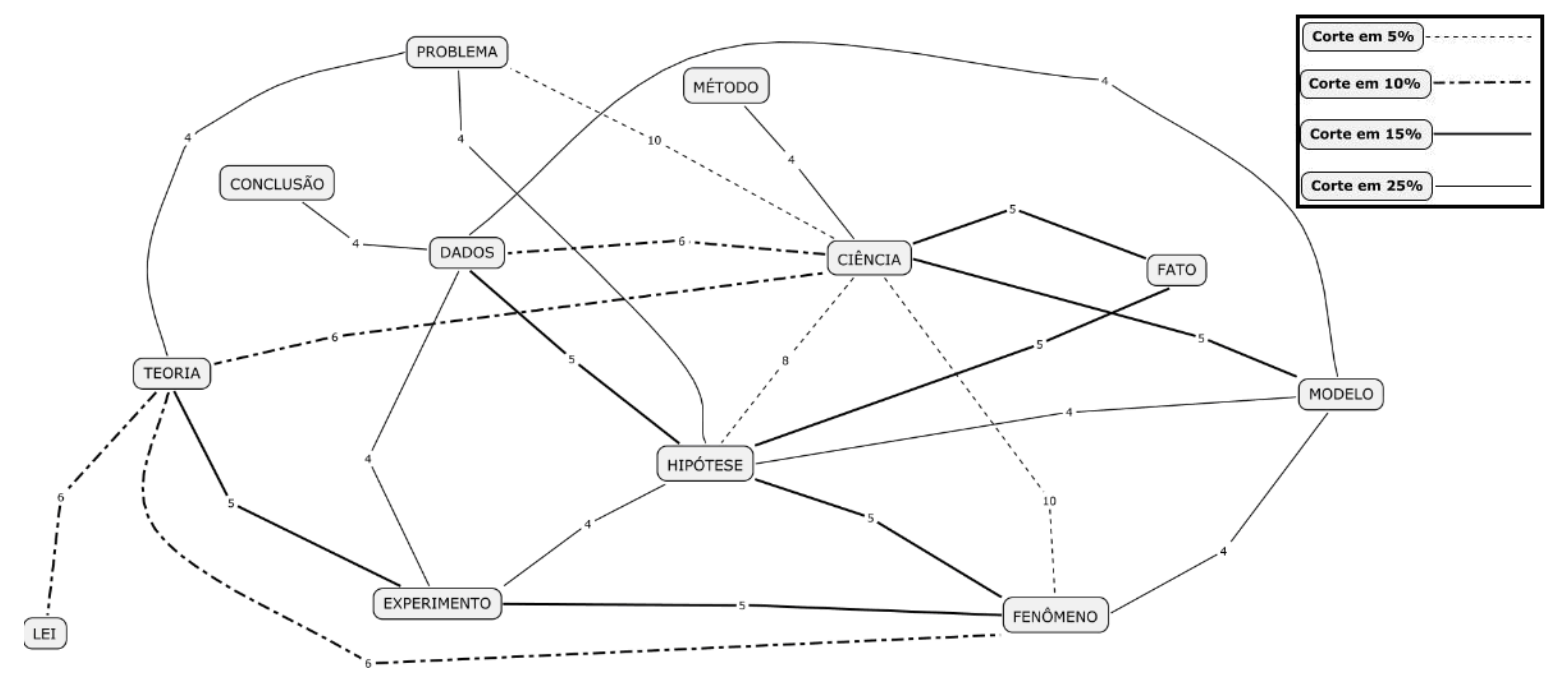

Figura 4.26 - Redes de conceitos com diferentes cortes percentuais obtidas a partir da matriz representativa (pré-2)

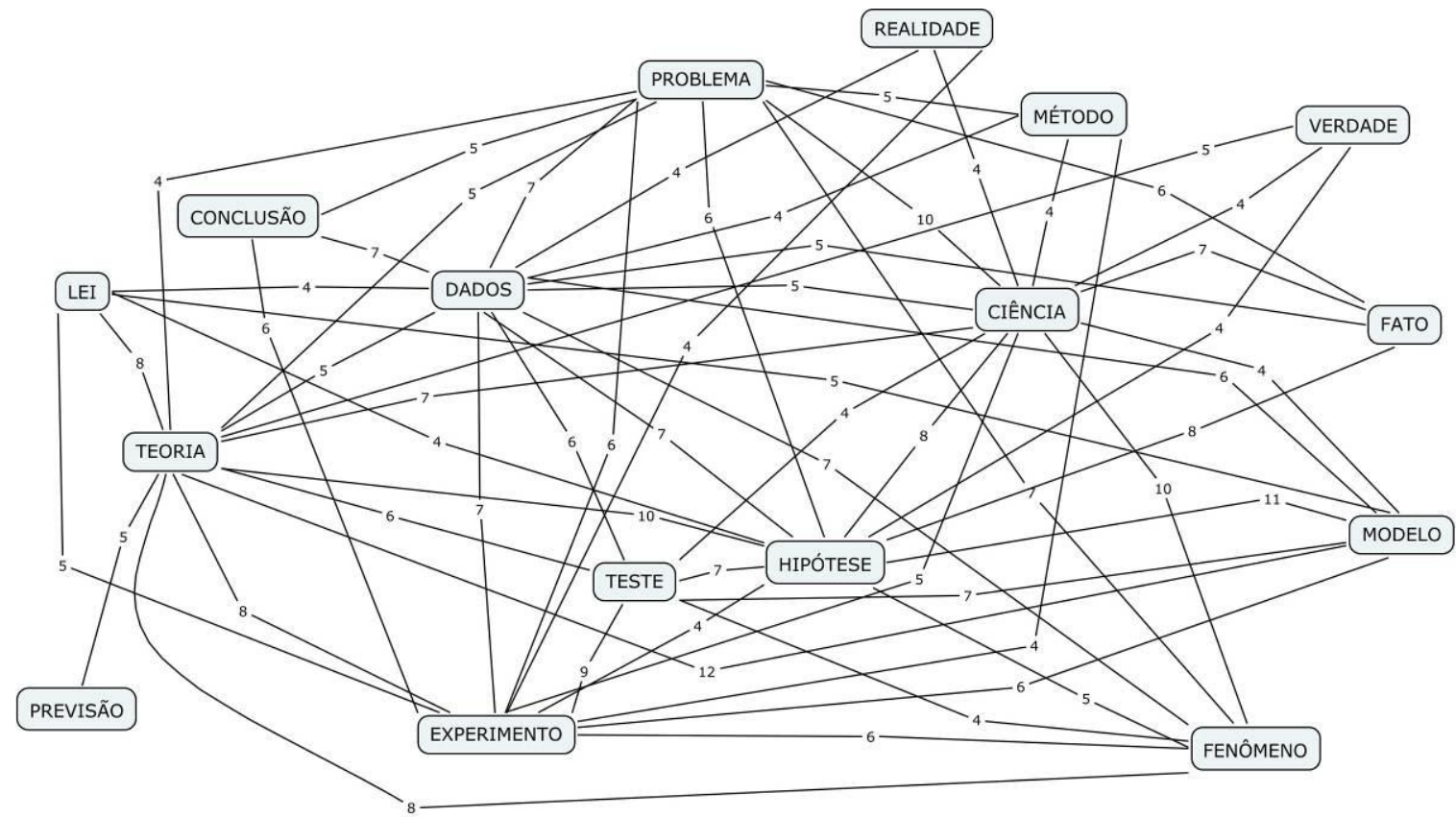

Figura 4.27 - Rede (50\%) (pré-1) referente aos dados da disciplina Química e Sociedade 


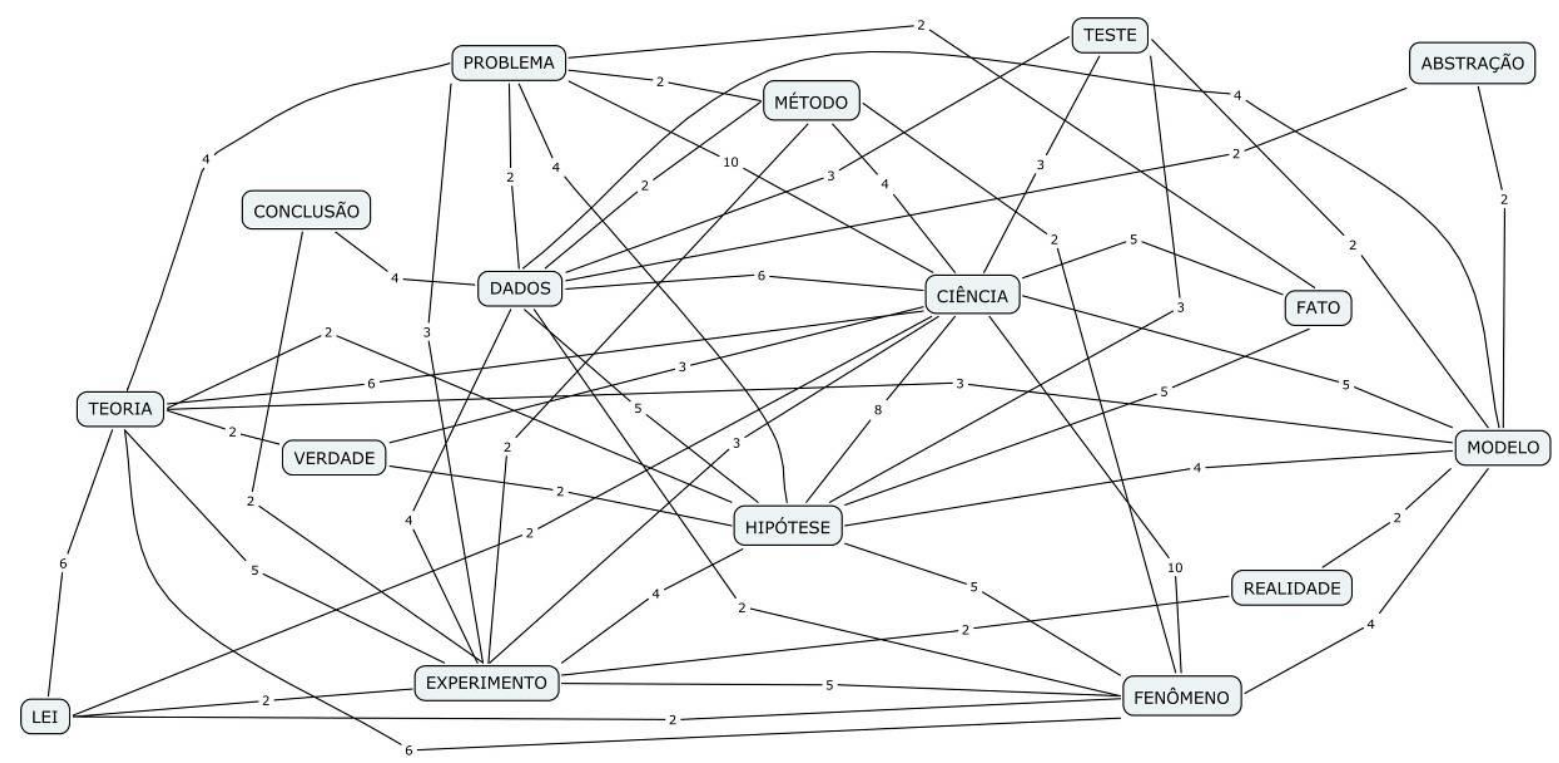

Figura 4.28 - Rede (50\%) (pré-2) referente aos dados da disciplina Química e Sociedade

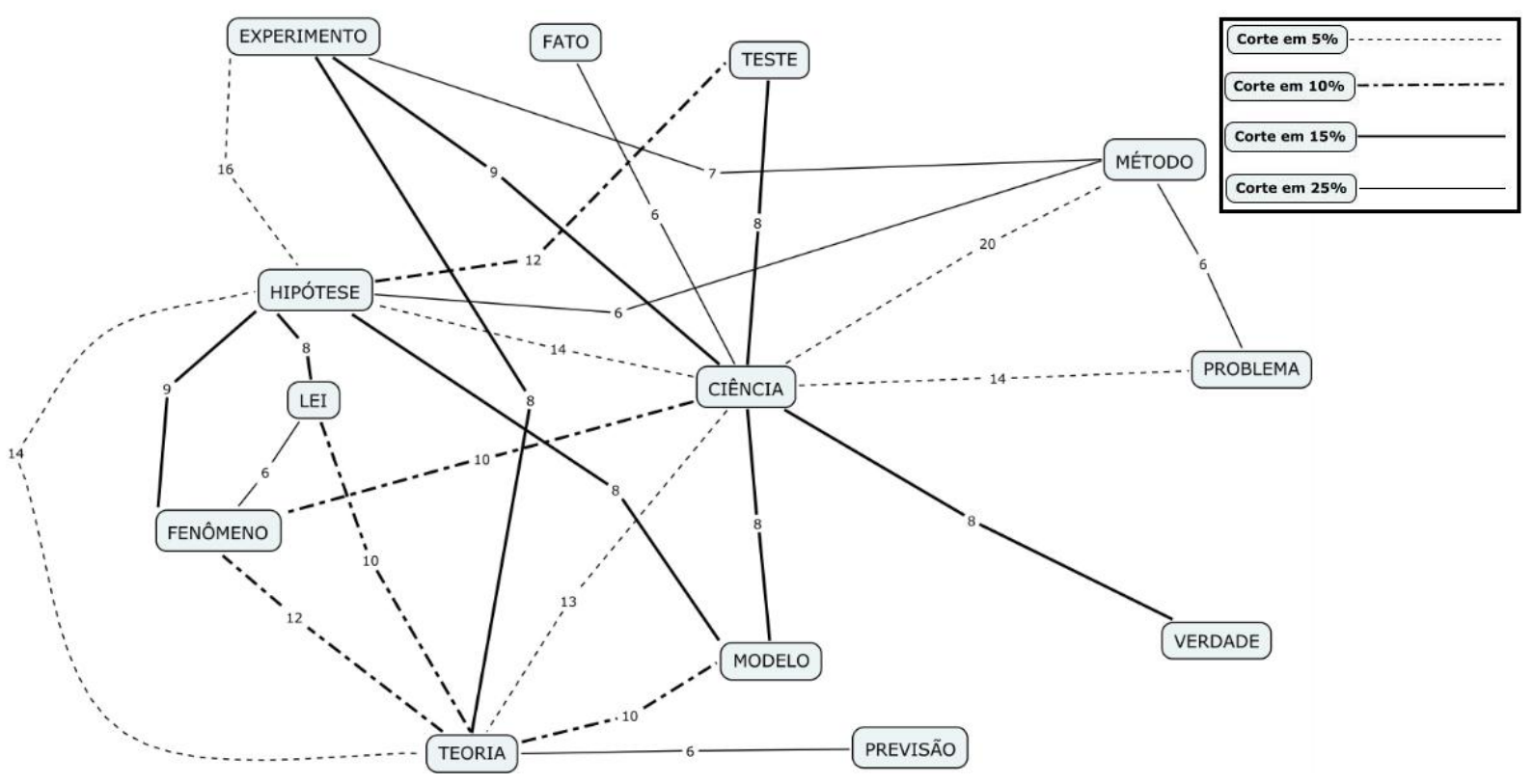

Figura 4.29 - Redes de conceitos com diferentes cortes percentuais obtidas a partir da matriz representativa (pós-1) 


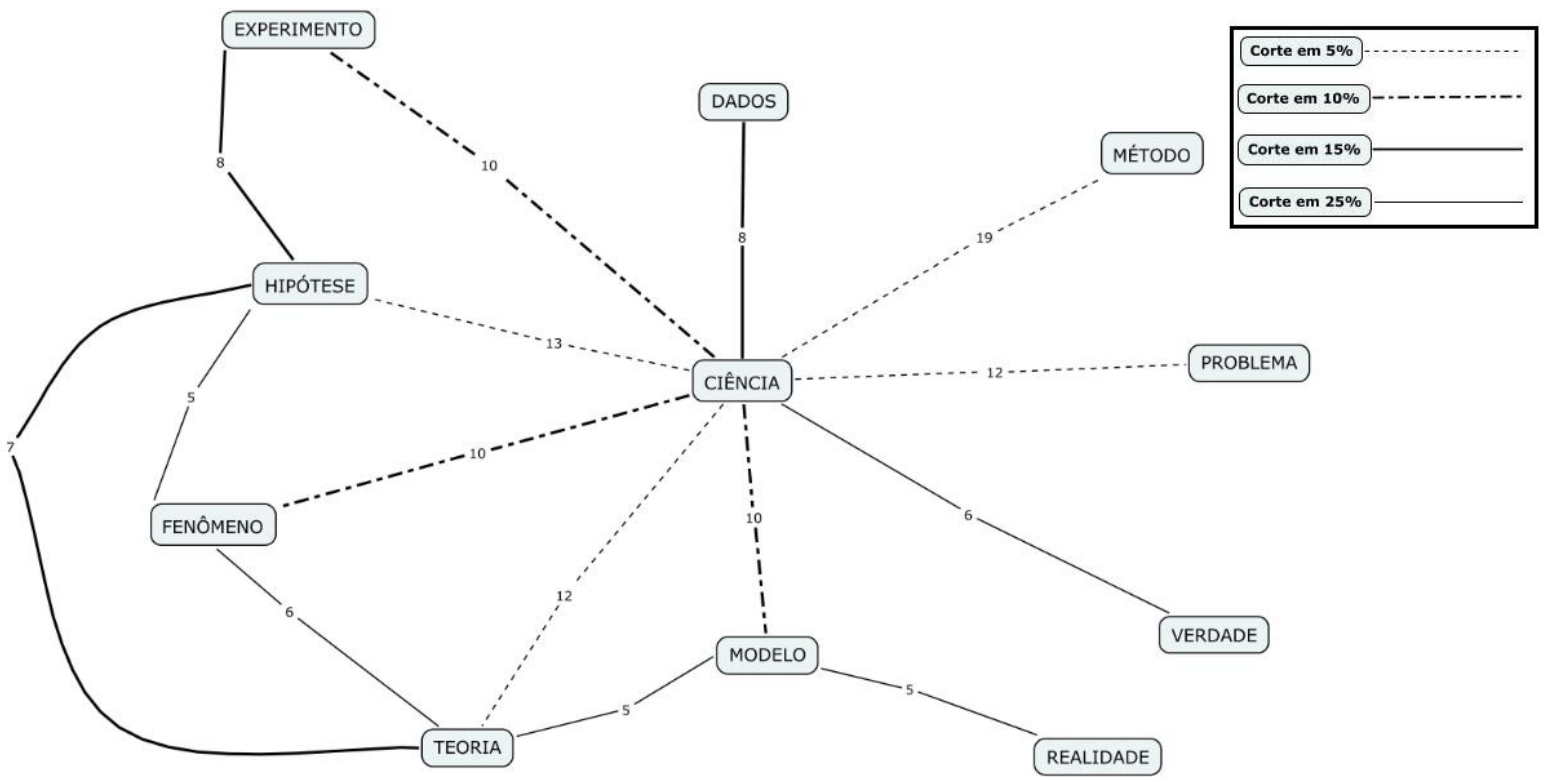

Figura 4.30 - Redes de conceitos com diferentes cortes percentuais obtidas a partir da matriz representativa (pós-2)

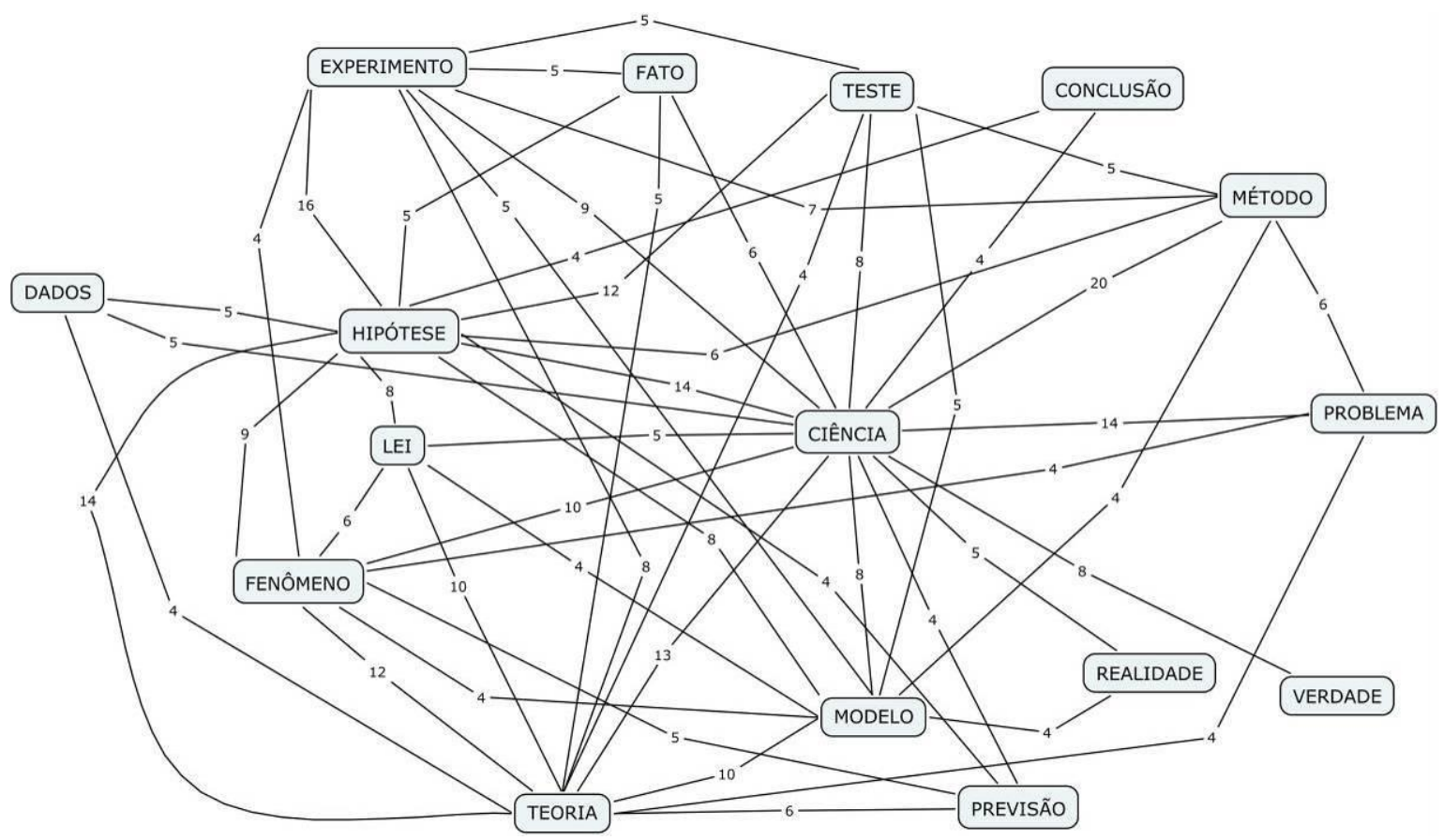

Figura 4.31 - Rede (50\%) (pós-1) referente aos dados da disciplina Química e Sociedade 


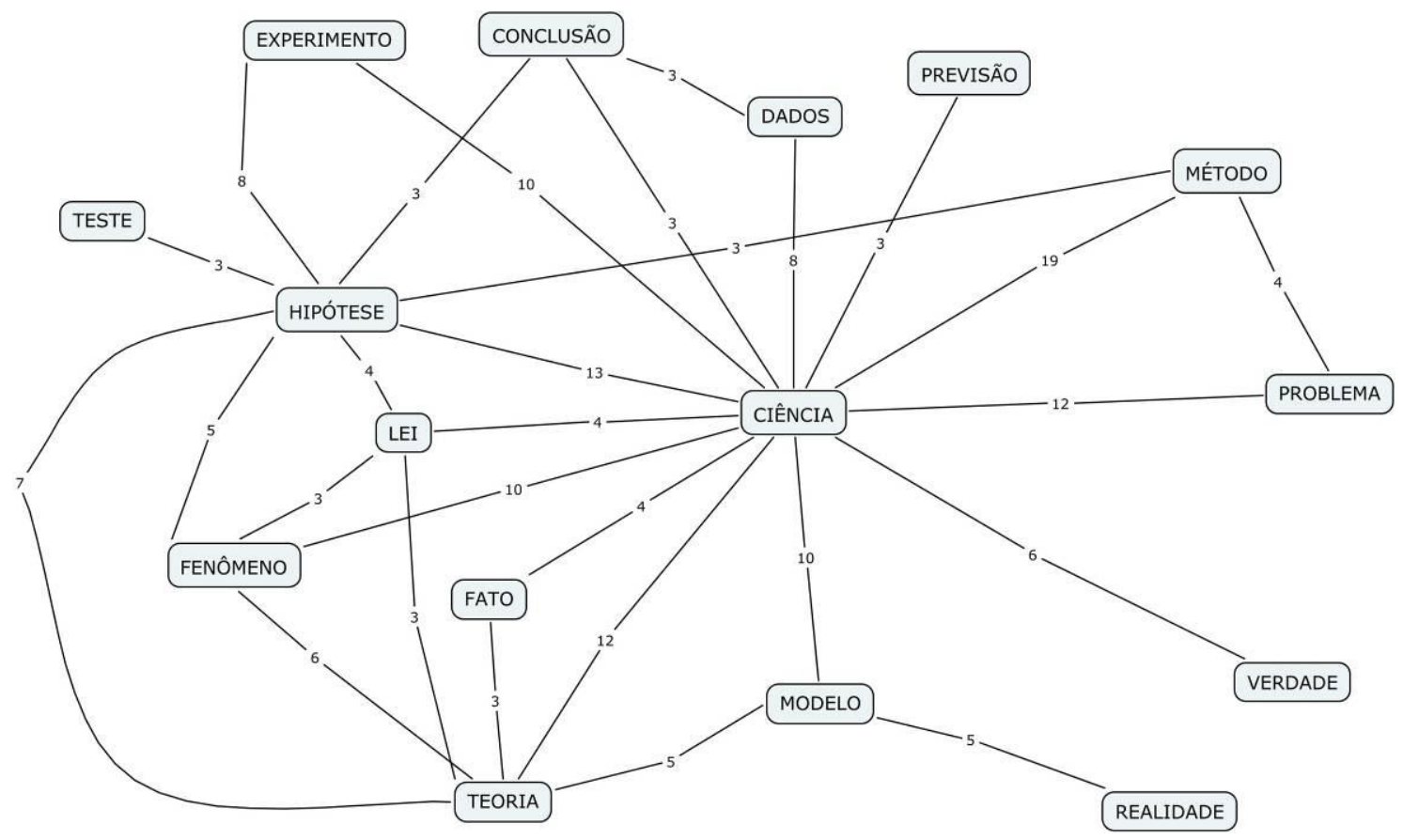

Figura 4.32 - Rede (50\%) (pós-2) referente aos dados da disciplina Química e Sociedade

Como é possível perceber pelas estruturas gráficas que foram apresentadas para os dados da disciplina Química e Sociedade, as redes de conceitos a partir de cortes percentuais se diferenciam bastante uma da outra, dependendo do corte percentual estabelecido. Além disso, as redes representadas nas figuras 4.31 e 4.32, por exemplo, evidenciam como a estrutura da rede construída depende dos valores numéricos presentes na matriz que a originou. No caso das redes (50\%) (pós-1) e (pós-2) exemplificadas, o mesmo corte percentual foi estabelecido para a construção das mesmas, no entanto, as redes se mostram estruturalmente diferentes devido aos diferentes valores encontrados nas matrizes que as originaram, o que implica uma grande diferença quanto ao número de ligações presentes.

As tabelas a seguir organizam alguns critérios que foram considerados durante a análise comparativa das redes obtidas, a fim de escolher as estruturas gráficas que melhor representassem as ideias e o entendimento dos alunos acerca do tema da atividade proposta nos dois momentos da disciplina Química e Sociedade. 
Tabela 4.5 - Comparação entre as redes com diferentes cortes percentuais obtidas a partir das matrizes representativas (pré-1) e (pré-2) quanto aos conceitos e ligações presentes

\begin{tabular}{|c|c|c|c|c|c|c|c|c|c|c|}
\hline & \multicolumn{5}{|c|}{$\begin{array}{l}\text { Redes com corte percentual obtidas a partir da } \\
\text { matriz representativa (pré-l) }\end{array}$} & \multicolumn{5}{|c|}{$\begin{array}{c}\text { Redes com corte percentual obtidas a partir da } \\
\text { matriz representativa (pré-2) }\end{array}$} \\
\hline & $5 \%$ & $10 \%$ & $15 \%$ & $25 \%$ & $50 \%$ & $5 \%$ & $10 \%$ & $15 \%$ & $25 \%$ & $50 \%$ \\
\hline $\begin{array}{l}\mathrm{N}^{\circ} \text { de conceitos } \\
\text { presentes }\end{array}$ & 8 & 10 & 12 & 12 & 16 & 4 & 7 & 10 & 12 & 16 \\
\hline $\begin{array}{l}\mathrm{N}^{\circ} \text { de conceitos } \\
\text { centrais }\end{array}$ & 0 & 3 & 9 & 10 & 15 & 1 & 2 & 4 & 8 & 13 \\
\hline $\begin{array}{l}\mathrm{N}^{\circ} \text { de conceitos } \\
\text { terminais }\end{array}$ & 4 & 4 & 2 & 1 & 1 & 3 & 4 & 3 & 3 & 0 \\
\hline $\mathrm{N}^{\circ}$ total de ligações & 6 & 11 & 21 & 30 & 57 & 3 & 7 & 14 & 23 & 49 \\
\hline $\mathrm{N}^{\circ}$ de grupos isolados & 3 & 1 & 1 & 1 & 1 & 1 & 1 & 1 & 1 & 1 \\
\hline
\end{tabular}

Tabela 4.6 - Comparação entre as redes com diferentes cortes percentuais obtidas a partir das matrizes representativas (pós-1) e (pós-2) quanto aos conceitos e ligações presentes

\begin{tabular}{|c|c|c|c|c|c|c|c|c|c|c|}
\hline & \multicolumn{5}{|c|}{$\begin{array}{c}\text { Redes com corte percentual obtidas a partir da } \\
\text { matriz representativa (pós-1) }\end{array}$} & \multicolumn{5}{|c|}{$\begin{array}{l}\text { Redes com corte percentual obtidas a partir } \mathrm{d} z \\
\text { matriz representativa (pós-2) }\end{array}$} \\
\hline & $5 \%$ & $10 \%$ & $15 \%$ & $25 \%$ & $50 \%$ & $5 \%$ & $10 \%$ & $15 \%$ & $25 \%$ & $50 \%$ \\
\hline $\begin{array}{l}\mathrm{N}^{\circ} \text { de conceitos } \\
\text { presentes }\end{array}$ & 6 & 10 & 11 & 13 & 16 & 5 & 8 & 9 & 11 & 16 \\
\hline $\begin{array}{l}\mathrm{N}^{\circ} \text { de conceitos } \\
\text { centrais }\end{array}$ & 2 & 3 & 6 & 8 & 13 & 1 & 1 & 2 & 5 & 8 \\
\hline $\begin{array}{l}\mathrm{N}^{\circ} \text { de conceitos } \\
\text { terminais }\end{array}$ & 3 & 6 & 3 & 3 & 1 & 4 & 7 & 5 & 5 & 4 \\
\hline $\mathbf{N}^{0}$ total de ligações & 6 & 11 & 19 & 25 & 50 & 4 & 7 & 10 & 15 & 28 \\
\hline $\mathrm{N}^{\circ}$ de grupos isolados & 1 & 1 & 1 & 1 & 1 & 1 & 1 & 1 & 1 & 1 \\
\hline
\end{tabular}

Em relação às redes $(5 \%)$ obtidas para o momento pré-instrução, referentes aos textos originais e modificados, inseridas nas figuras 4.25 e 4.26, é possível perceber que se tratam de redes com um pequeno número de ligações presentes, o que torna essas redes limitadas e pouco esclarecedoras quanto às principais relações estabelecidas pelos alunos em seus textos. De acordo com a tabela 4.5, as redes (5\%) apresentam um número de conceitos presentes consideravelmente inferior em relação aos 17 conceitos fornecidos na atividade proposta aos alunos.

Desta forma, por se tratarem de redes que apresentam poucos conceitos, verificam-se também valores muito pequenos ou até mesmo nulos para o número de conceitos centrais e/ou terminais, sendo que o baixo número de conceitos centrais consiste em um problema quando se pensa no uso dessas redes como uma forma de analisar a compreensão dos alunos sobre o 
tema em questão. Na rede (5\%) (pré-2), por exemplo, os conceitos considerados terminais estão todos relacionados a um único conceito central, o que gera um entendimento muito restrito quanto à visão dos alunos sobre o assunto trabalhado. A rede (5\%) (pré-1), por sua vez, por não apresentar nenhum conceito central, impossibilita qualquer percepção sobre os conceitos que mais se destacam para os alunos dentro do tema como se faz ciência.

A observação das redes com corte percentual em 10\%, 15\% e 25\%, também representadas nas figuras 4.25 e 4.26, torna clara a ideia de que essas redes se tornam mais ricas quanto às informações que fornecem conforme é aumentado o corte percentual estabelecido. Assim, as redes (25\%) (pré-1) e (pré-2) são preferíveis em comparação às redes com corte percentual em $10 \%$ ou $15 \%$, uma vez que apresentam um número maior de conceitos presentes, além do maior número de ligações entre esses conceitos. Outro fator que torna as redes (25\%) (pré-1) e (pré-2) mais ricas em informações quando comparadas às redes com corte percentual em $10 \%$ ou $15 \%$ consiste no número de conceitos centrais presentes, o que permite conhecer os conceitos mais relevantes presentes nos textos escritos pelos alunos.

Ao observar as redes (50\%) (pré-1) e (pré-2), apresentadas nas figuras 4.27 e 4.28 , percebe-se um número considerável de ligações presentes, totalizando 57 diferentes relações na primeira estrutura e 49 na segunda. Esse número excessivo de ligações presentes pode dificultar qualquer análise mais aprofundada que se queira fazer da rede de conceitos em questão. Além disso, verificam-se valores muito pequenos ou até mesmo nulos para o número de conceitos terminais e o número de conceitos centrais nessas redes é praticamente igual ao número total de conceitos presentes nas mesmas, formando assim redes em que praticamente tudo parece estar relacionado. Desta forma, as redes (50\%) (pré-1) e (pré-2) não se mostram adequadas para a compreensão das relações estabelecidas pelos alunos por suscitarem a ideia de que os alunos não estabelecem qualquer organização ou hierarquização mínima entre os conceitos considerados em sua estrutura de conhecimentos.

Desta forma, considerando os critérios observados acima e, dentre as redes obtidas a partir dos diversos cortes percentuais para as matrizes representativas (pré-1) e (pré-2), apresentam-se como estruturas gráficas adequadas a cada uma dessas matrizes as redes de conceitos com corte percentual em 25\%. Conforme descrito na tabela 4.5, essas redes são semelhantes quanto ao número de ligações presentes, além do número total de conceitos que apresentam e do número de conceitos centrais e terminais muito próximos.

O valor do PMC obtido na comparação entre as redes (25\%) (pré-1) e (pré-2) referentes aos dados da disciplina Química e Sociedade foi de 0,62, o que mostra que as 
estruturas gráficas apresentam $62 \%$ de semelhança. Assim, considerando os cortes percentuais estabelecidos e escolhidos, a rede construída com base na análise dos textos originais apresenta uma semelhança média em comparação com a rede gerada a partir da análise dos textos modificados.

Em relação às redes de conceitos referentes ao momento pós-instrução, a análise dos critérios organizados na tabela 4.6, referentes aos textos originais e modificados, também permite realizar comparações semelhantes às que foram feitas para as redes pré-instrução. As redes $(5 \%)$ que se encontram representadas nas figuras 4.29 e 4.30 , por exemplo, apresentam poucos conceitos presentes, além do número de ligações entre conceitos bastante baixo. Desta forma, tratam-se de redes que trazem informações muito limitadas em relação às principais relações estabelecidas entre os conceitos nos textos dos alunos.

A comparação entre as redes com corte percentual em 10\%, 15\% e 25\%, também representadas nas figuras 4.29 e 4.30 , evidencia novamente a ideia de que essas redes se tornam cada vez mais ricas quanto às informações que fornecem conforme é aumentado o corte percentual estabelecido. Neste contexto, no caso das redes referentes aos textos originais, é possível dizer que a rede com corte percentual em $25 \%$ é preferível em comparação às redes com corte percentual em 10\% ou 15\%, uma vez que aquela apresenta um número maior de conceitos presentes, além do maior número de ligações entre os conceitos.

Ainda em relação às redes com origem nos textos originais dos alunos, verifica-se que a rede (50\%) (pós-1), apresentada na figura 4.31, é formada por um número muito grande de ligações, totalizando 50 diferentes relações entre conceitos. Esse alto valor para o número de ligações presentes torna inviável qualquer análise mais aprofundada que se queira fazer da rede de conceitos em questão, pois uma simples visualização da estrutura gráfica já traz a ideia de que praticamente todos os conceitos presentes na rede parecem estar relacionados.

Para as redes referentes aos textos modificados dos alunos, verificou-se que a rede (50\%) (pós-2), apresentada na figura 4.32, consiste em uma estrutura gráfica mais adequada para representar as principais relações entre conceitos quando comparada às redes com os demais cortes percentuais. A rede (50\%) (pós-2) não apresenta um número excessivo de ligações entre os conceitos e é aquela em que o número de conceitos presentes mais se aproxima do número de termos indutores fornecidos na atividade realizada pelos alunos.

Desta forma, dentre as redes construídas a partir dos diversos cortes percentuais para as matrizes representativas (pós-1) e (pós-2), as redes com corte em 25\% e 50\%, 
respectivamente, apresentam-se como as estruturas gráficas mais adequadas a cada uma das matrizes citadas. De acordo com os valores que constam na tabela 4.6, essas redes são bastante semelhantes quanto ao número de ligações presentes, além do número total de conceitos que apresentam e do número idêntico de conceitos centrais.

O valor do PMC obtido na comparação entre as redes (25\%) (pós-1) e (50\%) (pós-2) referentes aos dados da disciplina Química e Sociedade foi de 0,49, o que mostra que as estruturas gráficas apresentam 49\% de semelhança. Assim, considerando os cortes percentuais estabelecidos e escolhidos, a rede construída com base na análise dos textos originais apresenta uma semelhança média em comparação com a rede gerada a partir da análise dos textos modificados.

\subsubsection{Análise dos mapas conceituais obtidos}

Conforme já mencionado, esta pesquisa inclui a construção de mapas conceituais tanto a partir dos textos originais quanto dos textos modificados dos alunos, uma vez que se pretende convergir e comparar as estruturas gráficas obtidas dos dois modos, de forma a demonstrar o quanto se aproximam uma da outra.

A construção dos mapas conceituais referentes à disciplina Química e Sociedade ocorreu a partir de redes de conceitos com determinados cortes percentuais escolhidos, sendo que foram elaborados mapas para os momentos pré e pós-instrução. Com o auxílio da ferramenta KWIC (Key Word In Context) do Hamlet ${ }^{\circledR}$, realizou-se a busca pelas frases de ligação entre os pares de conceitos relacionados nas redes escolhidas, de modo a construir as proposições que fazem parte dos mapas conceituais.

A construção do mapa conceitual pré-instrução referente aos textos modificados dos alunos da disciplina Química e Sociedade se deu a partir da rede (25\%) (pré-2), representada na figura 4.26, que contempla relações entre conceitos estabelecidas a partir de 4 vezes, possuindo número de conceitos e de ligações presentes adequados para a construção de uma estrutura gráfica organizada e de fácil compreensão. De forma semelhante, a construção do mapa conceitual pré-instrução referente aos textos originais ocorreu a partir da rede $(25 \%)$ (pré-1), representada na figura 4.25, em que são contempladas relações estabelecidas a partir de 6 vezes. Os mapas conceituais referentes ao momento pré-instrução são apresentados nas figuras 4.33 e 4.34 . 
Ao realizar a busca pelas frases de ligação entre os pares de conceitos relacionados na rede (25\%) (pré-1) para a construção do mapa conceitual apresentado na figura 4.33, percebeu-se que alguns pares de conceitos nem sempre estavam relacionados nos textos originais dos alunos de forma proposicional. Assim, das 30 diferentes ligações entre conceitos presentes na rede (25\%) (pré-1), 14 foram eliminadas durante a construção do mapa conceitual correspondente, pois se tratavam de pares de conceitos relacionados de forma proposicional por menos de 4 vezes.

Neste sentido, considerando que a proposta deste trabalho é justamente a de convergir os mapas (25\%) (pré-1) e (25\%) (pré-2), de forma a verificar a semelhança entre essas duas estruturas, não faria sentido construir o mapa conceitual (25\%) (pré-1) contemplando relações entre conceitos estabelecidas por menos de 4 vezes, já que estas relações também não são contempladas no mapa (25\%) (pré-2). Desta forma, o mapa conceitual (25\%) (pré-1) mostrado na figura 4.33 é constituído por um total de 16 diferentes ligações, em que se verifica que o número total de relações estabelecidas para cada par de conceitos é, em sua maioria, inferior em relação ao que se tem na rede de conceitos de origem. O mapa conceitual (25\%) (pré-2), por sua vez, é constituído por 23 diferentes ligações entre conceitos, das quais 16 são comuns ao mapa conceitual (25\%) (pré-1) e apenas 7 são exclusivas dessa estrutura gráfica, o que pode ser compreendido pelo destaque de algumas ligações na figura 4.34.

O valor do PMC obtido na comparação entre o mapa conceitual (25\%) (pré-1) e o mapa conceitual (25\%) (pré-2) referente aos dados da disciplina Química e Sociedade foi de 0,85, portanto, as estruturas gráficas apresentam $85 \%$ de semelhança. A alta semelhança entre os dois mapas conceituais também pode ser observada pelas comparações estabelecidas e organizadas no quadro 4.4, a seguir, onde alguns conceitos considerados centrais ou terminais encontram-se destacados em negrito por serem comuns às duas estruturas gráficas. 


\begin{tabular}{|c|c|c|}
\hline & Mapa conceitual (25\%) (pré-1) & Mapa conceitual (25\%) (pré-2) \\
\hline $\mathrm{N}^{\circ}$ de conceitos presentes & 11 & 12 \\
\hline $\mathrm{N}^{0}$ de conceitos centrais & 6 & 8 \\
\hline Natureza dos conceitos centrais & $\begin{array}{c}\text { ciência } \\
\text { dados } \\
\text { experimento } \\
\text { fenômeno } \\
\text { hipótese } \\
\text { teoria }\end{array}$ & $\begin{array}{c}\text { ciência } \\
\text { dados } \\
\text { experimento } \\
\text { fenômeno } \\
\text { hipótese } \\
\text { modelo } \\
\text { problema } \\
\text { teoria }\end{array}$ \\
\hline $\mathrm{N}^{\circ}$ de conceitos terminais & 2 & 3 \\
\hline Natureza dos conceitos terminais & $\begin{array}{c}\text { conclusão } \\
\text { lei }\end{array}$ & $\begin{array}{c}\text { conclusão } \\
\text { lei } \\
\text { método }\end{array}$ \\
\hline $\mathrm{N}^{\circ}$ total de ligações & 16 & 23 \\
\hline
\end{tabular}

Quadro 4.4 - Comparação entre os mapas conceituais (25\%) (pré-1) e (pré-2) quanto aos conceitos e ligações presentes 


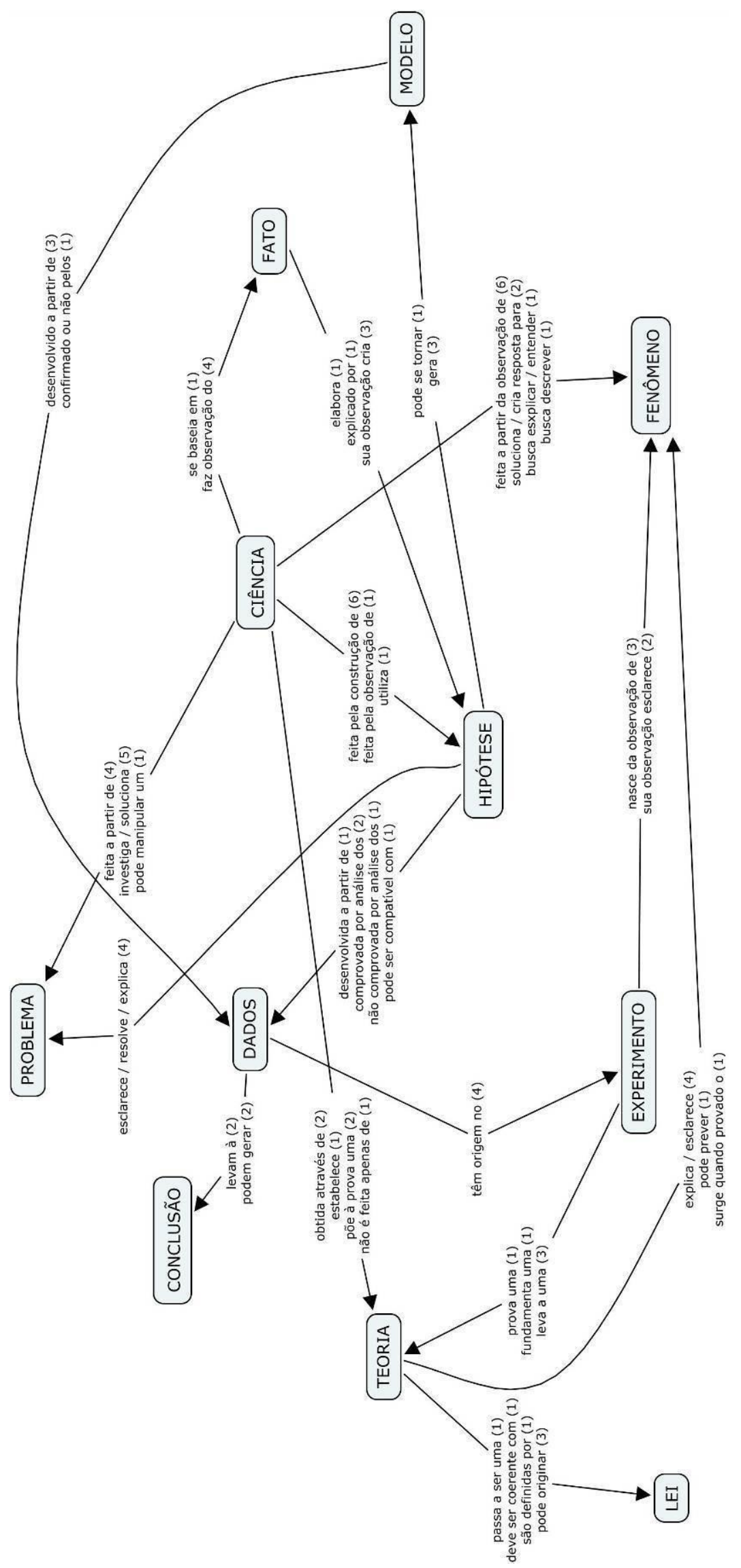

Figura 4.33 - Mapa conceitual (25\%) (pré-1) referente aos dados da disciplina Química e Sociedade 


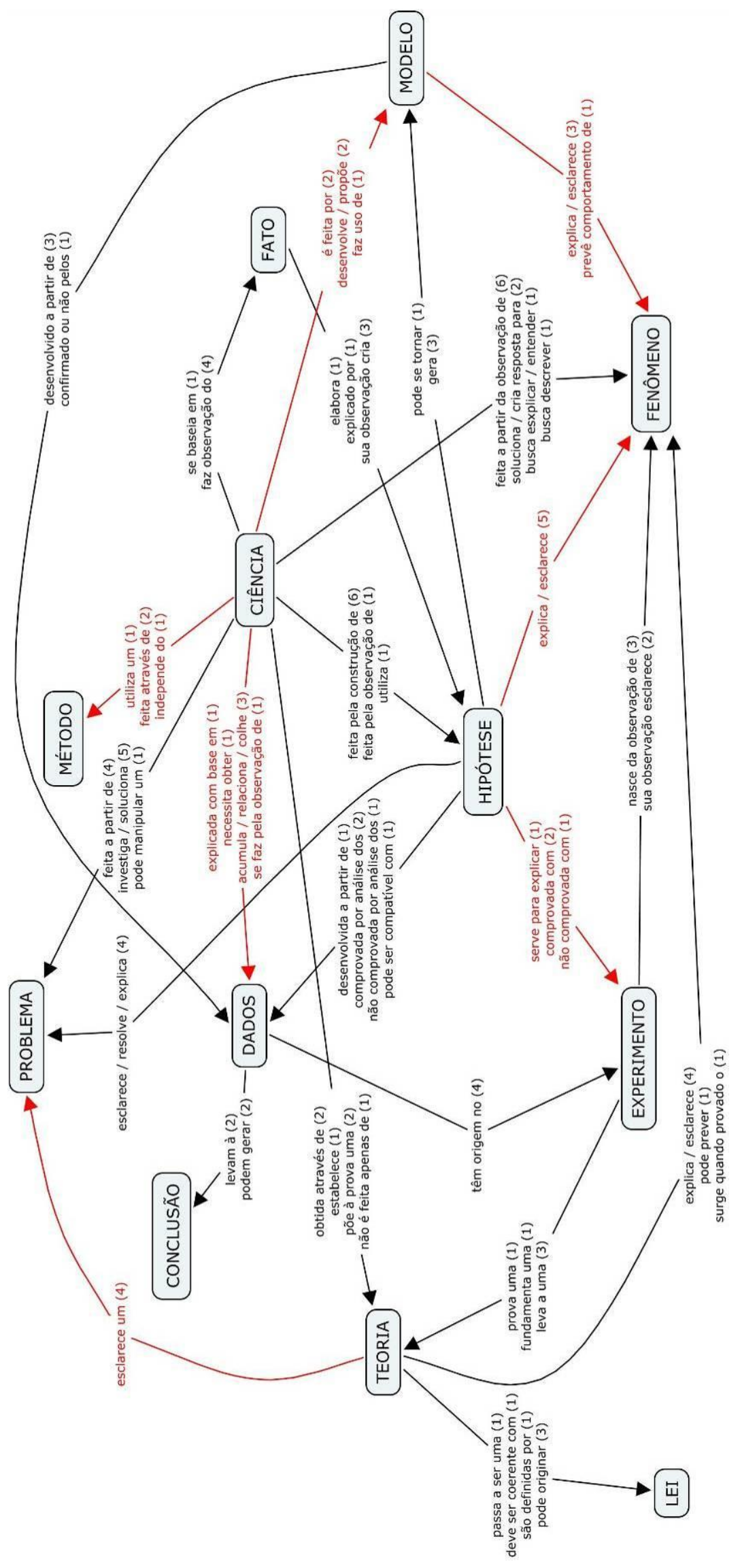

Figura 4.34 - Mapa conceitual (25\%) (pré-2) referente aos dados da disciplina Química e Sociedade 
Os mapas conceituais pós-instrução referentes aos textos originais e modificados dos alunos da disciplina Química e Sociedade também se basearam nas redes com corte percentual em 25\%, as quais se encontram representadas nas figuras 4.29 e 4.30. Nas referidas redes $(25 \%)$ (pós-1) e (pós-2) são contempladas relações entre conceitos estabelecidas a partir de 6 e 5 vezes, respectivamente, sendo que ambas as estruturas gráficas possuem número de conceitos e de ligações presentes adequados para a construção de mapas conceituais organizados e de fácil compreensão. Os mapas conceituais referentes ao momento pósinstrução são apresentados nas figuras 4.35 e 4.36.

Como se pode perceber, a rede (25\%) (pós-1) é constituída por 25 diferentes ligações entre conceitos, porém, com a busca das frases de ligação entre os pares de conceitos relacionados nesta rede para a construção do mapa conceitual correspondente verificou-se que alguns pares de conceitos nem sempre estavam relacionados nos textos originais dos alunos de forma proposicional. Desta forma, das 25 diferentes ligações entre conceitos presentes na rede (25\%) (pós-1), 12 foram eliminadas durante a construção do mapa conceitual mostrado na figura 4.35 por se tratarem de pares de conceitos relacionados de forma proposicional por menos de 5 vezes.

Neste aspecto, não seria coerente considerar tais relações entre conceitos estabelecidas menos de 5 vezes, uma vez que tal procedimento não estaria de acordo com o corte percentual em $25 \%$ estabelecido tanto para a rede referente aos textos originais quanto para aquela referente aos textos modificados. Ou seja, considerando que a proposta desta pesquisa é justamente a de convergir mapas conceituais construídos tanto a partir de textos originais quanto de textos modificados, de forma a verificar a semelhança entre essas duas estruturas, não faria sentido construir o mapa conceitual (25\%) (pós-1) contemplando relações entre conceitos estabelecidas por menos de 5 vezes, pois estas relações também não são contempladas no mapa (25\%) (pós-2).

Assim, o mapa conceitual (25\%) (pós-1) mostrado na figura 4.35 é constituído por um total de 13 diferentes ligações, em que se verifica que o número total de relações estabelecidas para cada par de conceitos é, em sua maioria, inferior em relação ao que se tem na rede de conceitos de origem. O mapa conceitual (25\%) (pós-2), por sua vez, é constituído por 15 diferentes ligações entre conceitos, das quais 13 são comuns ao mapa conceitual (25\%) (pós1) e apenas 2 são exclusivas dessa estrutura gráfica, o que pode ser compreendido pelo destaque de algumas ligações na figura 4.36. 
O valor do PMC encontrado na comparação entre os mapas conceituais (25\%) (pós-1) e (pós-2) referentes aos dados da disciplina Química e Sociedade foi de 0,94, o que indica que as estruturas gráficas apresentam 94\% de semelhança e, portanto, são altamente semelhantes. O quadro 4.5, a seguir, mostra algumas comparações que foram estabelecidas e organizadas sobre os mapas conceituais (25\%) (pós-1) e (pós-2), onde os destaques em negrito se referem aos conceitos considerados centrais ou terminais que são comuns às duas estruturas gráficas.

\begin{tabular}{|c|c|c|}
\hline & Mapa conceitual (25\%) (pós-1) & Mapa conceitual (25\%) (pós-2) \\
\hline $\mathrm{N}^{\circ}$ de conceitos presentes & 9 & 11 \\
\hline $\mathrm{N}^{0}$ de conceitos centrais & 4 & 5 \\
\hline Natureza dos conceitos centrais & $\begin{array}{c}\text { ciência } \\
\text { fenômeno } \\
\text { hipótese } \\
\text { teoria }\end{array}$ & $\begin{array}{c}\text { ciência } \\
\text { fenômeno } \\
\text { hipótese } \\
\text { modelo } \\
\text { teoria }\end{array}$ \\
\hline $\mathrm{N}^{\circ}$ de conceitos terminais & 3 & 5 \\
\hline Natureza dos conceitos terminais & $\begin{array}{c}\text { método } \\
\text { problema } \\
\text { verdade }\end{array}$ & $\begin{array}{l}\text { dados } \\
\text { método } \\
\text { problema } \\
\text { realidade } \\
\text { verdade }\end{array}$ \\
\hline$N^{0}$ total de ligações & 13 & 15 \\
\hline
\end{tabular}

Quadro 4.5 - Comparação entre os mapas conceituais (25\%) (pós-1) e (pós-2) quanto aos conceitos e ligações presentes 


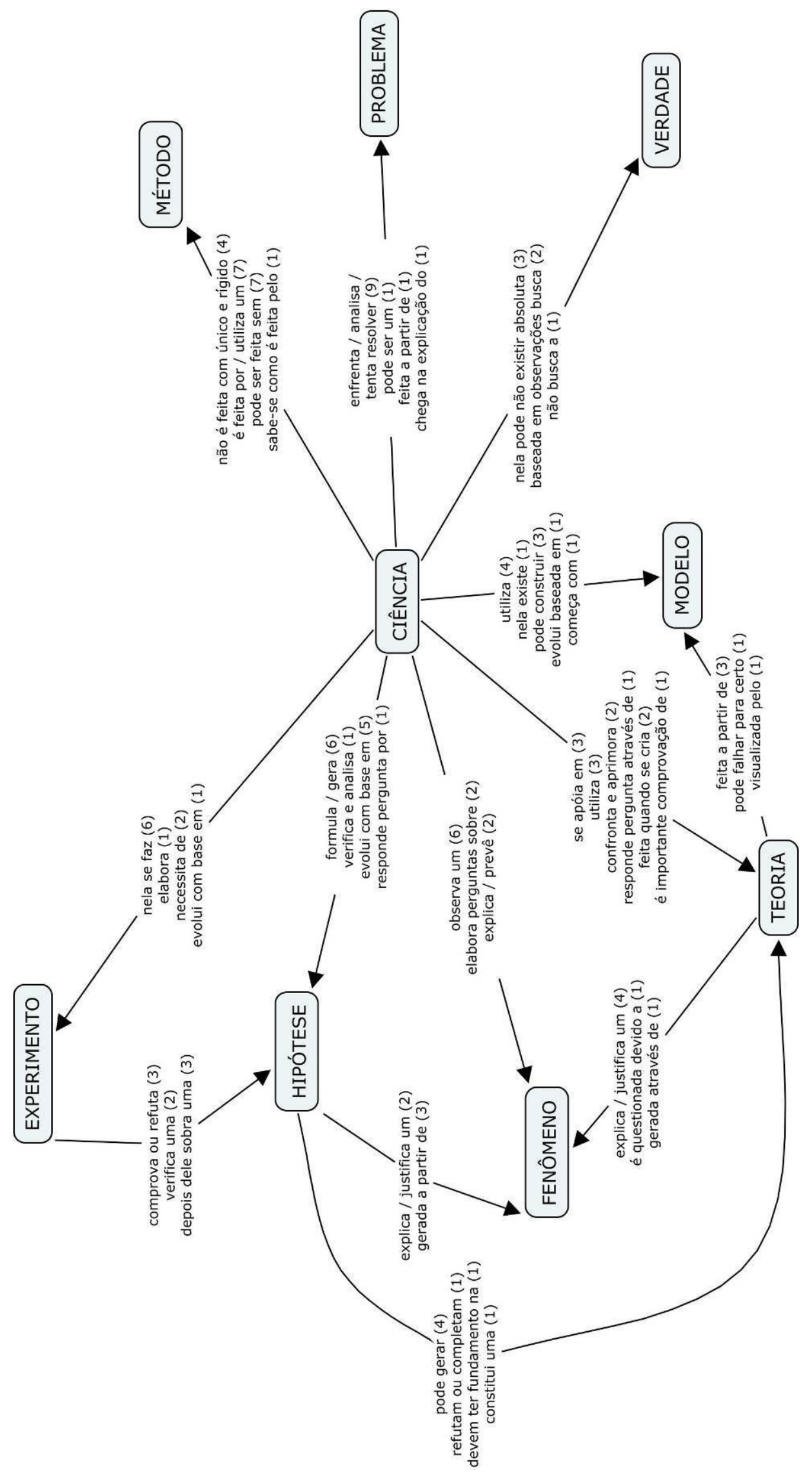

Figura 4.35 - Mapa conceitual (25\%) (pós-1) referente aos dados da disciplina Química e Sociedade 


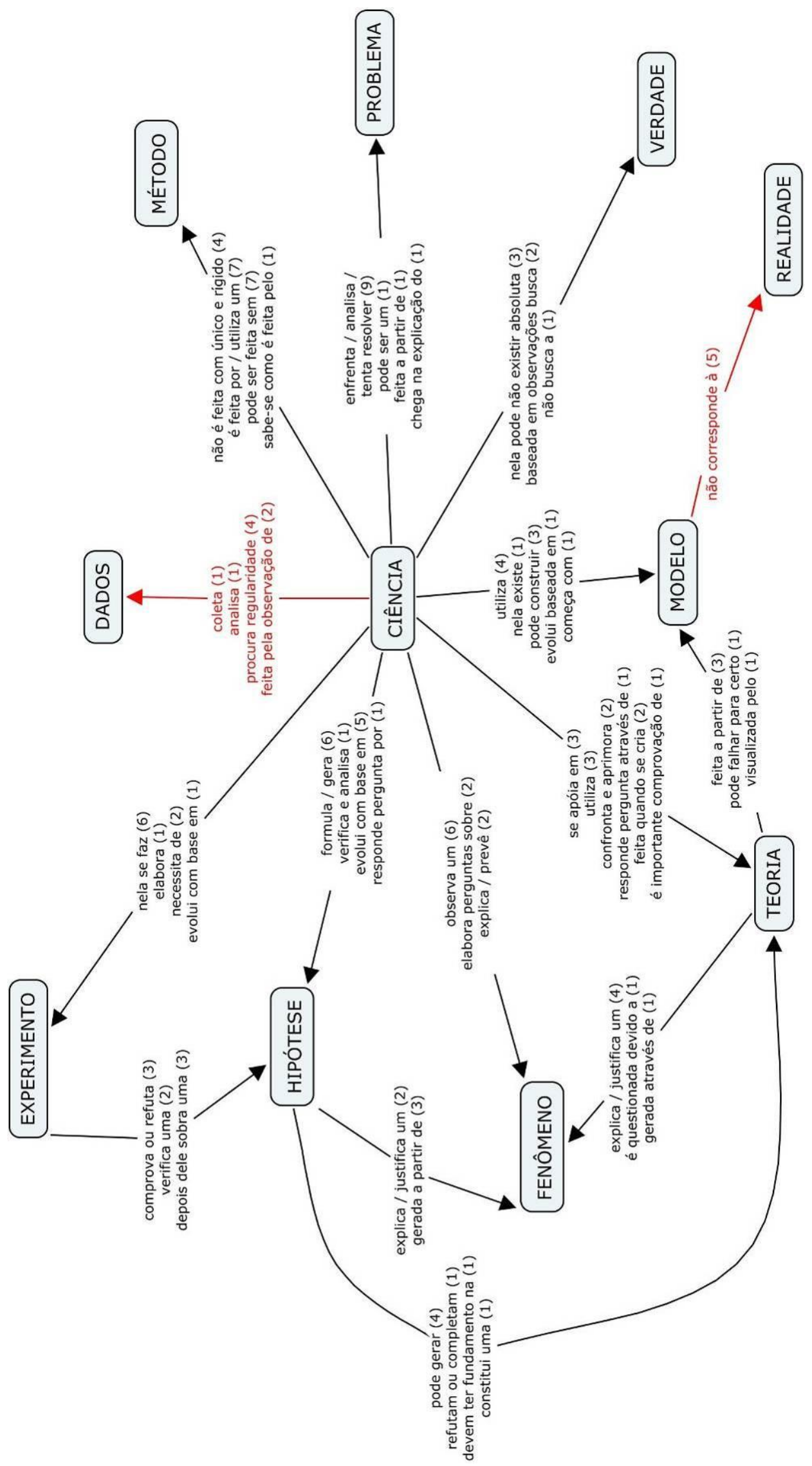

Figura 4.36 - Mapa conceitual (25\%) (pós-2) referente aos dados da disciplina Química e Sociedade 


\subsubsection{Análise geral das estruturas gráficas obtidas no contexto da Natureza da Ciência}

Apesar de não se tratar do foco da presente pesquisa, a observação das diferentes estruturas gráficas obtidas no âmbito da disciplina Química e Sociedade permite estabelecer algumas inferências sobre as ideias que mais se destacam nos textos dos alunos sobre como se faz ciência, sendo possível identificar algumas visões específicas acerca do significado do conhecimento científico para o grupo de alunos em questão.

Inicialmente, é possível dizer que muitas das ligações encontradas nas redes do tipo $(\mathrm{V}+\mathrm{P})$ e nas redes com cortes percentuais também são contempladas nos mapas conceituais construídos, referentes aos momentos pré e pós-instrução. Neste sentido, todas essas estruturas gráficas se mostram complementares, fornecendo informações ora similares, ora distintas, dependendo do foco que se dá ao analisar determinada estrutura gráfica. Assim, a análise a seguir se baseia principalmente nas informações presentes nos mapas conceituais construídos por meio dos dados coletados na disciplina Química e Sociedade, uma vez que essas representações gráficas esclarecem a natureza das relações estabelecidas entre os conceitos nos textos escritos pelos alunos.

Como se pode perceber pelas figuras 4.33 e 4.34, os mapas conceituais $(25 \%)$ referentes ao momento pré-instrução apresentam 6 conceitos considerados centrais e comuns às duas estruturas gráficas, são eles: ciência, dados, experimento, fenômeno, hipótese e teoria. Nos referidos mapas, o conceito ciência é aquele que aparece ligado a um maior número de conceitos, inclusive a alguns considerados centrais, o que é coerente com o caráter geral do tema do texto escrito pelos alunos.

Ao observar a natureza das relações estabelecidas entre o conceito ciência e os conceitos fenômeno, hipótese e problema nos mapas das figuras 4.33 e 4.34, é possível identificar uma ideia fundamental sobre o fazer científico, caracterizado pela tentativa de solucionar problemas por meio de hipóteses que possam ser testadas através de observações ou experiências (ALVES-MAZZOTTI; GEWANDSZNAJDER, 2004).

Conforme mencionado na seção 4.2, durante o processo de modificação dos textos originais dos alunos, percebeu-se que o importante conceito observação fornecido no enunciado da atividade realizada fora utilizado sempre compondo uma frase de ligação entre outros dois conceitos e, por este motivo, não foi considerado como uma palavra que deveria compor a lista de vocabulário utilizada pelo Hamlet $^{\circledR}$ em sua análise. No entanto, em ambos 
os mapas mencionados nota-se a grande utilização do conceito observação compondo frases de ligação entre outros conceitos, indicando assim a importância desse conceito para os alunos dentro do contexto de como se faz ciência.

Apesar da clara relação estabelecida pelos alunos entre os conceitos ciência e hipótese, o mapa conceitual mostrado na figura 4.34, referente aos textos modificados dos alunos, indica uma visão empírico-indutivista presente em parte dos textos escritos pelos alunos, evidenciada pela ligação em destaque no referido mapa conceitual entre os conceitos ciência e dados, além da ligação também presente no mapa conceitual da figura 4.33 entre os conceitos ciência e fato.

Proposições como "ciência é explicada com base em dados", "ciência se faz pela observação de dados", "ciência se baseia em fatos" ou "ciência faz observação de fatos" parecem considerar o conhecimento como resultado da inferência indutiva baseada apenas em dados puros, os quais não têm sentido por si mesmos e necessitam ser interpretados de acordo com um sistema teórico (CACHAPUZ et al., 2005). Neste aspecto, convém destacar também as proposições presentes nos mapas conceituais das figuras 4.33 e 4.34 que são contrárias a esta visão, tais como "ciência é obtida através de teorias" ou "teoria explica / esclarece fenômeno", demonstrando a importância da teoria como orientadora do processo de investigação científica. Além disso, a proposição “ciência põe à prova uma teoria”, colocada por parte dos alunos, evidencia uma visão de ciência contrária àquela considerada acumulativa e de crescimento linear, uma vez que considera o possível confronto entre teorias rivais (BORGES, 2007).

Finalmente, conforme indicado no mapa conceitual da figura 4.34, a ligação entre os conceitos ciência e método não foi estabelecida muitas vezes no momento pré-instrução, sendo contemplada apenas no mapa referente aos textos modificados dos alunos. Neste mapa, verifica-se a presença de proposições como "ciência utiliza um método" ou "ciência é feita através de método" que, apesar de não se tratarem de relações estabelecidas muitas vezes, evidenciam a presença de uma visão rígida, algorítmica e infalível da ciência por parte dos alunos, que considera a existência de um método científico formado por uma sequência de etapas definidas, visão esta muito comum entre os alunos e relativamente coerente com o momento pré-instrução, ao qual se refere o mapa conceitual da figura 4.34.

No entanto, ao observar os mapas conceituais referentes ao momento pós-instrução, mostrados nas figuras 4.35 e 4.36 , percebe-se que muitas relações foram estabelecidas pelos alunos entre os conceitos ciência e método, sendo que predominam as proposições com ideias 
contrárias à visão rígida comentada anteriormente, o que fica claro por meio de proposições como "ciência não é feita com um único e rígido método" ou "ciência pode ser feita sem método".

Ainda sobre os mapas conceituais referentes ao momento pós-instrução, percebe-se uma estrutura mais simplificada, além de estar centrada novamente no conceito ciência. Muitas das ideias presentes nos mapas conceituais das figuras 4.35 e 4.36 vão de encontro àquelas presentes nos mapas referentes ao momento pré-instrução, no entanto, verifica-se uma maior relativização das ideias acerca do conhecimento científico por parte dos alunos no momento pós-instrução.

A título de exemplo, é possível citar as proposições envolvendo os conceitos ciência e verdade, que sequer foram contempladas nos mapas pré-instrução: "ciência, nela pode não existir absoluta verdade" e "ciência não busca a verdade”. A ligação entre os conceitos modelo e realidade no mapa conceitual da figura 4.36 também merece destaque por não ter sido contemplada nos mapas referentes ao momento pré-instrução e evidenciar uma importante ideia sobre o conhecimento científico, considerando o modelo como uma representação simplificada e hipotética de algo que se supõe real (ALVES-MAZZOTTI; GEWANDSZNAJDER, 2004).

Outros destaques dos mapas conceituais pós-instrução referem-se à importância atribuída à teoria durante o fazer científico, além das ideias contrárias à visão acumulativa e de crescimento linear da ciência, sendo possível identificar em algumas frases de ligação entre conceitos a ideia de que uma teoria pode ser questionada e confrontada: "ciência confronta e aprimora teoria" e "teoria pode falhar para certo modelo".

Algumas frases de ligação entre o conceito teoria e os conceitos ciência, fenômeno e hipótese, por sua vez, valorizam o papel da teoria como orientadora do processo de desenvolvimento da ciência, evidenciando uma ideia contrária à visão empírico-indutivista identificada em parte das proposições presentes nos mapas pré-instrução, o que também pode ser observado pela análise das frases de ligação entre os conceitos ciência, dados e experimento no mapa conceitual da figura 4.36 .

Desta forma, é possível dizer que os mapas conceituais obtidos para a turma de alunos nos momentos pré e pós-instrução são interessantes para que o professor possa comparar a natureza das relações entre conceitos estabelecidas pelos alunos, podendo, desta forma, refletir a respeito da compreensão dos alunos sobre o tema trabalhado durante a disciplina. 


\section{Capítulo 5.}

\section{CONCLUSÕES}




\section{Capítulo 5. CONCLUSÕES}

O principal objetivo desta pesquisa consistiu em desenvolver uma metodologia que utiliza ferramentas computacionais para transformar textos escritos por alunos em estruturas gráficas como mapas e redes de conceitos. O interesse em desenvolver tal metodologia se justifica a partir da ideia de que textos produzidos por alunos são ricos em informações referentes a sua estrutura de conhecimentos, sendo uma das formas mais comuns de se explicitar o entendimento sobre determinado tema.

Além disso, considerando-se o quanto pode ser dificultosa e exaustiva a análise de muitos textos por um professor ou pesquisador, o desenvolvimento desta pesquisa também se justifica pelo que as estruturas gráficas obtidas com a proposta deste trabalho podem possibilitar. De forma mais clara e objetiva do que os textos escritos, a representação das relações estabelecidas entre conceitos por alunos por meio de mapas e redes de conceitos pode possibilitar a um pesquisador realizar diferentes comparações no decorrer de sua pesquisa ou a um professor conhecer as relações entre conceitos mais relevantes para um grupo de alunos.

A presente investigação foi desenvolvida a partir de dados coletados em duas disciplinas distintas de cursos de graduação do Instituto de Química da Universidade de São Paulo. A partir das respostas dos alunos foram realizados testes e posteriores análises que possibilitaram o desenvolvimento metodológico desta pesquisa, incluindo: (i) testes com dois softwares de análise de textos $\left(\right.$ ALA-Reader ${ }^{\circledR}$ e Hamlet $\left.^{\circledR}\right)$ para a quantificação das relações entre conceitos; (ii) testes para verificar a influência na quantificação das relações entre conceitos partindo-se do texto como foi escrito e das proposições extraídas do mesmo e (iii) testes para a obtenção de diferentes tipos de estruturas gráficas que representam as relações entre conceitos.

Em relação aos testes realizados com as duas ferramentas computacionais ALAReader $^{\circledR}$ e Hamlet ${ }^{\circledR}$ para a quantificação das relações entre conceitos presentes em um texto, algumas considerações podem ser feitas:

- O programa Hamlet $^{\circledR}$ se mostrou mais eficiente e prático do que o programa ALAReader $^{\circledR}$ para os objetivos da presente pesquisa, cujo foco permaneceu no desenvolvimento de uma metodologia para a obtenção de estruturas gráficas representativas de grupos de alunos e não de um único estudante. As vantagens no uso do programa Hamlet ${ }^{\circledR}$ referem-se a dois 
pontos principais: (i) a ausência de limitação de linhas tanto para a lista de vocabulário quanto para o texto a ser analisado e (ii) o fato de o programa contabilizar na matriz de similaridade todas as vezes que um par de conceitos relacionados aparece ao longo do texto.

- É possível dizer que a primeira vantagem destacada para o programa Hamlet $^{\circledR}$ auxilia bastante o professor / pesquisador principalmente quando se pensa no trabalho com uma turma de alunos, pois em vez de ler um texto por vez e gerar uma matriz de similaridade para o texto de cada estudante, o programa é capaz de ler um único arquivo de texto com muitas linhas e gerar uma única matriz representativa da turma. A segunda vantagem em destaque também tem grande importância, pois dependendo do objetivo da atividade e do tema do texto escrito pelos alunos, pode ser extremamente importante para o professor / pesquisador saber que determinadas relações entre conceitos foram estabelecidas várias vezes.

Após a definição da ferramenta computacional que seria utilizada para a quantificação das relações entre conceitos presentes nos textos dos alunos na forma de matrizes, foram realizados testes para verificar a influência nessa quantificação partindo-se dos textos como foram escritos (texto original) e das proposições extraídas dos mesmos (texto modificado), sendo possível estabelecer algumas conclusões:

- A matriz gerada pelo Hamlet $^{\circledR}$ para quantificar as relações entre conceitos depende essencialmente da estrutura do texto em questão, tendo sido possível perceber uma diferença considerável quanto ao número de pares de conceitos identificados e quantificados na matriz, dependendo da estrutura do texto analisado - texto original ou texto modificado. Para os dados coletados em ambas as disciplinas, verificou-se que o número total de relações entre conceitos presentes na matriz proveniente da análise dos textos originais é consideravelmente maior do que o que se tem na matriz proveniente dos textos modificados. Em geral, percebeuse que no caso da matriz proveniente dos textos originais, quase todos os conceitos foram relacionados alguma vez, restando poucas relações inexistentes entre conceitos (poucos zeros na matriz).

Dentro do contexto da investigação da estrutura de conhecimentos dos alunos sobre os temas trabalhados nas disciplinas em que os dados desta pesquisa foram coletados, as matrizes obtidas a partir das duas estruturas possíveis de texto (original e modificado) se mostraram muito diferentes. A matriz obtida a partir da análise do texto modificado quantifica exatamente as relações proposicionais entre conceitos estabelecidas pelo aluno. Já a matriz obtida após a análise do texto original permite conhecer os conceitos que de alguma forma foram relacionados e considerados relevantes pelo aluno durante a elaboração de seu texto, 
sem necessariamente estabelecerem relações de caráter proposicional. Neste último caso, a matriz de associação de conceitos obtida pode ser considerada como uma matriz de proximidade entre os mesmos, onde o critério de proximidade está relacionado com a presença dos conceitos em um mesmo parágrafo. Assim, tendo o parágrafo do texto como unidade de computação das relações conceituais, o fato de dois conceitos distintos estarem na composição do parágrafo, mesmo que não haja uma frase de ligação (verbo) expressando a relação direta entre estes dois conceitos, indica que os dois conceitos são próximos, pois são utilizados na explicitação de uma ou mais ideias (expressas no parágrafo).

As matrizes representativas da turma que foram obtidas neste trabalho possibilitaram uma série de inferências e comparações relevantes no que diz respeito às relações entre conceitos estabelecidas nos textos dos alunos. Porém, a obtenção de matrizes consistiu em uma etapa intermediária desta pesquisa, anterior à construção de estruturas gráficas como mapas e redes de conceitos, as quais se mostraram extremamente esclarecedoras, uma vez que permitiram compreender de maneira mais clara e objetiva as principais ideias presentes nos textos.

Os testes realizados neste trabalho envolveram a construção de três tipos diferentes de estruturas gráficas para representar as relações entre conceitos quantificadas nas matrizes representativas obtidas pelo Hamlet ${ }^{\circledR}$ : (i) rede de conceitos considerando o(s) vizinho(s) mais próximo(s) (rede $V+P$ ); (ii) rede de conceitos a partir de corte percentual (rede \%) e (iii) mapa conceitual. Sobre tais representações, podem ser feitos alguns apontamentos:

- As redes de conceitos são estruturas gráficas que destacam as relações de proximidade entre os conceitos envolvidos. Embora muitas das ligações encontradas nas redes $(\mathrm{V}+\mathrm{P})$ também tenham sido contempladas nas redes com corte percentual, cada tipo de rede se diferenciou pelo foco das informações que forneceram.

- Por se tratarem de representações que apresentam todos os conceitos préestabelecidos e fornecidos na questão que originou os textos dos alunos, neste trabalho as redes $(\mathrm{V}+\mathrm{P})$ se mostraram interessantes para análises centradas nesses conceitos. Neste aspecto, destacaram-se os conceitos considerados centrais e terminais presentes nas redes $(\mathrm{V}+\mathrm{P})$ construídas nesta pesquisa, que permitiram estabelecer inferências sobre sua importância para os alunos no âmbito de cada uma das disciplinas em que os dados foram coletados. 
- Para cada conjunto de dados que fizeram parte desta pesquisa, as redes (V+P) referentes aos textos originais e modificados apresentaram tanto semelhanças quanto diferenças em relação: (i) às ligações presentes; (ii) à maneira como os conceitos estão relacionados e (iii) ao número de vezes que cada relação é estabelecida, tendo sido encontrada uma semelhança de média para baixa entre essas redes, conforme exposto pelos cálculos do PMC mostrados no capítulo 4.

- As redes construídas a partir de corte percentual podem ser consideradas estruturas gráficas centradas nas relações, uma vez que mostram apenas os conceitos e as relações mais citadas pelos estudantes em seus textos. Assim, essas redes apresentaram-se como representações bastante úteis para investigações interessadas em fazer um recorte ou destacar os aspectos considerados mais relevantes pelos alunos sobre determinado tema.

- Com a construção de redes a partir de diversos valores de corte percentual, foi possível perceber como a estrutura da rede de conceitos depende deste corte e também dos valores numéricos presentes na matriz que a originou. Dependendo do corte percentual, a rede pode apresentar muitos grupos de conceitos isolados ou excesso de conceitos relacionados, o que dificulta a análise e compromete a utilidade da estrutura gráfica. Além disso, notou-se que redes baseadas no mesmo corte percentual podem apresentar estruturas bastante diferentes quando provenientes de matrizes distintas.

- Como esperado, as redes de conceitos mostraram-se mais ricas quanto às informações fornecidas de acordo com o aumento do corte percentual estabelecido. No entanto, foi possível perceber que valores muito baixos ou muito altos podem originar redes carentes ou com excesso de informações. As redes (5\%) que foram construídas, por exemplo, tratavam-se de representações muito simples, contemplando uma parcela mínima do número total de conceitos fornecidos nas atividades realizadas pelos alunos para a elaboração de seus textos. Para a maioria das redes $(50 \%)$ construídas neste trabalho, por sua vez, verificaram-se estruturas em que tudo parecia estar relacionado. Assim, a obtenção de diferentes redes baseadas em diversos valores de corte percentual possibilitou uma análise comparativa a fim de escolher as estruturas gráficas que melhor representassem as ideias e o entendimento dos alunos acerca do que foi trabalhado nas disciplinas em que os dados foram coletados. Desta forma, a definição do número mínimo de relações para estabelecer o corte depende de cada caso estudado, de maneira que se deve buscar, em um processo interativo de construção e reconstrução da rede, uma boa relação entre o número total de ligações, de forma que a rede 
construída seja legível, além do valor mínimo de ligações, que deve representar um valor relevante para a amostra em estudo.

- Para cada conjunto de dados que fizeram parte desta pesquisa, as redes de conceitos a partir de determinados cortes percentuais referentes aos textos originais e modificados apresentaram tanto semelhanças quanto diferenças em relação: (i) às ligações presentes; (ii) à maneira como os conceitos estão relacionados e (iii) ao número de vezes que cada relação é estabelecida, tendo sido encontrada uma semelhança média entre essas redes, conforme exposto pelos cálculos do PMC mostrados no capítulo 4.

Por apresentarem as relações conceituais com maior frequência no conjunto dos textos analisados, as redes com corte percentual foram utilizadas na construção de mapas conceituais. Estes mapas conceituais permitem verificar não somente a existência de relação entre os conceitos, mas os significados das relações entre os mesmos expressos nos textos. Assim, optou-se pela construção de mapas conceituais partindo-se tanto dos textos originais quanto dos textos modificados, com o objetivo de comparar as estruturas gráficas obtidas dos dois modos, de forma a demonstrar o quanto as mesmas se aproximam uma da outra. Sobre o processo de construção dos mapas conceituais, é importante destacar as seguintes observações e conclusões:

- Inicialmente, pensava-se que o mapa conceitual mais fiel ao que foi escrito nos textos dos alunos e, portanto, que mais se aproximaria da estrutura de conhecimentos dos mesmos sobre determinado tema seria aquele construído a partir de uma matriz representativa obtida a partir dos textos modificados. No entanto, é possível dizer que a busca pelas frases de ligação para a construção de um mapa conceitual proveniente de uma matriz referente aos textos originais permitiu obter uma estrutura gráfica com semelhança considerável em relação ao mapa conceitual referente aos textos modificados. Esta busca se deu através de um processo que consistiu em: 1) extrair do conjunto de textos cada parágrafo onde aparece o par de conceitos; 2) extrair deste parágrafo a frase de ligação que, se houver, expressa a relação entre os conceitos; 3) marcar na rede a frase de ligação obtida; 4) após listar todas as frases, procurar condensá-las em poucas frases representativas, anotando o número de ocorrência das mesmas. Após executar estes passos, foi possível verificar que algumas ligações deveriam ser excluídas, pois não existiam nos textos frases de ligação entre os conceitos. Isto também fez diminuir o valor do número de ocorrência de ligação entre os conceitos para valores inferiores ao valor de corte estabelecido. Neste momento, julgou-se a pertinência de manter a ligação presente no mapa que, quando mantida, exigiu voltar à matriz com o objetivo de marcar na 
rede novas ligações com valores de ocorrência menores que o valor de corte originalmente estabelecido, porém maiores que o novo valor mínimo estabelecido. Este processo foi repetido até que fossem obtidos mapas conceituais finais que apresentassem um compromisso entre clareza e número de relações relevantes.

- Para cada conjunto de dados que fizeram parte desta pesquisa, os mapas conceituais referentes aos textos originais, obtidos da forma descrita no parágrafo anterior e modificados apresentaram muitas semelhanças em relação: (i) às ligações presentes; (ii) à maneira como os conceitos estão relacionados e (iii) ao número de vezes que cada relação é estabelecida, tendo sido encontrada uma alta semelhança entre essas estruturas, conforme exposto pelos cálculos do PMC mostrados no capítulo 4. Assim, a principal conclusão aqui presente é que as duas abordagens para a construção do mapa conceitual que passam pela obtenção da matriz de associação entre conceitos a partir dos textos brutos (1) ou textos modificados (2) na forma de proposições diretas entre conceitos, convergem para estruturas gráficas muito semelhantes.

- A semelhança observada entre os mapas construídos nesta pesquisa a partir de textos originais e modificados sugere que a utilização do programa Hamlet ${ }^{\circledR}$ para a obtenção de matrizes que quantificam relações entre conceitos presentes em um texto na forma como foi escrito é eficiente quando comparada ao processo manual e mais demorado de se extraírem proposições de um texto para obter uma matriz.

Finalmente, através da análise das estruturas gráficas obtidas para os dois casos estudados, pecebe-se que as redes e os mapas conceituais obtidos para um grupo de alunos em um único momento ou em momentos distintos de um curso podem ser interessantes para que o professor / pesquisador possa comparar as relações entre conceitos estabelecidas pelos alunos, bem como a natureza dessas relações, podendo, desta forma, refletir e planejar seu curso a partir da compreensão dos alunos sobre o tema trabalhado. 


\section{REFERÊNCIAS}

ALVES-MAZZOTTI, A. J.; GEWANDSZNAJDER, F. O método nas ciências naturais e sociais. São Paulo: Thomson Learning, $2^{\mathrm{a}}$ ed., 2004. 204 p.

BOAVENTURA NETTO, P. O.; JURKIEWICZ, S. Grafos: Introdução e prática. São Paulo: Editora Blucher, 2009. 176 p.

BORGES, R. M. R. Em debate: Cientificidade e educação em ciências. $2^{\mathrm{a}}$ ed., Porto Alegre: ediPUCRS, 2007. 118 p.

BRIER, A.; HOPP, B. Hamlet II, Software for computer-assisted text analysis. 2010. Tutorial sobre o funcionamento do programa. Disponível em:

<http://apb.newmdsx.com/hamlet2.html> Acesso em: 01 jul. 2012.

CACHAPUZ, A. et al. (orgs.). A necessária renovação do ensino das ciências. São Paulo: Cortez, 2005. 264 p.

CAÑAS, A. J. et al. Cmaptools: A Knowledge Modeling and Sharing Environment. In: CAÑAS, A. J.; NOVAK, J. D.; GONZÁLEZ, F. M. (eds.), Concept maps: theory, methodology, technology, Proceedings of the First International Conference on Concept Mapping, p.125 - 133, Pamplona, Espanha: CMC, 2004.

CLARIANA, R. B. Deriving individual and group knowledge structure from network graphs and from essays. In: IFENTHALER, D. et al. (eds.), Computer-Based Diagnostics and Systematic Analysis of Knowledge, 2010. p. 117 - 130.

Multi-decision Approaches for Eliciting Knowledge Structure. In:

IFENTHALER, D. et al. (eds.), Computer-Based Diagnostics and Systematic Analysis of Knowledge, 2010. p. $41-59$.

CLARIANA, R. B.; KOUL, R. A computer based approach for translating text into concept map-like representations. In: CAÑAS, A. J.; NOVAK, J. D.; GONZÁLEZ, F. M. (eds.), Concept maps: theory, methodology, technology, Proceedings of the First International Conference on Concept Mapping, p.131 - 134, Pamplona, Espanha: CMC, 2004.

The effects of learner prior knowledge when creating concept maps from a text passage. International Journal of Instructional Media, v. 35, n. 2, p. 229 $-236,2008$. 
CLARIANA, R. B.; WALLACE, P. A Computer-based approach for deriving and measuring individual and team knowledge structure from essay questions. Journal of Educational Computing Research. v. 37, n.3, p. 211-227, 2007.

CLARIANA, R. B.; WALLACE, P. E.; GODSHALK, V. M. Deriving and measuring group knowledge structure from essays: The effects of anaphoric reference. Education Technology Research and Development. v. 57, n. 6, p. 725 - 737, 2009.

GOLDSMITH, T. E.; JOHNSON, P. J.; ACTON, W. H. Assessing structural knowledge. Journal of educational psychology. v. 83, n. 1, p. 88 - 96, 1991.

HOFFMANN, J. M. L. Avaliação mediadora: uma prática em construção da pré-escola à universidade. Porto Alegre: Educação \& Realidade, 1993. 160 p.

HOFFMANN, J. M. L. O cenário da avaliação no ensino de ciências, história e geografia. In: SILVA, J. F.; HOFFMANN, J. M. L.; ESTEBAN, M. T. (orgs) Práticas avaliativas e aprendizagens significativas: em diferentes áreas do currículo. Porto Alegre: Mediação, 2003.

JUNQUEIRA, M. M.; MAXIMIANO, F.A. Redes de conceitos obtidas a partir de textos 1: comparando métodos para se obter a rede.. In: REUNIÃO DA SOCIEDADE BRASILEIRA DE QUÍMICA, 34, 2011, Florianópolis. Anais da 34ª Reunião Anual da Sociedade Brasileira de Química, Florianópolis: UFSC, 2011.

JUNQUEIRA, M. M.; SILVA, P. A.; MAXIMIANO, F. A. Transformando textos escritos por alunos em redes de conceitos 2: comparação entre redes pré e pós-instrução. In: ENCONTRO NACIONAL DE ENSINO DE QUÍMICA, 15, 2010, Brasília. Anais do XV Encontro Nacional de Ensino de Química, Brasília: UnB, 2010.

KINCHIN, I. M.; HAY, D. B.; ADAMS, A. How a qualitative approach to concept map analysis can be used to aid learning by illustrating patterns of conceptual development. Educational Research. v. 42, n. 1, p. 43 - 57, 2000.

KOWATA, J. H.; CURY, D.; BOERES, M. C. S. Concept maps core elements candidates recognition from text. In: SÁNCHEZ, J.; CAÑAS, A. J.; NOVAK, J. D. (eds.), Concept maps: making learning meaningful, Proceedings of the Fourth International Conference on Concept Mapping, p.120 - 127, Viña del Mar, Chile: CMC, 2010. 
LENARDÃO, E. J. et al. "Green chemistry" - Os 12 princípios da Química Verde e sua inserção nas atividades de ensino e pesquisa. Química Nova, v. 26, n. 1, p. 123 - 129, 2003.

LUCKESI, C. C. Avaliação da aprendizagem escolar: estudos e proposições. $15^{\mathrm{a}}$ ed. São Paulo: Cortez, 2003. 184 p.

MARTINS, J. V.; MAXIMIANO, F. A. Obtendo um mapa conceitual a partir de textos escritos pelos alunos. In: $31^{\text {a }}$ REUNIÃO ANUAL DA SOCIEDADE BRASILEIRA DE QUÍMICA, 2008, Águas de Lindóia. Livro de Resumos da $31^{\text {a }}$ Reunião Anual da Sociedade Brasileira de Química, Águas de Lindóia: SBQ, 2008a.

MARTINS, J. V.; MAXIMIANO, F. A. Investigando concepções de alunos do ensino médio através de mapas conceituais representativos. In: $16^{\circ}$ SIMPÓSIO INTERNACIONAL DE INICIAÇÃO CIENTÍFICA, 2008, São Paulo. CD online USP digital. São Paulo: SIICUSP, 2008b.

MOREIRA, M. A. Teorias de aprendizagem. São Paulo: EPU, 1999. 195 p.

MOREIRA, M A. Mapas conceituais e aprendizagem significativa. Instituto de Física. UFRGS. 2003. Disponível em: <http://www.if.ufrgs.br/moreira/mapasport.pdf.> Acesso em 01 jul. 2012.

NOVAK, J. D.; GOWIN, D. B. Learning how to learn. Nova Iorque: Cambridge University Press, 1984. 199 p.

NOVAK, J. D. Learning, creating and using knowledge: concepts maps as facilitative tools in schools and corporations. Londres: Lawrence Erlbaum Associates Mahwah, 1998. $317 \mathrm{p}$.

NOVAK, J. D.; CAÑAS, A. J. Theoretical origins of concept maps, how to construct them, and uses in education. Reflecting Education. v. 3, n. 1, p. 29 - 42, 2007.

NOVAK, J. D. Meaningful learning: the essential factor for conceptual change in limited or inappropriate propositional hierarchies leading to empowerment of learners. Science

Education. v. 86, n. 4, p. $548-571,2002$.

NUUTILA, E.; TORMA, S. Text graphs: accurate concept mapping with well-defined meaning. In: CAÑAS, A. J.; NOVAK, J. D.; GONZÁLEZ, F. M. (eds.), Concept maps: theory, methodology, technology, Proceedings of the First International Conference on Concept Mapping, Pamplona, Espanha: CMC, 2004. 
OKADA, A. Cartografia Cognitiva: mapas do conhecimento para pesquisa, aprendizagem e formação docente. Cuiabá: KMC, 2008. 390 p.

PERRENOUD, P. Avaliação: da excelência à regulação das aprendizagens - entre duas lógicas. Porto Alegre: Artmed, 1999. 183 p.

PICONEZ, S. C. B. A Construção de Conhecimentos por Mapas Conceituais. Webteca do Site do Núcleo de Estudos em Educação de Jovens e Adultos e Formação Permanente de Professores. 2012. Disponível em <http://www.nea.fe.usp.br > Acesso em 01 jul. 2012.

PRADO, A. G. S. Química Verde, os desafios da química do novo milênio. Química Nova, v. 26, n. 5 , p. $738-744,2003$.

SANMARTÍ, N. Avaliar para aprender. Tradução de Carlos Henrique Lucas Lima. Porto Alegre: Artmed, 2009. 136 p.

SILVA, J. F. Avaliação do ensino e da aprendizagem numa perspectiva formativa reguladora. In: SILVA, J. F.; HOFFMANN, J. M. L.; ESTEBAN, M. T. (orgs) Práticas avaliativas e aprendizagens significativas: em diferentes áreas do currículo. Porto Alegre: Mediação, 2003 .

SILVA, P. A.; JUNQUEIRA, M. M.; MAXIMIANO, F. A. Transformando textos escritos por alunos em redes de conceitos 1: definindo a estrutura dos textos. In: ENCONTRO NACIONAL DE ENSINO DE QUÍMICA, 15, 2010, Brasília. Anais do XV Encontro Nacional de Ensino de Química, Brasília: UnB, 2010.

SILVA, J. L. P. B.; MORADILLO, E. F. Avaliação, ensino e aprendizagem de ciências. Ensaio - Pesquisa em Educação e em Ciências. v. 4, n. 1, p. 1 - 12, 2002.

SCHVANEVELDT, R. W.; DEARHOLT, D. W.; DURSO, F. T., Graph theoretic foundations of pathfinder networks. Computers and Mathematics with Applications. v. 15, p. 337 $345,1988$.

SCHVANEVELDT, R. W.; DEARHOLT, D. W.; DURSO, F. T., Network structures in proximity data. The Psychology of Learning and Motivation. v. 24, p. 249 - 284, 1989.

SHAVELSON, R. J.; RUIZ-PRIMO, M. A.; WILEY, E. W. Windows into the mind. Higher Education. v. 49, p. 413 - 430, 2005. 
VILLALON, J.; CALVO, R. A. Analysis of a gold standard for concept map mining - how humans summarize text using concept maps. In: SÁNCHEZ, J.; CAÑAS, A. J.; NOVAK, J. D. (eds.), Concept maps: making learning meaningful, Proceedings of the Fourth International Conference on Concept Mapping, p.14 - 22, Viña del Mar, Chile: CMC, 2010 .

ZABALA, A. A prática educativa: como ensinar. Tradução de Ernani F. da F. Rosa. Porto Alegre: ArtMed, 1998. 224 p.

WHITE, R.; GUNSTONE, R. Probing understanding. Grã-Bretanha: Burgess Science Press, 1992. 196 p. 